Universidade DE SÃo Paulo

Instituto DE FÍ́sicA

\title{
Interação Entre Elétrons e Nucleotídeos
}

\author{
Lucas Medeiros Cornetta
}

Orientador: Prof. Dr. Márcio Teixeira do Nascimento Varella

Dissertação apresentada ao Instituto de Física para a obtenção do título de Mestre em Ciências.

Banca Examinadora:

Prof. Dr. Márcio Teixeira do Nascimento Varella (IFUSP)

Prof. Dr. Caetano Rodrigues Miranda (IFUSP)

Prof. Dr. Márcio Henrique Franco Bettega (UFPR) 



\section{Agradecimentos}

Primeiramente, agradeço ao CNPq pelo apoio financeiro sem o qual o presente trabalho não seria possível. Agradeço também à CPG-IFUSP pelos auxílios.

A meus pais e familiares, os quais serei eternamente grato por desde sempre me apoiarem, aconselharem e motivarem. Agradeço também a todos os meus amigos próximos pelo apoio e, principalmente, por aturarem meus impulsos pela física.

A todos os meus colegas e amigos de graduação e pós-graduação pelos ensinamentos, conversas e discussões sobre a ciência, a natureza e a vida.

Agradeço ao grupo de Física Molecular e Modelagem por toda ajuda e apoio fornecido durante o projeto e pela oportunidade de trabalhar com grandes pesquisadores e amigos.

Finalmente, agradeço ao Prof. Dr. Márcio Teixeira do Nascimento Varella pela oportunidade, orientação, apoio, ensinamentos, conselhos e pela grande amizade.

A todos muito obrigado,

Lucas Medeiros Cornetta. 



\section{Resumo}

Estudos teóricos e experimentais acerca de danos em biomoléculas induzidos pela captura eletrônica em meio biológico têm sido largamente discutidos ao longo da última década. No presente trabalho, abordou-se o problema da captura eletrônica pelo nucleotídeo monofosfato 3'-dGMP com técnicas de estrutura eletrônica, explorando estados ligados do ânion. Buscou-se investigar o ânion em fase gasosa e em solução aquosa, além de estimar barreiras de energia pontecial e energia livre associadas à sua dissociação (quebra da ligação ribose-fosfato). Utilizando os modelos de solvatação implícita (PCM) e explícita (simulação computacional com o método de Monte Carlo), concluiu-se que, em meio aquoso, o estado fundamental do ânion $3^{\prime}$-dGMP ${ }^{-}$apresenta caráter $\pi^{*}$ sobre a base nitrogenada (orbital com ocupação simples), em oposição ao resultado em fase gasosa, que prevê um estado ligado por dipolo. A barreira de dissociação, relativa ao estiramento da ligação entre os grupos ribose e fosfato, foi estimada em 16-30 kcal/mol, dependendo da técnica de solvatação utilizada. 



\section{Abstract}

Theoretical and experimental studies on the damage to biomolecules induced by electron attachment in the biological environment have been widely discussed over the past decade. In the present work, we addressed electron capture by the monophosphate nucleotide $3^{\prime}$-dGMP with electronic structure techniques, exploring bound anion states. We have investigated these anion states in gas phase and in aqueous solution, and estimated the potential and free energy barriers related to the dissociation reaction (breakage of the ribose-phosphate bond). Employing implicit (PCM) and explicit (computer simulation with the Monte Carlo method) solvation models, we have concluded that, in aqueous environment, the ground state of the $3^{\prime}$-dGMP ${ }^{-}$specie has $\pi^{*}$ character with the singly occupied molecular orbital localized on the base. In contrast, the gas phase results point out a dipole-bound ground state. The free energy barrier for the dissociation mechanism, according to the present results, would be around $16-30 \mathrm{kcal} / \mathrm{mol}$ in aqueous solution, depending on the salvation model. 



\section{Sumário}

1 Introdução e Motivações 1

1.1 Nucleotídeos e dGMP . . . . . . . . . . . . . . . . . . 4

2 Métodos Teóricos I - Estrutura Eletrônica de Moléculas $\begin{array}{ll}\text { Isoladas } & 9\end{array}$

2.1 Separação e Aproximação de Born-Oppenheimer . . . . . . 9

2.1.1 Validade da Aproximação BO . . . . . . . . . . . . 14

2.2 Funções de Onda Multi-Eletrônicas . . . . . . . . . . . . . 15

2.3 O Método de Hartree-Fock . . . . . . . . . . . . . . . . . 17

2.3.1 O Método de Hartree-Fock Roothaan . . . . . . . . 22

2.3.2 Correlação Eletrônica . . . . . . . . . . . . . . . . 25

2.4 Teoria do Funcional da Densidade . . . . . . . . . . . . . 27

2.4.1 Teoremas de Hohenberg e Kohn . . . . . . . . . . . 27

2.4 .2 Equações de Kohn-Sham . . . . . . . . . . . . . . . 31

2.4.3 O funcional híbrido B3LYP . . . . . . . . . . 35

2.5 Energia Livre . . . . . . . . . . . . . . . . . . . . 38

2.6 Otimização de Geometria . . . . . . . . . . . . . . . . . 39

2.7 Funções Base . . . . . . . . . . . . . . . . . . . . . . . . 40

2.7.1 A Base Schaefer . . . . . . . . . . . . . . . . 42

2.8 Aplicações . . . . . . . . . . . . . . . . . . . . . . . 43

3 Métodos Teóricos II - Efeitos do Solvente 45

3.1 Modelos de solvatação . . . . . . . . . . . . . . 47

3.1.1 Solvatação implícita - Modelos contínuos . . . . . . 47

3.1.2 Simulação Computacional . . . . . . . . . . . . 51 
3.1.3 Análise da Simulação - Erros e Distribuição Radial de Pares . . . . . . . . . . . . . . . . 57

3.1.4 O Método QM/MM . . . . . . . . . . . 58

3.1.5 O Método s-QM/MM . . . . . . . . . . . . 59

3.1.6 Energia Livre de Solvatação - Teoria da Perturbação Termodinâmica . . . . . . . . . . . . . . . . 61

3.2 Aplicações . . . . . . . . . . . . . . . . . . . . . 64

4 Análise dos Resultados $\quad 67$

4.1 Moléculas Isoladas . . . . . . . . . . . . . . . . 67

$4.1 .1 \quad 3$-dGMP . . . . . . . . . . . . . . . 67

4.1.2 Ânion $3^{\prime}-\mathrm{dGMP}^{-} \ldots \ldots \ldots$. . . . . . . . 69

4.2 Moléculas Solvatadas - Solvatação Implícita . . . . . . . . 74

$4.2 .1 \quad 3$-dGMP . . . . . . . . . . . . . . . . 74

4.2 .2 Ânion $3^{\prime}-\mathrm{dGMP}^{-} \ldots \ldots \ldots . \ldots . \ldots 76$

4.3 Moléculas Solvatadas - Solvatação Explícita . . . . . . . 80

5 Conclusões e Considerações Finais $\quad 99$

$\begin{array}{ll}\text { A Geometrias } & 101\end{array}$ 


\section{Lista de Figuras}

1.1 (Modificado da referência[1])(a) Contagem de quebras de fitas duplas (A) e simples (B) em termos da energia do elétron incidente, em eV. (b) Contagem de produto $\mathrm{H}^{-}$em função da energia do elétron incidente. A contagem de produto $\mathrm{H}^{-}$ na reação $e^{-}+\mathrm{RH} \rightarrow \mathrm{RH}^{*-} \rightarrow \mathrm{R}+\mathrm{H}^{-} \ldots \ldots$. . . . .

1.2 (Modificado da referência[2])Resultados obtidos no experimento de Excitação e Prova realizado realizado por Wang et al.. Observou-se experimentalmente a dissociação dos nucleotídeos monofosfatos dTMP e dGMP em solução aquosa. 
1.3 (Modificado da referência [3])(a) Quando moléculas de água absorvem radiação de alta energia, elas podem ionizar produzindo $\mathrm{H}_{2} \mathrm{O}^{+}$e $e^{-}$livres. Após perderem sua energia cinética devido a colisões inelásticas, os elétrons atingem um estágio de pré-hidratados $e_{\text {pre }}^{-}$, que possuem um período de meiavida relativamente curto. (b) Os íons $\mathrm{H}_{2} \mathrm{O}^{+}$reagem com mais moléculas de água para formar águas protonadas $\mathrm{H}_{3} \mathrm{O}^{+}$ e radicais hidroxilas $\mathrm{OH}^{-}$. Pensou-se por muito tempo que a maior parte dos danos em DNA era causado por esses radicais livres. (c) Elétrons pré-hidratados formam complexos ao interagirem com moléculas de água, tornando-se elétrons hidratados. (d) Um trabalho realizado por Wang et al.[2] mostrou que elétrons pré-hidratados podem reagir com bases de certos nucleotídeos (dGMP e dTMP) em solução aquosa. Isso sugere que elétrons de baixas energias podem reagir com bases do DNA para formar ânions transientes. Em alguns casos, esses ânions podem ocasionar uma quebra de ligação molecular, ocasionado possíveis danos na molécula de DNA. 4

1.4 Esquema do mecanismo de dissociação induzida por captura eletrônica. . . . . . . . . . . . . . . . . . . .

1.5 Estruturas bidimensionais das moléculas (a) 3'-dAMP (b) 5'-dAMP (c) 3'-dTMP (d) 5'-dTMP (e) 3'-dGMP (f) 5'-dGMP (g) $3^{\prime}$-dCMP (h) 5 -dCMP. . . . . . . . . . . . .

1.6 Esquema da dissociação da (a) $3^{\prime}$-dGMP ${ }^{-}$- em que a quebra ocorre entre o carbono $\mathrm{C}_{3^{\prime}}$, da ribose, e o oxigênio $\mathrm{O}_{3^{\prime}}$, do grupo fosfato - e (b) $5^{\prime}$-dGMP ${ }^{-}$- em que a quebra ocorre entre o carbono $\mathrm{C}_{5^{\prime}}$, da ribose, e o oxigênio $\mathrm{O}_{5^{\prime}}$, do grupo fosfato . . . . . . . . . . . . . . . . .

3.1 Ciclo termodinâmico para a determinação da energia livre de solvatação. Na notação adotada, $S$ representa a geometria e o conjunto de parâmetros do campo de força do soluto. . 
3.2 Ciclo termodinâmico para a determinação da barreira de energia livre. Na notação adotada, $S^{\text {opt }}$ e $S^{t s}$ representam as geometrias otimizadas e de transição do soluto, e os respectivos conjuntos de parâmetros do campo de força. . . .

4.1 Geometria otimizada da molécula 3'-dGMP e a numeração dos sítios atômicos. O código de cores segue a seguinte relação: H - branco; C - cinza; N - azul; O - vermelho; P - laranja. . . . . . . . . . . . . . . .

4.2 (a) O orbital HOMO e (b) LUMO da molécula dGMP neutra, na geometria otimizada com o método B3LYP. . . .

4.3 Geometria otimizada da molécula $3^{\prime}-\mathrm{dGMP}^{-}$e a numeração dos sítios atômicos. O código de cores segue a seguinte relação: H - branco; C - cinza; N - azul; O - vermelho; P - laranja. . . . . . . . . . . . . . . . .

4.4 O orbital SOMO da molécula $3^{\prime}-\mathrm{dGMP}^{-}$, na geometria otimizada com o método B3LYP. . . . . . . . . . . . . .

4.5 Geometria do estado de transição da molécula $3^{\prime}-\mathrm{dGMP}^{-} \mathrm{e}$ a numeração dos sítios atômicos. O código de cores segue a seguinte relação: H - branco; C - cinza; N - azul; O vermelho; P - laranja. . . . . . . . . . . . . . . . . 71

4.6 Orbital SOMO do estado de transição. . . . . . . . . . . . 72

4.7 Orbital SOMO ao longo da reação (1.4). . . . . . . . . . . 73

4.8 O orbital HOMO da molécula 3'-dGMP neutra, na geometria $\mathbf{R}_{n}$, em PCM cuja cavidade foi construída pela metodologia (a) UFF (DFT/B3LYP/D95*_Sch) (b) SMD (DFT/B3LYP/D95*_ Sch) (c) UAHF $(\mathrm{HF} / 6-31 \mathrm{G}(\mathrm{d})) \ldots \ldots 74$

4.9 O orbital LUMO da molécula 3'-dGMP neutra, na geometria $\mathbf{R}_{n}$, em PCM cuja cavidade foi construída pela metodologia (a) UFF (DFT/B3LYP/D95*-Sch) (b) SMD (DFT/B3LYP/D95*_ Sch) (c) UAHF $(\mathrm{HF} / 6-31 \mathrm{G}(\mathrm{d})) \ldots \ldots . \ldots 75$ 
4.10 O orbital HOMO da molécula 3'-dGMP neutra, na geometria otimizada em PCM cuja cavidade foi construída pela metodologia (a) UFF (DFT/B3LYP/D95*-Sch) (b) SMD (DFT/B3LYP/D95*-Sch) (c) UAHF (HF/6-31G(d)). . . .

4.11 O orbital LUMO da molécula 3'-dGMP neutra, na geometria otimizada em PCM cuja cavidade foi construída pela metodologia (a) UFF (DFT/B3LYP/D95*-Sch) (b) SMD (DFT/B3LYP/D95*-Sch) (c) UAHF (HF/6-31G(d)). . . .

4.12 O orbital SOMO da molécula $3^{\prime}-\mathrm{dGMP}^{-}$, na geometria $\mathbf{R}_{a}$, em PCM cuja cavidade foi construída pela metodologia (a) UFF (DFT/B3LYP/D95*-Sch) (b) SMD (DFT/B3LYP/D95*_ Sch) (c) UAHF $(\mathrm{HF} / 6-31 \mathrm{G}(\mathrm{d})) \ldots \ldots \ldots$

$4.13 \mathrm{O}$ orbital SOMO da molécula $3^{\prime}-\mathrm{dGMP}^{-}$, na geometria otimizada em PCM cuja cavidade foi construída pela metodologia (a) UFF (DFT/B3LYP/D95*_Sch) (b) SMD (DFT/B3LYP/D95*_ Sch) (c) UAHF $(\mathrm{HF} / 6-31 \mathrm{G}(\mathrm{d})) \ldots \ldots . \ldots 77$

$4.14 \mathrm{O}$ orbital SOMO da molécula $3^{\prime}-\mathrm{dGMP}^{-}$, na geometria de transição em PCM cuja cavidade foi construída pela metodologia (a) UFF (DFT/B3LYP/D95*-Sch) (b) SMD (DFT/B3LYP/D95*_ Sch) (c) UAHF (HF/6-31G(d)).

4.15 Simulação com o conjunto de cargas UFF: (a) A entalpia por molécula e (b) a densidade obtida ao longo da amostragem. A entalpia média obtida foi $\langle H / N\rangle=-10.44 \pm$ $0.04 \mathrm{kcal} / \mathrm{mol}$ e a densidade média obtida foi $\langle\rho\rangle=1.008 \pm$ $0.007 \mathrm{~g} / \mathrm{cm}^{3} \ldots \ldots \ldots \ldots \ldots \ldots \ldots$

4.16 Simulação com o conjunto de cargas SMD: (a) A entalpia por molécula e (b) a densidade obtida ao longo da amostragem. A entalpia média obtida foi $\langle H / N\rangle=-10.38 \pm$ $0.05 \mathrm{kcal} / \mathrm{mol}$ e a densidade média obtida foi $\langle\rho\rangle=1.006 \pm$ $0.008 \mathrm{~g} / \mathrm{cm}^{3} \ldots \ldots \ldots \ldots \ldots \ldots \ldots$ 
4.17 Simulação com o conjunto de cargas UAHF: (a) A entalpia por molécula e (b) a densidade obtida ao longo da amostragem. A entalpia média obtida foi $\langle H / N\rangle=-10.39 \pm$ $0.05 \mathrm{kcal} / \mathrm{mol}$ e a densidade média obtida foi $\langle\rho\rangle=1.007 \pm$ $0.008 \mathrm{~g} / \mathrm{cm}^{3} \ldots \ldots \ldots \ldots \ldots \ldots \ldots$

4.18 Simulação com o conjunto de cargas UFF: (a) A entalpia por molécula e (b) a densidade obtida ao longo da amostragem. A entalpia média obtida foi $\langle H / N\rangle=-10.35 \pm$ $0.03 \mathrm{kcal} / \mathrm{mol}$ e a densidade média obtida foi $\langle\rho\rangle=1.007 \pm$ $0.007 \mathrm{~g} / \mathrm{cm}^{3} \ldots \ldots \ldots \ldots \ldots \ldots$

4.19 Simulação com o conjunto de cargas SMD: (a) A entalpia por molécula e (b) a densidade obtida ao longo da amostragem. A entalpia média obtida foi $\langle H / N\rangle=-10.32 \pm$ $0.05 \mathrm{kcal} / \mathrm{mol}$ e a densidade média obtida foi $\langle\rho\rangle=1.003 \pm$ $0.008 \mathrm{~g} / \mathrm{cm}^{3} \ldots \ldots \ldots \ldots \ldots \ldots$

4.20 Simulação com o conjunto de cargas UAHF: (a) A entalpia por molécula e (b) a densidade obtida ao longo da amostragem. A entalpia média obtida foi $\langle H / N\rangle=-10.33 \pm$ $0.05 \mathrm{kcal} / \mathrm{mol}$ e a densidade média obtida foi $\langle\rho\rangle=1.003 \pm$ $0.008 \mathrm{~g} / \mathrm{cm}^{3} \ldots \ldots \ldots \ldots \ldots \ldots \ldots$

4.21 Distribuição de pares da simulação com o conjunto de cargas UFF: (a) OPT (b) TS. . . . . . . . . . . . . . . . . . .

4.22 Distribuição de pares da simulação com o conjunto de cargas SMD: (a) OPT (b) TS.

4.23 Distribuição de pares da simulação com o conjunto de cargas UAHF: (a) OPT (b) TS. . . . . . . . . . . . . . . .

4.24 Correlação estatística da simulação com as cargas UFF, e seu respectivo ajuste: (a) OPT (b) TS. . . . . . . . . . .

4.25 Correlação estatística da simulação com as cargas SMD, e seu respectivo ajuste: (a) OPT (b) TS. . . . . . . . . . . 
4.26 Correlação estatística da simulação com as cargas UAHF, e seu respectivo ajuste: (a) OPT (b) TS. . . . . . . . . . . 89

4.27 SOMO da geometria obtida através da simulação com o conjunto de cargas (UFF): (a) OPT (b) TS. . . . . . . . . . . 91

4.28 SOMO da geometria obtida atrvés da simulação com o conjunto de cargas (SMD): (a) OPT (b) TS. . . . . . . . . . . 91

4.29 SOMO da geometria obtida através da simulação com o conjunto de cargas (UAHF): (a) OPT (b) TS. . . . . . . . 92 


\section{Lista de Tabelas}

2.1 Base proposta por Schaefer para os átomos H, C, N, O e P. 43

3.1 Raios de van der Waals - VdW - dos átomos constituintes da molécula 3'-dGMP, em $\AA$. . . . . . . . . . . . . . 49

3.2 Geometria da água no modelo SPC, os valores estão em $\AA . \quad 65$

3.3 Valores dos parâmetros OPLS da água. Os valores de $q$ estão dados em termos da carga elementar, os valores de $\epsilon$ estão em kcal $/ \mathrm{mol}$ e os valores de $\sigma$ estão em $\AA$. . . . . . . . . . 65

4.1 Valores de $V A E$ (4.1), $V D E$ (4.2) e $A E A$ (4.3) em fase gasosa. 71

4.2 Barreira de energia potencial $\Delta E_{\text {gas }}$, em fase gasosa, obtida através do método DFT/B3LYP. Os valores entre parêntesis estão corrigidos com a energia de ponto zero. . . . . . . . . 72

4.3 Comparação entre os efeitos da solvatação implícita nas geometrias otimizadas no vácuo, $\mathbf{R}_{n}$, e em PCM, $\mathbf{R}_{n}^{P C M}$, da molécula 3'-dGMP neutra. . . . . . . . . . . . . . 77

4.4 Comparação entre os efeitos da solvatação implícita nas geometrias otimizadas no vácuo, $\mathbf{R}_{a}$, e em PCM, $\mathbf{R}_{a}^{P C M}$, da molécula $3^{\prime}-\mathrm{dGMP}^{-}$carregada. . . . . . . . . . 78

4.5 Energia livre de solvatação da molécula $3^{\prime}-\mathrm{dGMP}^{-}$, com PCM. . . . . . . . . . . . . . . . 78

4.6 Energia de polarização do soluto na geometria otimizada. . 79

4.7 Energia livre de solvatação do estado de transição da molécula $3^{\prime}-\mathrm{dGMP}^{-}$, com PCM. . . . . . . . . . . . . . 79

4.8 Polarização do soluto no estado de transição. . . . . . . . . 80 
4.9 Barreira de energia livre. . . . . . . . . . . . . . . 80

4.10 Valores dos parâmetros OPLS do soluto $3^{\prime}$-dGMP ${ }^{-}$. Os valores de $\epsilon$ estão em kcal/mol e os valores de $\sigma$ estão em $\AA$.

4.11 Valores das cargas $q$ do soluto $3^{\prime}$-dGMP ${ }^{-}$na geometria otimizada. Os valores das cargas estão dados em termos da carga elementar. . . . . . . . . . . . . . . . . .

4.12 Valores das cargas $q$ do soluto $3^{\prime}$-dGMP ${ }^{-}$na geometria de transição. Os valores das cargas estão dados em termos da carga elementar. . . . . . . . . . . . . . . . . .

4.13 Número de moléculas de solvente na primerira camada de solvatação. . . . . . . . . . . . . . . . . . . . .

4.14 Correlação estatística. . . . . . . . . . . . . . . 90

$4.15 \Delta G$, em kcal $/ \mathrm{mol}$, da molécula $3^{\prime}-\mathrm{dGMP}^{-}$da geometria otimizada - perturbação das cargas $q$. . . . . . . . . . . .

$4.16 \Delta G$, em kcal $/ \mathrm{mol}$, da molécula $3^{\prime}-\mathrm{dGMP}^{-}$da geometria otimizada - perturbação dos parâmetros $\epsilon$. . . . . . . . . . .

$4.17 \Delta G$, em kcal $/ \mathrm{mol}$, da molécula $3^{\prime}-\mathrm{dGMP}^{-}$da geometria otimizada - perturbação dos parâmetros $\sigma$.

$4.18 \Delta G$, em $\mathrm{kcal} / \mathrm{mol}$, da molécula $3^{\prime}-\mathrm{dGMP}^{-}$do estado de transição - perturbação das cargas $q$. . . . . . . . . . . . . 94

$4.19 \Delta G$, em $\mathrm{kcal} / \mathrm{mol}$, da molécula $3^{\prime}$-dGMP ${ }^{-}$do estado de transição - perturbação dos parâmetros $\epsilon$. . . . . . . . . .

$4.20 \Delta G$, em $\mathrm{kcal} / \mathrm{mol}$, da molécula $3^{\prime}-\mathrm{dGMP}^{-}$do estado de transição - perturbação dos parâmetros $\sigma$. . . . . . . . . 95

4.21 Diferença das energias de polarização $\Delta \Delta G_{p o l}$, em kcal $/ \mathrm{mol} . \quad 95$

4.22 Barreiras de energia livres da dissociação, $\Delta G$, e a diferença entre o $\Delta G_{\text {solv }}$ do estado de transição e estado otimizado. .

A.1 Geometria da espécie neutra 3'-dGMP, $\mathbf{R}_{n}$, com o método DFT/B3LYP/D95*_Sch. As coordenadas estão em A. . . . 
A.2 Geometria da espécie carregada $3^{\prime}-\mathrm{dGMP}^{-}, \mathbf{R}_{a}$, obtida com o método DFT/B3LYP/D95*-Sch. As coordenadas estão em A. . . . . . . . . . . . . . . . . . . . . . 103

A.3 Geometria do estado de transição da espécie carregada $3^{\prime}$-dGMP ${ }^{-}$, $\mathbf{R}_{a}^{T S}$, obtida com o método DFT/B3LYP/D95*-Sch. As coordenadas estão em A. . . . . . . . . . . . . . . . . . . . . 104

A.4 Geometria otimizada da espécie neutra 3'-dGMP em PCM/UFF, com o método DFT/B3LYP/D95*-Sch. As coordenadas estão em A. . . . . . . . . . . . . . . . . . . . . . 105

A.5 Geometria otimizada da espécie neutra 3'-dGMP em PCM/SMD, com o método DFT/B3LYP/D95*-Sch. As coordenadas estão em A. . . . . . . . . . . . . . . . . . . . . . 106

A.6 Geometria otimizada da espécie neutra 3'-dGMP em PCM/UAHF, com o método HF/6-31G(d). As coordenadas estão em A. 107

A.7 Geometria otimizada da molécula 3'-dGMP ${ }^{-}$em PCM/UFF, com o método DFT/B3LYP/D95*_Sch. As coordenadas estão em A. . . . . . . . . . . . . . . . . . . . . . . . . . . . 108

A.8 Geometria otimizada da molécula $3^{\prime}$-dGMP ${ }^{-}$em PCM/SMD, com o método DFT/B3LYP/D95*_Sch. As coordenadas estão em A. . . . . . . . . . . . . . . . . . . . . . . . . . 109

A.9 Geometria otimizada da molécula 3'-dGMP ${ }^{-}$em PCM/UAHF, com o método HF/6-31G(d). As coordenadas estão em $\AA$. 



\section{Capítulo 1}

\section{Introdução e Motivações}

O dano causado por elétrons em biomoléculas tem sido alvo de muitos estudos teóricos e experimentais ao longo da última década. Muitos processos físicos estão associados a tais danos, e as fenomenologias relacionadas a esses mecanismos ainda estão sendo investigadas.

Num quadro geral, o dano causado em biomoléculas está associado a uma cascata de eventos sucessivos, iniciados pela absorção de radiação eletromagnética altamente energética. Quando fótons de altas energias (raios- $\gamma$, raios-X, radiação ultra-violeta ou radiação proveniente de espécies carregadas altamente aceleradas) incidem em um material biológico, eventualmente ocasionam danos em biomoléculas presentes nesse ambiente. Podem ocorrer reações como, por exemplo, quebras de fita simples ou dupla em segmentos de DNA ou RNA (apenas fita simples nesse caso) presentes em células vivas, ocasionando uma eventual morte celular. Por esse motivo, radiação eletromagnética nessa faixa de energia muitas vezes é usada em procedimentos como radioterapias, no intuito de destruir células cancerígenas. Por outro lado, outros exemplos de danos são as próprias carcinogêneses ou mutações gênicas. Isso conduz a uma grande motivação acerca de investigações detalhadas dos processos físicos envolvidos nesses fenômenos e, atualmente, sabe-se que esses danos (como dissociações, por exemplo) não são resultados diretos da incidência desses fótons [4, 5].

Quando um material biológico, constituído principalmente de água e soluções aquosas, é atingido por radiação de alta energia, podem ocor- 
rer manifestações de interesse. Entre outros fenômenos, ao colidir com uma molécula de $\mathrm{H}_{2} \mathrm{O}$, o fotón altamente energético pode ocasionar uma dissociação, produzindo $\mathrm{H}^{+}$e o radical livre $\mathrm{OH}^{-}$, como também pode ocasionar a ionização da água, segundo a reação[4] $\mathrm{H}_{2} \mathrm{O} \rightarrow \mathrm{H}_{2} \mathrm{O}^{+}+e^{-}$, que pode ocorrer mediante a fótons com energias $\gtrsim 15 \mathrm{eV}$.

Assim, atinge-se um estágio do processo onde elétrons secundários (secondary electrons - SE) são o produto em maior abundância (cerca de $5 \times 10^{4} / \mathrm{MeV}$ de radiação incidente), ao lado de radicais hidroxilas, íons e outros radicais livres. Devido às sucessivas colisões inelásticas com os constituintes do meio biológico, os SE atingem energias menores que $20 \mathrm{eV}$, à temperatura ambiente, em intervalos de tempo da ordem de $\sim 10^{-12} \mathrm{~s}$, e tornam-se aí o que se chama de elétrons pré-hidratados[6]. Os elétrons préhidratados podem permanecer no meio aquoso e termalizar, sofrendo um processo de solvatação tornando-se elétrons hidratados, uma espécie pouco reativa, ou podem atingir energias suficientemente baixas para sofrerem eventuais capturas em regiões de alta eletroafinidade de biomoléculas que ali residem.

Por muito tempo considerou-se que as biomoléculas fossem danificadas, prioritariamente, pela ação dos radicais hidroxilas. O primeiro trabalho experimental que sugere que elétrons de baixas energias podem, por si só, causar danos em fitas simples e duplas de DNA foi realizado por Boudaïfa et al.[1]. O experimento proposto dispunha de um arranjo onde ocorriam colisões entre elétrons livres com energia cinética entre 0 e 20 eV e segmentos de DNA plasmídico absorvido em filme, e os resultados observados estão dispostos na Fig. 1.1. O estudo mostra que elétrons de baixas energias (4$10 \mathrm{eV}$ ) podem de fato causar quebras em fitas duplas (double strand-break - DSBs) e simples (single strand-break - SSBs) de DNA[3].

Um outro trabalho recente relacionado ao fenômeno foi proposto por Wang et al.[2]. Um experimento de excitação e prova (pump-probe) foi realizado na qual pôde-se observar a dissociação de nucleotídeos quando submetidos à captura eletrônica em meio aquoso. A reação que buscou-se 


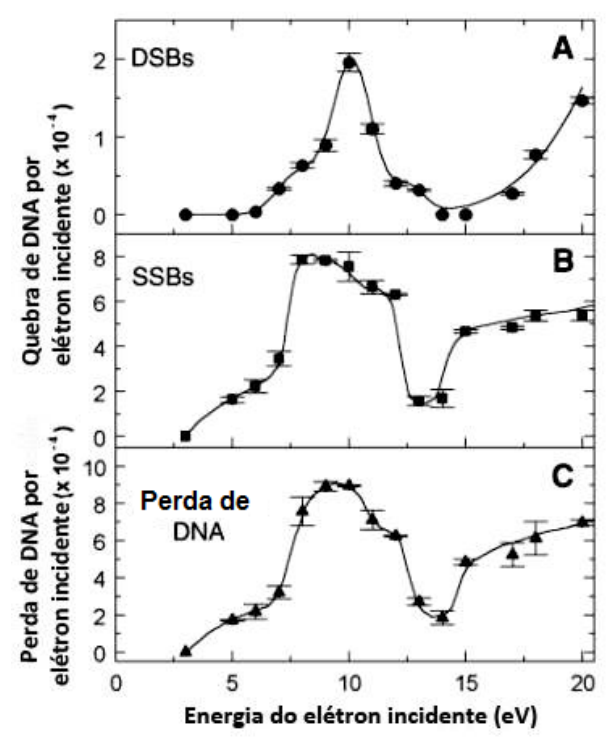

(a)

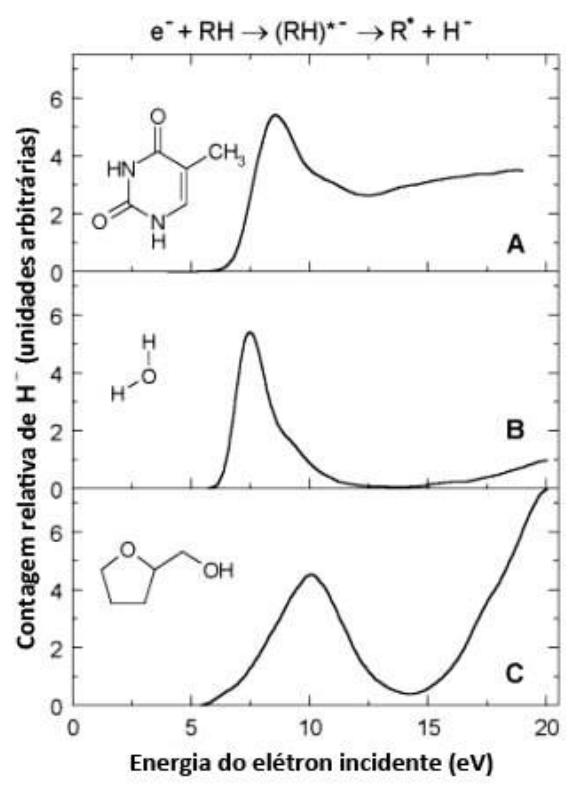

(b)

Figura 1.1: (Modificado da referência[1])(a) Contagem de quebras de fitas duplas (A) e simples (B) em termos da energia do elétron incidente, em eV. (b) Contagem de produto $\mathrm{H}^{-}$em função da energia do elétron incidente. A contagem de produto $\mathrm{H}^{-}$na reação $e^{-}+\mathrm{RH} \rightarrow \mathrm{RH}^{*-} \rightarrow \mathrm{R}+\mathrm{H}^{-}$.

observar foi $e_{\text {pre }}^{-}+\mathrm{dXMP} \rightarrow \mathrm{dXMP}{ }^{*-} \rightarrow$ dissociação de dXMP (Fig. 1.2).

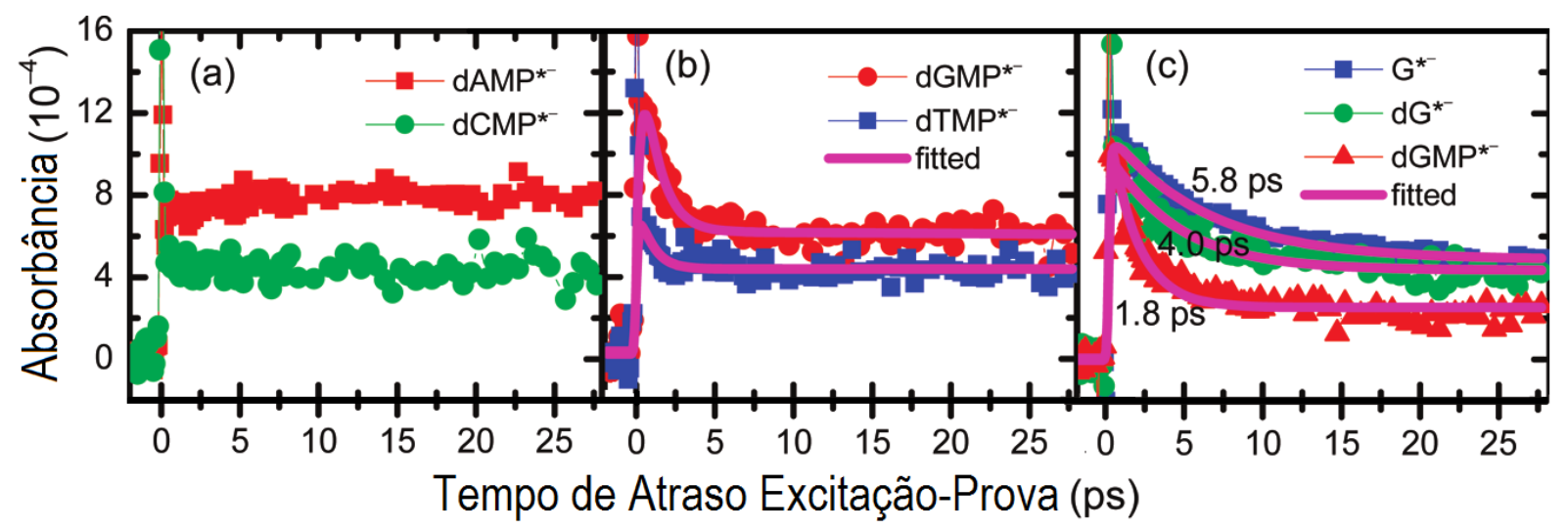

Figura 1.2: (Modificado da referência[2])Resultados obtidos no experimento de Excitação e Prova realizado realizado por Wang et al.. Observou-se experimentalmente a dissociação dos nucleotídeos monofosfatos dTMP e dGMP em solução aquosa.

As medidas apontam que o elétron pode, de fato, ser capturado pelas bases nitrogenadas dTMP e dGMP formando ânions transientes, que podem dissociar em um intervalo de $\sim 5$ ps. Por outro lado, dissociações dos nucleotídeos dAMP e dCMP não foram observadas nesse estudo.

O que foi proposto sobre o fenômeno[3] é que o elétron de baixa energia, 
ao colidir com a biomolécula, é aprisionado em um estado transiente. Ao capturar o elétron em um estado transiente, o sistema pode espalhar o elétron, devolvendo-o ao meio contínuo, ou pode acoplá-lo num estado ligado cujo tempo de vida é suficientemente grande para que a energia cinética do elétron incidente seja transferida para os graus de liberdade de vibração nuclear, e possivelmente ocorrer uma dissociação (Fig. 1.3).

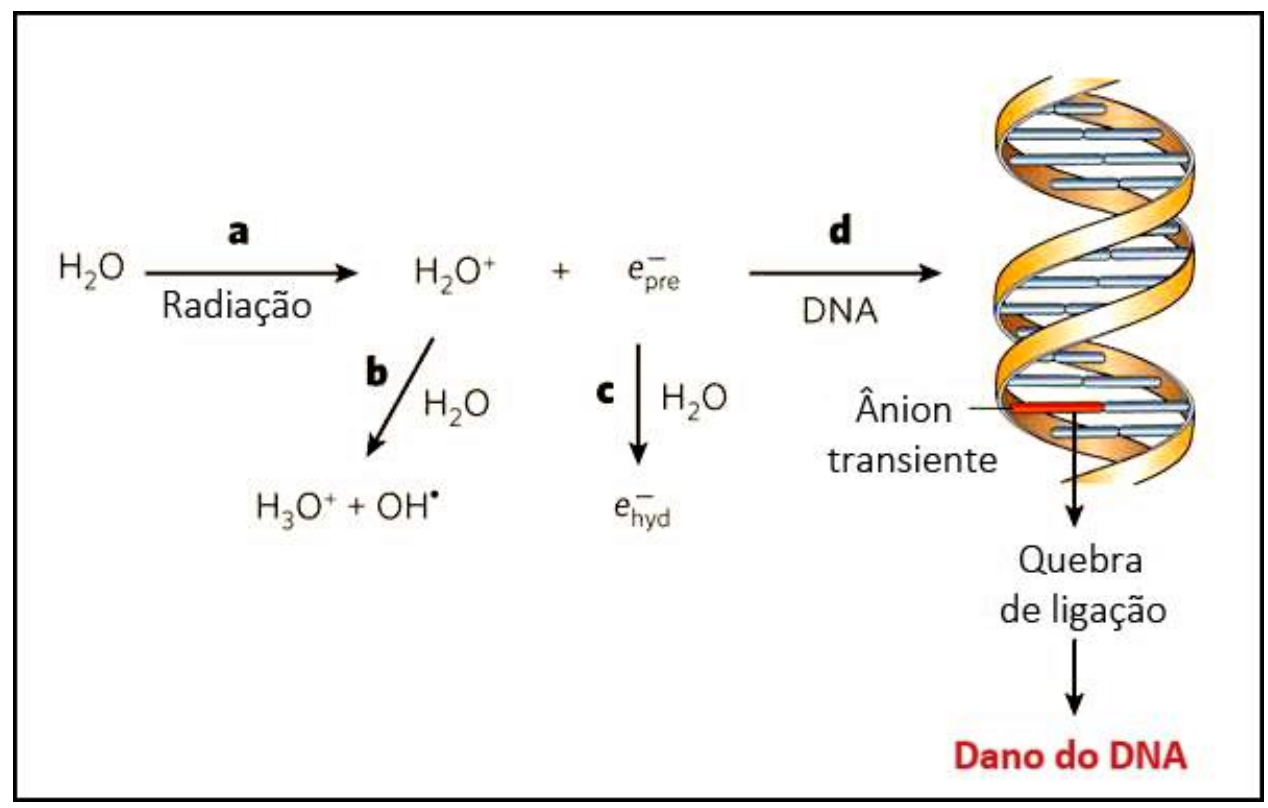

Figura 1.3: (Modificado da referência [3])(a) Quando moléculas de água absorvem radiação de alta energia, elas podem ionizar produzindo $\mathrm{H}_{2} \mathrm{O}^{+}$e $e^{-}$livres. Após perderem sua energia cinética devido a colisões inelásticas, os elétrons atingem um estágio de préhidratados $e_{\text {pre }}^{-}$, que possuem um período de meia-vida relativamente curto. (b) Os íons $\mathrm{H}_{2} \mathrm{O}^{+}$reagem com mais moléculas de água para formar águas protonadas $\mathrm{H}_{3} \mathrm{O}^{+}$e radicais hidroxilas $\mathrm{OH}^{-}$. Pensou-se por muito tempo que a maior parte dos danos em DNA era causado por esses radicais livres. (c) Elétrons pré-hidratados formam complexos ao interagirem com moléculas de água, tornando-se elétrons hidratados. (d) Um trabalho realizado por Wang et al.[2] mostrou que elétrons pré-hidratados podem reagir com bases de certos nucleotídeos (dGMP e dTMP) em solução aquosa. Isso sugere que elétrons de baixas energias podem reagir com bases do DNA para formar ânions transientes. Em alguns casos, esses ânions podem ocasionar uma quebra de ligação molecular, ocasionado possíveis danos na molécula de DNA.

\section{$1.1 \quad$ Nucleotídeos e dGMP}

Para se investigar fenômenos envolvendo quebra de fita de DNA, o modelo molecular mínimo é o nucleotídeo. Isso se deve ao fato de que o 
nucleotídeo contém a base nitrogenada, onde o elétron é devidamente capturado, e contém os grupos açúcar e fosfato, que representam o backbone da fita onde a ruptura supostamente ocorre. Processos envolvendo a captura eletrônica por nucleotídeos foram investigados experimentalmente em trabalhos citados anteriormente.

Assim, teoricamente, a captura eletrônica por biomoléculas como nucleotídeos possui diferentes regimes de energia e podem ser abordadas pelo ponto de vista de espalhamento eletrônico ou por técnicas de estado ligado, sendo a última mais conveniente para descrever capturas eletrônicas de elétrons com energias cinéticas próximas a $\sim 0 \mathrm{eV}$ e computacionalmente mais eficaz para se estudar processos em solução, devido às condições de contorno do problema de espalhamento.

Estudou-se os quatro nucleotídeos monofosfatos do DNA (dAMP, dCMP, dTMP e dGMP) anteriormente e, à luz de um mecanismo geral, econtrouse $[7,8]$ orbitais de natureza $\pi^{*}$ no ânion $\mathrm{dXMP}^{-}$relacionados à captura eletrônica e, além disso, estimou-se barreiras de energia potencial (ou barreira de ativação) associada a diversas possíveis rupturas da biomolécula. Concluiu-se que as rupturas de caráter mais apreciável e, portanto, são as que possuem as menores barreiras de ativação, são estiramentos entre o grupo fosfato e o açúcar, além do estiramento da ligação $N$-glicosídica entre o açúcar e a base nitrogenada (entretanto, ao contrário das duas primeiras, essa última ruptura não dá origem a uma quebra da fita de DNA).

Considerando a aproximação Born-Oppenheimer (que será discutida no capítulo 2), o mecanismo de captura está disposto na Fig. 1.3. No esquema, estão representadas a curva de energia potencial adiabáticas do estado eletrônico da espécie neutra, $S_{0}$, e as curvas de energia potencial de dois estados eletrônicos do ânion. Como citado anteriormente, se tratando das bases dXMP (em que X pode ser A, C, T ou G), o elétron deve ser capturado em um orbital $\pi^{*}$ localizado na base nitrogenada. A energia do elétron incidente transferida para os graus de liberdade de vibração nuclear da molécula pode fazer com que a mesma se desloque para o cruzamento 
entre as duas curvas de energia potencial, havendo assim uma probabilidade do sistema passar para um estado $\sigma^{*}$, localizado sobre a ligação da reação, que é dissociativo.
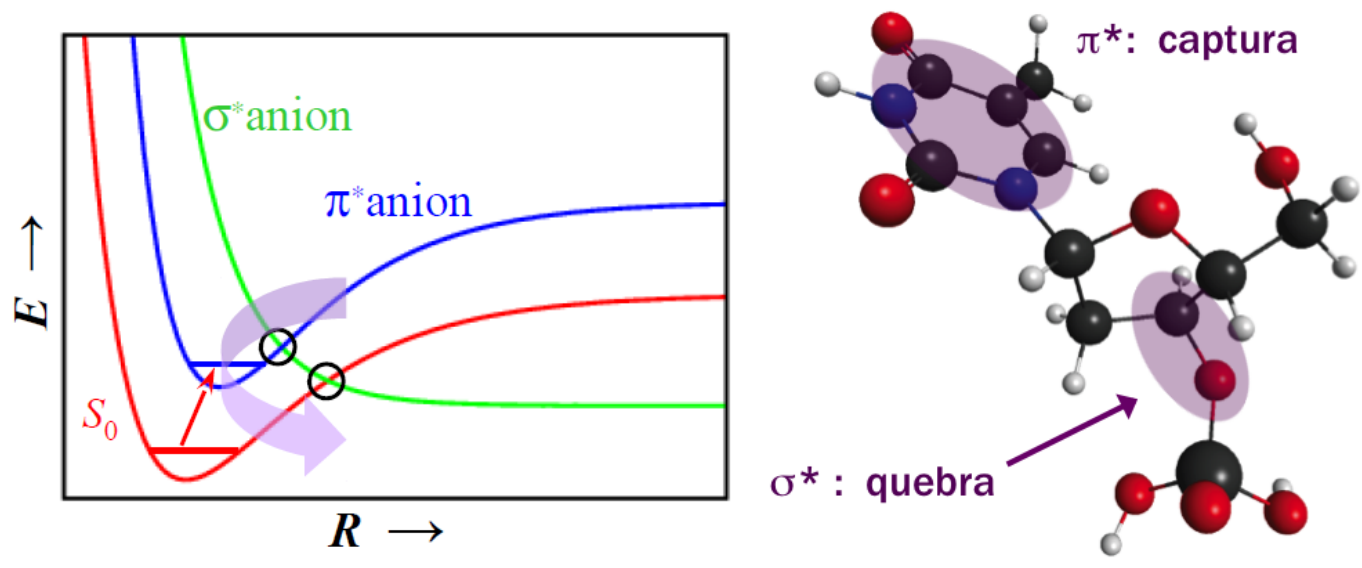

Figura 1.4: Esquema do mecanismo de dissociação induzida por captura eletrônica.

$$
A B+e_{\text {pre }}^{-}(E<20 \mathrm{eV}) \rightarrow A B^{*-} \rightarrow A^{-}+B
$$

As duas possíveis quebras entre o grupo fosfato e o açúcar em nucleotídeos monofosfatos estão relacionadas com as duas possíveis configurações do fosfato na molécula. A saber, o fosfato pode estar ligado ao carbono $\mathrm{C}_{3^{\prime}}$ ou $\mathrm{C}_{5^{\prime}}$ da ribose. As moléculas assim dispostas são chama-

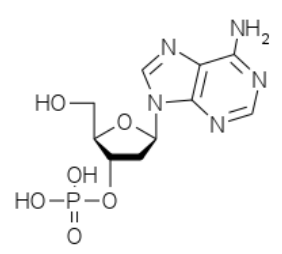

(a)

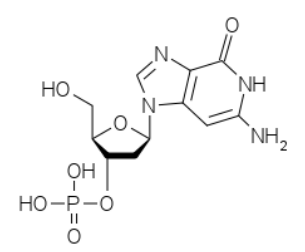

(e)

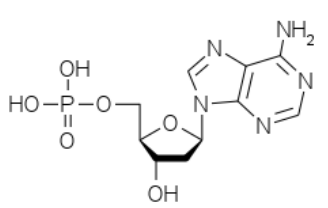

(b)

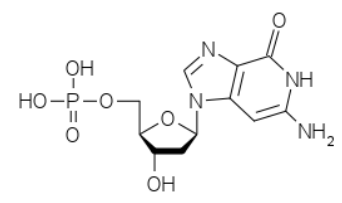

(f)

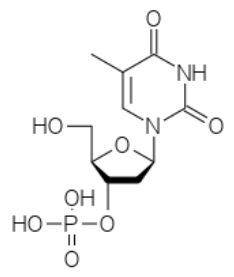

(c)

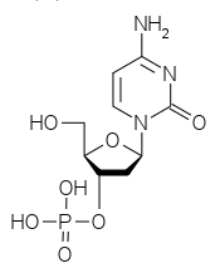

(g)

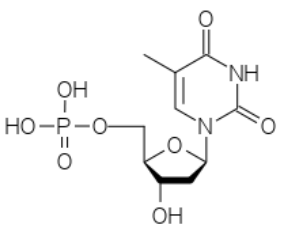

(d)

Figura 1.5: Estruturas bidimensionais das moléculas (a) 3'-dAMP (b) 5'-dAMP (c) 3'-dTMP (d) 5'-dTMP (e) 3'-dGMP (f) 5'-dGMP (g) 3'-dCMP (h) 5'-dCMP.

das de $3^{\prime}$-dXMP e 5'-dXMP (X=A, C, G ou T). No caso da guanina $(\mathrm{G})$, 
por exemplo, as nomenclaturas são 2'-deoxyguanosina-3'-monofosfato e 2'deoxyguanosina-5'-monofosfato. As ligações que se rompem no processo de dissociação em pauta são as ligações $\mathrm{C}_{3^{\prime}}-\mathrm{O}_{3^{\prime}}$ ou $\mathrm{C}_{5^{\prime}}-\mathrm{O}_{5^{\prime}}$ (Fig. 1.5), em que os oxigênios $\mathrm{O}_{3^{\prime}}$ e $\mathrm{O}_{5^{\prime}}$ pertencem ao grupo fosfato, nas duas possíveis configurações.
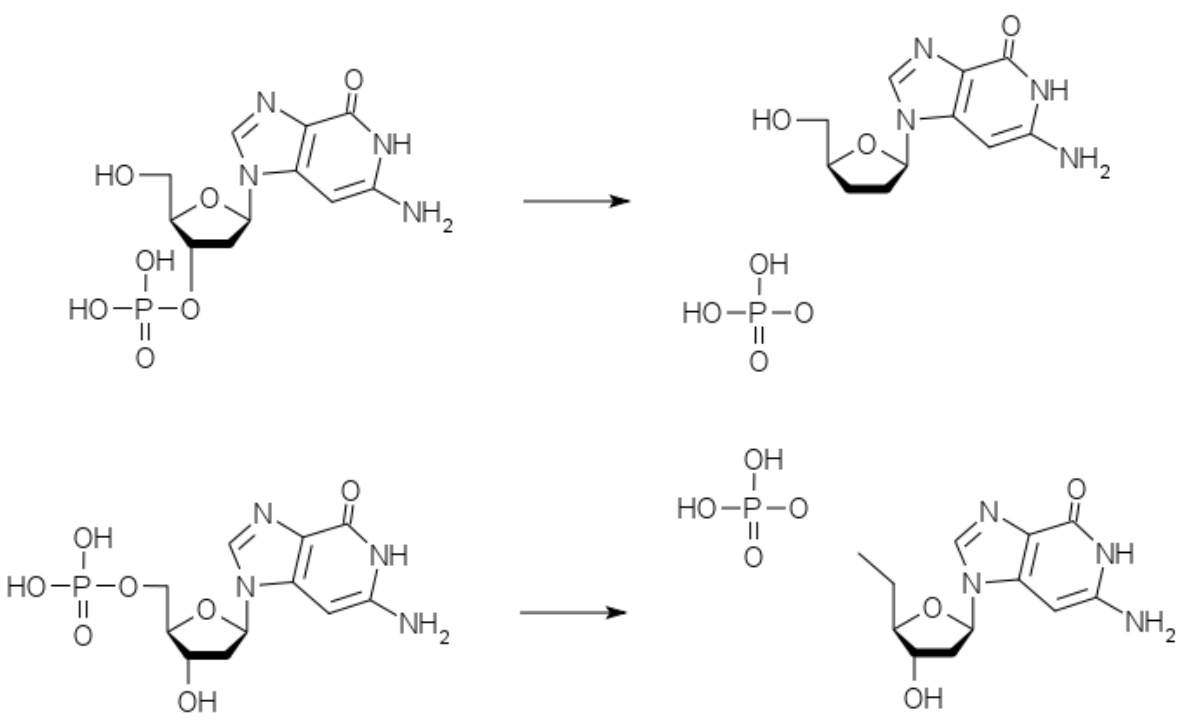

Figura 1.6: Esquema da dissociação da (a) $3^{\prime}$-dGMP ${ }^{-}$- em que a quebra ocorre entre o carbono $\mathrm{C}_{3^{\prime}}$, da ribose, e o oxigênio $\mathrm{O}_{3^{\prime}}$, do grupo fosfato - e (b) $5^{\prime}$-dGMP ${ }^{-}$- em que a quebra ocorre entre o carbono $\mathrm{C}_{5^{\prime}}$, da ribose, e o oxigênio $\mathrm{O}_{5^{\prime}}$, do grupo fosfato.

A barreira de ativação do processo é dada por:

$$
\Delta E=E(\mathrm{ts})-E(\mathrm{opt})
$$

em que $E$ (ts) e $E$ (opt.) são as energias do estado de transição e do estado otimizado, respectivamente.

Trabalhos teóricos recentes discutem os valores de $\Delta E[9,10,11]$ com o uso de diferentes métodos de estrutura eletrônica em diferentes modelos de solvatação. Concluiu-se em um deles[10] que a barreira associada à ruptura da guanina - 3'-dGMP - é a menor entre todos os nucleotídeos, fazendo com que ela seja a ligação mais fraca na estrutura de fita do DNA. Além disso, o fato de a molécula dGMP ser altamente polar, faz com que a estrutura eltrônica da $3^{\prime}-\mathrm{GMP}^{-}$em fase gasosa possua um caráter de dipolo[8], ao invés de uma estrutura $\pi^{*}$, contrariando o mecanismo de 
captura previamente previsto.

O projeto envolve rediscutir o mecanismo de captura eletrônica do nucleotídeo associado à guanina 3'-dGMP, procurando questionar a estrutura eletrônica no vácuo e em solução aquosa. Além disso, buscou-se estimar barreiras de energia potencial e energia livre relacionadas à ruptura ânion $3^{\prime}-\mathrm{dGMP}^{-}$.

\section{Organização do Texto}

No capítulo 2 está decrito de maneira resumida os métodos de estrutura eletrônica utilizados no trabalho, como o método Hartree-Fock (HF) e a Teoria do Funcional da Densidade (DFT). Além disso está disposta uma sucinta discussão dos conjuntos de base utilizados e as metodologias para a investigação de geometrias otimizadas e estados de transição. Em seguida, no capítulo 3, estão descritos os métodos de solvatação implícita (modelos contínuos - PCM) e explícita (simulações computacionais) utilizados para a modelagem da solução aquosa e para os estudos de seus efeitos na estrutura eletrônica e na termoquímica do processo de dissociação. Finalmente, no capítulo 4, mostra-se os resultados obtidos e suas análises. Além das análises ao longo dos resultados, ao final do capítulo encontra-se uma discussão geral dos resultados obtidos e das conclusões. No capítulo 5 estão dispostas breves considerações finais. 


\section{Capítulo 2}

\section{Métodos Teóricos I - Estrutura Eletrônica de Moléculas Isoladas}

O projeto aborda o problema em questão do ponto de vista de estrutura eletrônica. Quanticamente, a estrutura eletrônica e diversas propriedades de um sistema molecular são dadas através de soluções da equação de Schrödinger. Porém, a equação de Schrödinger dificilmente possui uma solução analítica, principalmente ao se tratar de sistemas físicos envolvendo muitos corpos, sendo necessário recorrer a métodos de aproximação. Assim, utilizam-se métodos de mecânica quântica para se resolver a equação de Schrödinger independente do tempo aproximadamente. Este capítulo descreve de forma sucinta os fundamentos e as características dos métodos utilizados nesse trabalho.

\subsection{Separação e Aproximação de Born-Oppenheimer}

A equação de Schrödinger independente do tempo para um sistema molecular de $N$ elétrons e $M$ núcleos é[12, 13, 14]:

$$
\hat{\mathcal{H}} \Psi=E \Psi
$$

Em que $\Psi \equiv \Psi(\mathbf{X})$ é a função de onda molecular, $\mathbf{X}$ é um vetor multidimensional que representa a posição de todos os núcleos e elétrons e $\hat{\mathcal{H}}$ é o operador hamiltoniano do sistema, usualmente chamado de hamiltoni- 
ano molecular. Em unidades atômicas $\left(m_{e}=\hbar=e=\left(4 \pi \epsilon_{0}\right)^{-1}=1\right)$, o hamiltoniano molecular possui a seguinte expressão:

$$
\begin{aligned}
\hat{\mathcal{H}}=-\sum_{\mu=1}^{M} \frac{1}{2 M_{\mu}} \nabla_{\mu}^{2} & -\frac{1}{2} \sum_{i=1}^{N} \nabla_{i}^{2}-\sum_{i=1}^{N} \sum_{\mu=1}^{M} \frac{Z_{\mu}}{\left|\mathbf{r}_{i}-\mathbf{R}_{\mu}\right|}+\sum_{i=1}^{N} \sum_{j<i}^{N} \frac{1}{\left|\mathbf{r}_{i}-\mathbf{r}_{j}\right|}+ \\
& +\sum_{\mu=1}^{M} \sum_{\nu<\mu}^{M} \frac{Z_{\mu} Z_{\nu}}{\left|\mathbf{R}_{\mu}-\mathbf{R}_{\nu}\right|}
\end{aligned}
$$

Em que $M_{\mu}$ é a massa do $\mu$-ésimo núcleo, $\mathbf{r}_{i}$ e $\mathbf{R}_{\mu}$ são as posições do $i$-ésimo elétron e do $\mu$-ésimo núcleo, respectivamente. As quantidades $\left|\mathbf{r}_{i}-\mathbf{R}_{\mu}\right| \equiv R_{i \mu},\left|\mathbf{r}_{i}-\mathbf{r}_{j}\right| \equiv r_{i j}$ e $\left|\mathbf{R}_{\mu}-\mathbf{R}_{\nu}\right| \equiv R_{\mu \nu}$ são as posições relativas entre um elétron e um núcleo, entre dois elétrons e entre dois núcleos, respectivamente. $\mathrm{O}$ operador diferencial $\nabla_{i}^{2}$ corresponde às derivadas com relação as coordenadas do vetor $\mathbf{r}_{i}$, enquanto que o operador $\nabla_{\mu}^{2}$ corresponde às derivadas com relação as coordenadas do vetor $\mathbf{R}_{\mu}$. Ou seja, com uma notação ligeiramente simplificada:

$$
\hat{\mathcal{H}}=-\sum_{\mu=1}^{M} \frac{1}{2 M_{\mu}} \nabla_{\mu}^{2}-\frac{1}{2} \sum_{i=1}^{N} \nabla_{i}^{2}-\sum_{(i, \mu)} \frac{Z_{\mu}}{R_{i \mu}}+\sum_{(i, j)} \frac{1}{r_{i j}}+\sum_{(\mu, \nu)} \frac{Z_{\mu} Z_{\nu}}{R_{\mu \nu}}
$$

em que as três últimas somas são realizadas sobre os pares indicados.

Esse operador pode ser escrito como:

$$
\hat{\mathcal{H}}=\hat{T}_{N}+\hat{T}_{e}+\hat{V}_{N e}+\hat{V}_{e}+\hat{V}_{N}
$$

Em que $\hat{T}$ é o operador associado à energia cinética dos núcleos, $\hat{T}_{e}$ é o operador associado à energia cinética dos elétrons, $\hat{V}_{N e}$ é a energia potencial de interação núcleo-elétron, $\hat{V}_{e}$ é a interação elétron-elétron e $\hat{V}_{N}$ é a interação núcleo-núcleo, todos eles dispostos na expressão acima. O hamiltoniano molecular pode ser entendido como uma soma de um termo eletrônico $\hat{\mathcal{H}}_{\text {ele }}=\hat{T}_{e}+\hat{V}_{N e}+\hat{V}_{e}$ e um termo nuclear $\hat{\mathcal{H}}_{n}=\hat{T}_{N}+\hat{V}_{N}$.

A separação de Born-Oppenheimer é usualmente considerada como um ponto de partida para se tratar quanticamente sistemas moleculares, e sua principal ideia é a de se propor uma função de onda que separa o movi- 
mento dos núcleos e dos elétrons. A motivação central da proposta se dá ao fato dos núcleos possuírem massas muito maiores que a dos elétrons e isso, portanto, origina uma desigualdade notável entre seus movimentos no decorrer da dinâmica do sistema. Apesar de a argumentação formal e condições de validade dessa proposta serem muito mais complexas do que essa desigualdade, medidas espectroscópicas justificam experimentalmente a tendência de os movimentos de núcleos e elétrons serem fisicamente distintos, de modo que os últimos se movem aproximadamente em um campo de núcleos fixos. Matematicamente, a separação descreve um estado eletrônico como uma função das coordenadas eletrônicas como sendo obtida para uma determinada configuração fixa dos núcleos, e portanto diz-se que o estado eletrônico é uma função paramétrica das coordenadas nucleares, $\psi(\mathbf{r} \mid \mathbf{R})$, em que aqui, o vetor $\mathbf{R}$ representa apenas a posição dos núcleos e $\mathbf{r}$ representa a posição dos elétrons. Isto é, $\mathbf{R}=\left\{\mathbf{R}_{1}, \ldots, \mathbf{R}_{M}\right\}$, $\mathbf{r}=\left\{\mathbf{r}_{1}, \ldots, \mathbf{r}_{N}\right\}$ e $\mathbf{X}=\{\mathbf{R}, \mathbf{r}\}$.

Assim, a equação de Schrödinger (2.1) pode ser separada. A parte eletrônica da equação toma a seguinte forma:

$$
\hat{\mathcal{H}}_{e l e} \psi(\mathbf{r} \mid \mathbf{R})=\epsilon \psi(\mathbf{r} \mid \mathbf{R})
$$

Em que o auto valor $\epsilon=\epsilon(\mathbf{R})$ é uma função das coordenadas nucleares devido a dependência paramétrica das funções de onda eletrônicas. A equação (2.6) pode ser resolvida para uma família de funções $\psi_{m}(\mathbf{r} \mid \mathbf{R})$, com $m=0,1,2, \ldots$.

$$
\hat{\mathcal{H}}_{e l e} \psi_{m}(\mathbf{r} \mid \mathbf{R})=\epsilon_{m}(\mathbf{R}) \psi_{m}(\mathbf{r} \mid \mathbf{R})
$$

Isso significa que a equação de Schrödinger eletrônica pode ser resolvida para toda configuração de núcleos fixos R. Nesse regime, a energia do sistema associada a um certo estado eletrônico $m$, como uma função de $\mathbf{R}$, é descrita como uma hipersuperfície $M$-dimensional da forma: 


$$
E_{m}(\mathbf{R})=\epsilon_{m}(\mathbf{R})+\sum_{\mu=1}^{M} \sum_{\nu<\mu}^{M} \frac{Z_{\mu} Z_{\nu}}{\left|\mathbf{R}_{\mu}-\mathbf{R}_{\nu}\right|}
$$

Além disso, temos que o conjunto de soluções da equação de Schrödinger eletrônica são considerados devidamente normalizados. Temos, portanto, a seguinte relação de ortonormalidade:

$$
\int \psi_{n}^{*}(\mathbf{r} \mid \mathbf{R}) \psi_{m}(\mathbf{r} \mid \mathbf{R}) \mathrm{d} \mathbf{r}=\delta_{n m}
$$

Em que $\delta_{n m}$ é o delta de Kroenecker. Na notação do Dirac, a relação de ortonormalidade acima é descrita através do produto interno entre os vetores de estado eletrônicos:

$$
\left\langle\psi_{n} \mid \psi_{m}\right\rangle=\delta_{n m}
$$

Em vista dessa observação, é possível expandir a função de onda molecular $\Psi(\mathbf{X})$ em termos das auto-funções do hamiltoniano eletrônico.

$$
\Psi(\mathbf{X})=\sum_{m} \Phi_{m}(\mathbf{R}) \psi_{m}(\mathbf{r} \mid \mathbf{R})
$$

Essa expansão é conhecida como expansão de Born-Huang e os coeficientes $\Phi_{m}(\mathbf{R})$ estão associados à função de onda nuclear.

Para se determinar os coeficientes da expansão acima, substitui-se a expressão (2.10) na equação (2.1):

$$
\hat{\mathcal{H}}\left(\sum_{m} \Phi_{m}(\mathbf{R}) \psi_{m}(\mathbf{r} \mid \mathbf{R})\right)=E \sum_{m} \Phi_{m}(\mathbf{R}) \psi_{m}(\mathbf{r} \mid \mathbf{R})
$$

E, com o uso das equações (2.6) e (2.7):

$$
\sum_{m}\left(-\sum_{\mu=1}^{M} \frac{1}{2 M_{\mu}} \nabla_{\mu}^{2}+\left(E_{m}(\mathbf{R})-E\right)\right) \Phi_{m}(\mathbf{R}) \psi_{m}(\mathbf{r} \mid \mathbf{R})=0
$$

Projetando-se a equação (2.12) sobre um estado eletrônico $\psi_{n}(\mathbf{r} \mid \mathbf{R})$, ou 
seja, multiplicando-se ambos os lados pela função de onda eletrônica $\psi_{n}^{*}(\mathbf{r} \mid \mathbf{R})$ e integrando-a sobre todas as coordenadas eletrônicas, obtemos:

$$
\begin{aligned}
& \left(-\sum_{\mu=1}^{M} \frac{1}{2 M_{\mu}} \nabla_{\mu}^{2}+E_{n}(\mathbf{R})-\sum_{\mu=1}^{M} \frac{1}{M_{\mu}}\left(\nabla_{\mu}^{2}\right)_{n n}\right) \Phi_{n}(\mathbf{R})= \\
E \Phi_{n}(\mathbf{R})+ & +\sum_{m \neq n} \sum_{\mu=1}^{M} \frac{1}{M_{\mu}}\left(\left(\nabla_{\mu}\right)_{n m} \cdot \nabla_{\mu}+\frac{\left(\nabla_{\mu}^{2}\right)_{n m}}{2}\right) \Phi_{n}(\mathbf{R})
\end{aligned}
$$

com

$$
\left(\nabla_{\mu}\right)_{n m} \equiv\left\langle\psi_{n}\left|\nabla_{\mu}\right| \psi_{m}\right\rangle=\int \psi_{n}^{*}(\mathbf{r} \mid \mathbf{R}) \nabla_{\mu} \psi_{m}(\mathbf{r} \mid \mathbf{R}) \mathrm{d} \mathbf{r}
$$

e

$$
\left(\nabla_{\mu}^{2}\right)_{n m} \equiv\left\langle\psi_{n}\left|\nabla_{\mu}^{2}\right| \psi_{m}\right\rangle=\int \psi_{n}^{*}(\mathbf{r} \mid \mathbf{R}) \nabla_{\mu}^{2} \psi_{m}(\mathbf{r} \mid \mathbf{R}) \mathrm{d} \mathbf{r}
$$

Os elementos de matriz $\left(\nabla_{\mu}\right)_{n m}$ e $\left(\nabla_{\mu}^{2}\right)_{n m}$ diagonais $(n=m)$ são chamados de termos de acoplamentos adiabáticos, enquanto que os elementos não diagonais $(n \neq m)$ são acoplamentos não adiabáticos.

A aproximação adiabática considera os termos de acoplamentos não adiabáticos (elementos não diagonais) como sendo desprezíveis, resultando na seguinte equação de Schrödinger nuclear:

$$
\left(-\sum_{\mu=1}^{M} \frac{1}{2 M_{\mu}} \nabla_{\mu}^{2}+E_{n}(\mathbf{R})-\sum_{\mu=1}^{M} \frac{1}{M_{\mu}}\left(\nabla_{\mu}^{2}\right)_{n n}\right) \Phi_{n}(\mathbf{R})=E \Phi_{n}(\mathbf{R})
$$

Essa aproximação define uma equação para o movimento nuclear vibracional a partir da solução para o problema eletrônico (2.7), no qual, a princípio, os núcleos foram considerados fixos. Tomando o limite de massa nuclear infinita, o último termo do hamiltoniano aproximado tornase desprezível, definindo-se assim o que chamamos de aproximação de BornOppenheimer (BO).

$$
\frac{1}{M_{\mu}}\left(\nabla_{\mu}^{2}\right)_{n n} \sim 0
$$




$$
\left(-\sum_{\mu=1}^{M} \frac{1}{2 M_{\mu}} \nabla_{\mu}^{2}+E_{n}(\mathbf{R})\right) \Phi_{n}^{(B O)}(\mathbf{R})=E \Phi_{n}^{(B O)}(\mathbf{R})
$$

\subsubsection{Validade da Aproximação BO}

É possível demonstrar que os elementos de matriz (2.14) e (2.15) satisfazem, para $n \neq m$, a seguinte relação:

$$
\left(\nabla_{\mu}^{2}\right)_{n m}=\left[\left(\nabla_{\mu}\right)_{n m}\right]^{2}+\nabla_{\mu} \cdot\left(\nabla_{\mu}\right)_{n m}
$$

Isso indica que o acoplamento não adiabático entre estados eletrônicos distintos depende essencialmente do elemento de matriz $\left(\nabla_{\mu}\right)_{n m}$, o qual é desprezado na aproximação adiabática. Por outro lado, esse termo está relacionado com a diferença de energia entre estados eletrônicos da seguinte maneira:

$$
\left(\nabla_{\mu}\right)_{n m}=\frac{\left\langle\psi_{n}\left|\nabla_{\mu} \hat{\mathcal{H}}_{e l e}\right| \psi_{m}\right\rangle}{U_{n}(\mathbf{R})-U_{m}(\mathbf{R})}
$$

onde

$$
U_{n}(\mathbf{R}) \equiv E_{n}(\mathbf{R})-\sum_{\mu=1}^{M} \frac{1}{M_{\mu}}\left(\nabla_{\mu}^{2}\right)_{n n}
$$

O resultado acima significa que a aproximação adiabática e a aproximação de Born-Oppenheimer são válidas em regiões onde os estados eletrônicos são energeticamente distantes, sendo tipicamente válida para estados fundamentais em torno da configuração nuclear de mínima energia. Entretanto, para estados excitados ou para o estado fundamental longe da configuração de mínima energia, a aproximação adiabática pode não ser satisfatória, fazendo com que a descrição do sistema necessite de métodos menos aproximados.

Em termos gerais, a separação Born-Oppenheimer nos fornece a possibilidade de tratarmos o problema eletrônico, o qual se encarrega das propriedades físicas de interesse do ponto de vista de estrutura eletrônica. Mesmo assim, a equação (2.6) não possui, no geral, uma solução analítica e portanto necessita de métodos de resoluções aproximadas, que serão dis- 
cutidos nas próximas seção.

\subsection{Funções de Onda Multi-Eletrônicas}

Em um sistema de muitos corpos não podemos, em geral, solucionar a equação de Schrödinger exatamente. Entretanto, a separação de BornOppenheimer nos proporciona uma equação para o problema eletrônico (2.6) que deve ser resolvida, num sistema molecular, para um conjunto de $N$ elétrons indistinguíveis.

Pela Aproximação de Partícula Independente, podemos construir a função de onda de muitos elétrons a partir de funções de onda de um único elétron. Cada uma dessas funções pode ser construída como um produto entre a parte espacial e o termo de $\operatorname{spin}^{1}$, definindo o que chamamos de spinorbitais.

$$
\chi\left(\mathbf{r}_{i}\right)=\phi\left(\mathbf{r}_{i}\right) \xi\left(S_{i}\right)
$$

em que, aqui, o índice $i$ se refere ao $i$-ésimo elétron, $\phi\left(\mathbf{r}_{i}\right)$ a função de onda orbital e $\xi\left(S_{i}\right)$ é o termo de spin do spin-orbital. Para uma partícula de spin $s$, a função $\xi$ pode assumir $2 s+1$ possíveis estados. No caso particular do elétron, um férmion de spin $1 / 2$, a função pode assumi apenas dois valores, associados às duas possíveis configurações up e down, as quais usaremos a seguinte notação:

$$
\xi\left(S_{i}\right)= \begin{cases}\alpha(i), & \uparrow \\ \beta(i), & \downarrow\end{cases}
$$

com

$$
\langle\alpha(i) \mid \alpha(i)\rangle=\langle\beta(i) \mid \beta(i)\rangle=1, \quad\langle\alpha(i) \mid \beta(i)\rangle=0
$$

A equação (2.21) constrói um elemento de uma família $\left\{\chi_{i}\right\}$ de spinorbitais associados a um único elétron. A partir disso, deve-se construir uma função de onda eletrônica que respeite o princípio da exclusão de Pauli, uma vez que estamos tratando de férmions. O princípio da exclusão exige que a função de onda seja antissimétrica quando submetida à troca de dois

\footnotetext{
${ }^{1} \mathrm{~A}$ rigor, o produto aqui descrito vale especialmente para átomos leves, nos quais acoplamentos spinórbitas são desprezíveis.
} 
elétrons. Uma proposta que respeita a antissimetria é a forma determinantal de Slater, em que a função de onda é escrita por um determinante de spin-orbitais:

$$
\psi(\mathbf{r})=\frac{1}{\sqrt{N !}}\left|\begin{array}{ccc}
\chi_{i}\left(\mathbf{r}_{1}\right) & \cdots & \chi_{k}\left(\mathbf{r}_{1}\right) \\
\chi_{i}\left(\mathbf{r}_{2}\right) & \cdots & \chi_{k}\left(\mathbf{r}_{2}\right) \\
\vdots & \ddots & \vdots \\
\chi_{i}\left(\mathbf{r}_{N}\right) & \cdots & \chi_{k}\left(\mathbf{r}_{N}\right)
\end{array}\right|
$$

em que

$$
\chi_{j}\left(\mathbf{r}_{i}\right)=\phi_{j}\left(\mathbf{r}_{i}\right) \xi\left(S_{i}\right)
$$

Definimos uma forma mais compacta:

$$
\chi_{j}\left(\mathbf{r}_{i}\right) \equiv \chi_{j}^{(i)}, \quad \phi_{j}\left(\mathbf{r}_{i}\right) \equiv \phi_{j}^{(i)}
$$

Note que a forma determinantal inverte seu sinal quando se realiza a troca das coordenadas entre dois elétrons, isto é, ao invertermos duas linhas da matriz a qual estamos calculando o determinante, a função de onda muda de sinal. Em uma notação mais simplificada:

$$
\psi(\mathbf{r})=(N !)^{-1 / 2}|| \chi_{i} \ldots \chi_{k}|\rangle
$$

Dessa forma conseguimos construir uma função de onda eletrônica que satisfaz o princípio da exclusão de Pauli. Além disso, construimos a função de onda com spin-orbitais linearmente independentes. Podemos, então, sempre escolhermos os orbitais $\phi$ 's ortonormais:

$$
\left\langle\phi_{j} \mid \phi_{k}\right\rangle=\int \phi_{j}^{*}\left(\mathbf{r}_{i}\right) \phi_{k}\left(\mathbf{r}_{i}\right) \mathrm{d} \mathbf{r}_{i}=\delta_{j k}
$$

Com essa escolha, o a função de onda eletrônica definida através do determinante (2.24) fica devidamente normalizado.

$$
\langle\psi \mid \psi\rangle=\int \psi^{*}(\mathbf{r}) \psi(\mathbf{r}) \mathrm{d} \mathbf{r}=1
$$

No caso geral, cada orbital molecular pode estar sendo ocupado por dois 
elétrons com diferentes estados de spin e, à princípio, podemos montar $K$ orbitais da seguinte maneira:

$$
\chi_{2 i-1}=\phi_{i} \alpha(i) \text { e } \chi_{2 i}=\phi_{i} \beta(i), \quad i=1,2, \ldots, K
$$

Ou seja, temos um total de $2 K$ spin-orbitais distintos. Com isso em mãos, é possível construirmos um número enorme de diferentes determinantes. A saber, esse número é dado pelo binomial:

$$
\left(\begin{array}{c}
2 K \\
N
\end{array}\right)=\frac{(2 K) !}{N !(2 K-N) !}
$$

A partir disso, precisamos determinar quais os orbitais moleculares tornam a função (2.24) uma solução de (2.6). Muitos métodos de estrutura eletrônica foram desenvolvidos até os dias de hoje, e os métodos utilizados no trabalho serão brevemente discutidos a seguir.

\subsection{O Método de Hartree-Fock}

O método de Hartree-Fock é um dos métodos mais populares em cálculos de estrutura eletrônica. Ele procura uma solução aproximada para o problema eletrônico (2.6) considerando apenas um único determinante de Slater para um sistema de $N$ elétrons:

$$
\psi(\mathbf{r})=\frac{1}{\sqrt{N !}}\left|\begin{array}{ccc}
\chi_{1}\left(\mathbf{r}_{1}\right) & \cdots & \chi_{N}\left(\mathbf{r}_{1}\right) \\
\chi_{1}\left(\mathbf{r}_{2}\right) & \cdots & \chi_{N}\left(\mathbf{r}_{2}\right) \\
\vdots & \ddots & \vdots \\
\chi_{1}\left(\mathbf{r}_{N}\right) & \cdots & \chi_{N}\left(\mathbf{r}_{N}\right)
\end{array}\right|=(N !)^{-1 / 2}|| \chi_{1} \ldots \chi_{N}|\rangle
$$

O funcional de Energia pode ser definido através da equação (2.6) como

$$
E[\psi]=\left\langle\psi\left|\hat{\mathcal{H}}_{\text {ele }}\right| \psi\right\rangle
$$

Lembrando que $\hat{\mathcal{H}}_{\text {ele }}=\hat{T}_{e}+\hat{V}_{N e}+\hat{V}_{e}$, o funcional definido acima pode ser 
desenvolvido da seguinte maneira ${ }^{2}$ :

$$
E[\psi]=\sum_{i}^{N} h_{i}+\frac{1}{2} \sum_{i=1}^{N} \sum_{j=1}^{N}\left(J_{i j}-K_{i j}\right)
$$

Em que:

$$
\begin{gathered}
h_{i} \equiv\left\langle\chi_{i}^{(i)}\left|-\frac{1}{2} \nabla_{i}^{2}-\sum_{\mu=1}^{M} \frac{Z_{\mu}}{R_{i \mu}}\right| \chi_{i}^{(i)}\right\rangle=\left\langle\chi_{i}^{(i)}|\hat{h}(i)| \chi_{i}^{(i)}\right\rangle \\
J_{i j} \equiv\left\langle\chi_{i}^{(i)} \chi_{j}^{(j)}\left|\frac{1}{r_{i j}}\right| \chi_{i}^{(i)} \chi_{j}^{(j)}\right\rangle \\
K_{i j} \equiv\left\langle\chi_{i}^{(i)} \chi_{j}^{(j)}\left|\frac{1}{r_{i j}}\right| \chi_{j}^{(i)} \chi_{i}^{(j)}\right\rangle
\end{gathered}
$$

A equação (2.35) define o valor esperado do operador de uma partícula $h_{i}$, enquanto que as equações (2.36) e (2.37) definem integrais de duas partículas.

Em seguida utiliza-se um procedimento variacional para minimizar o funcional (2.34) em relação aos spin-orbitais moleculares. Para isso, faz-se uso do método dos multiplicadores de Lagrange com o vínculo (2.28). No caso, devido ao vínculo, utilizamos $N^{2}$ multiplicadores de Lagrange e a condição de mínimo se torna:

$$
\delta\left(\left\langle\psi\left|\hat{\mathcal{H}}_{\text {ele }}\right| \psi\right\rangle-\sum_{i=1}^{N} \sum_{j=i}^{N} \varepsilon_{i j}\left(\left\langle\chi_{j} \mid \chi_{k}\right\rangle-\delta_{j k}\right)\right)=0
$$

Ao se desenvolver a condição de mínimo acima, obtemos um conjunto de equações conhecidas como equações de Hartree-Fock:

$$
\hat{F}(i)\left|\chi_{j}^{(i)}\right\rangle=\sum_{k=1}^{N} \varepsilon_{k j}\left|\chi_{j}^{(i)}\right\rangle
$$

Aqui, o operador $\hat{F}(i)$ é o operador de Fock e é definido a partir de

\footnotetext{
${ }^{2}$ Os termos de spin são ortogonais e não são influenciados pela ação do operador hamiltoniano.
} 
outros operadores:

$$
\hat{F}(i) \equiv \hat{h}(i)+\sum_{k=1}^{N}\left(\hat{\mathcal{J}}_{k}(i)-\hat{\mathcal{K}}_{k}(i)\right)
$$

os quais $\hat{\mathcal{J}}_{k}(i)$ e $\hat{\mathcal{K}}_{k}(i)$ são, respectivamente, os operadores de Coulomb e Exchange, cujas ações em um determinado orbital estão definidas a seguir:

$$
\begin{gathered}
\hat{\mathcal{J}}_{k}(i)\left|\chi_{j}^{(i)}\right\rangle=\left[\int \chi_{k}^{(n) *}\left(\mathbf{r}_{n}\right) \frac{1}{r_{i n}} \chi_{k}^{(n)} \mathrm{d} \mathbf{r}_{n}\right]\left|\chi_{j}^{(i)}\right\rangle \\
\hat{\mathcal{K}}_{k}(i)\left|\chi_{j}^{(i)}\right\rangle=\left[\int \chi_{k}^{(n) *} \frac{1}{r_{i n}} \chi_{j}^{(n)} \mathrm{d} \mathbf{r}_{n}\right]\left|\chi_{k}^{(i)}\right\rangle
\end{gathered}
$$

Isto é, os operadores acima são definidos explicitamente a partir de orbitais moleculares.

Os multiplicadores de Lagrange $\varepsilon_{i j}$ constituiem elementos de uma matriz hermitiana $\left\{\varepsilon_{i j}\right\}$, que pode, portanto, ser diagonalizada. A invariância da equação (2.40) sob uma transformação unitária nos permite a colocar, assim, sob a forma de uma equação usual de auto-valores e auto-estados:

$$
\hat{F}(i)\left|\chi_{j}^{(i)}\right\rangle=\varepsilon_{j}\left|\chi_{j}^{(i)}\right\rangle
$$

em que $\varepsilon_{j} \equiv \varepsilon_{j j}$.

As equações (2.43) para $j=1,2, \ldots$ são conhecidas como equações canônicas de Hartree-Fock e determinam os spin-orbitais moleculares que minimizam o funcional de energia eletrônica, com os auto-valores $\varepsilon$ 's estando associados às energias de cada orbital. Entretanto, o operador de Fock atuando num determinado estado depende explicitamente dos outros estados, o que faz com que o sistema de equações seja não linear. Por esse motivo o sistema é resolvido através de um processo iterativo, conhecido com ciclo de auto-consistência, ou SCF (Self-Consistent Field). Nesse procedimento, inicialmente são gerados spin-orbitais arbitrariamente. Em seguida a equação (2.43) é montada e resolvida, gerando assim um novo conjunto de spin-orbitais. O procedimento se repete até que o conjunto 
de orbitais, e o funcional de energia eletrônica, atinjam uma convergência pré-estabelecida.

\section{Método Hartree-Fock Restrito}

Em sistemas de camada fechada cada orbital está duplamente ocupado com eletróns cujos estados de spin são opostos. Com isso, as equações canônicas de Hartree-Fock podem ser simplificadas de modo a serem expressas em termos dos orbitais moleculares, apenas. Esse método é chamado de Hartree-Fock Restrito (RHF - Restricted Hartree-Fock).

$$
\hat{F}(i)\left|\phi_{j}^{(i)}\right\rangle=\varepsilon_{j}\left|\phi_{j}^{(i)}\right\rangle, \quad j=1,2, \ldots, \frac{N}{2}
$$

O operador de Fock é dado, aqui, por:

$$
\hat{F}(i) \equiv \hat{h}(i)+\sum_{k=1}^{N / 2}\left(2 \hat{\mathcal{J}}_{k}(i)-\hat{\mathcal{K}}_{k}(i)\right)
$$

com os operadores de Coulomb e Exchange agora dados em termos dos orbitais moleculares:

$$
\begin{aligned}
& \hat{\mathcal{J}}_{k}(i)\left|\phi_{j}^{(i)}\right\rangle=\left[\int \phi_{k}^{*}\left(\mathbf{r}_{n}\right) \frac{1}{r_{i n}} \phi_{k}\left(\mathbf{r}_{n}\right) \mathrm{d} \mathbf{r}_{n}\right]\left|\phi_{j}^{(i)}\right\rangle \\
& \hat{\mathcal{K}}_{k}(i)\left|\phi_{j}^{(i)}\right\rangle=\left[\int \phi_{k}^{*}\left(\mathbf{r}_{n}\right) \frac{1}{r_{i n}} \phi_{j}\left(\mathbf{r}_{n}\right) \mathrm{d} \mathbf{r}_{n}\right]\left|\phi_{k}^{(i)}\right\rangle
\end{aligned}
$$

Essas expressões são equivalentes às expressões gerais definidas anteriormente, com a diferença de que agora todos os operadores dizem respeito apenas à parte espacial dos spin-orbitais.

No método RHF realiza-se o ciclo SCF buscando determinar os orbtiais moleculares.

\section{Método Hartree-Fock Não-Restrito}

Em sistemas de camada aberta, isto é, com o número de elétrons $N$ ímpar, existem $n_{\alpha}$ elétrons cujo estado de spin é $\alpha$ e $n_{\beta}$ elétrons cujo estado de spin é $\beta$. O método para resolver o problema eletrônico pelo método 
Hartree-Fock é chamado de método Hartree-Fock Não-Restrito (UHF Unrestricted Hartree-Fock).

Um dos métodos Hartree-Fock não-restritos é o proposto por PopleNesbet, o qual o Hamiltoniano gera um funcional de energia eletrônico expresso da seguinte maneira:

$$
\begin{aligned}
E[\psi] & =\sum_{q=1}^{n_{\alpha}}\left\langle\chi_{q}^{\alpha}|\hat{h}| \chi_{q}^{\alpha}\right\rangle+\frac{1}{2} \sum_{q, l=1}^{n_{\alpha}}\left\langle\chi_{q}^{\alpha}\left|\hat{\mathcal{J}}_{l^{\alpha}}-\hat{\mathcal{K}}_{l^{\alpha}}\right| \chi_{q}^{\alpha}\right\rangle+ \\
& +\sum_{q=1}^{n_{\beta}}\left\langle\chi_{q}^{\beta}|\hat{h}| \chi_{q}^{\beta}\right\rangle+\frac{1}{2} \sum_{q, l=1}^{n_{\beta}}\left\langle\chi_{q}^{\beta}\left|\hat{\mathcal{J}}_{l^{\beta}}-\hat{\mathcal{K}}_{l^{\beta}}\right| \chi_{q}^{\beta}\right\rangle+ \\
& +\frac{1}{2} \sum_{q, l=1}^{n_{\alpha}, n_{\beta}}\left\langle\chi_{q}^{\alpha}\left|\hat{\mathcal{J}}_{l^{\beta}}\right| \chi_{q}^{\alpha}\right\rangle+\frac{1}{2} \sum_{q, l=1}^{n_{\beta}, n_{\alpha}}\left\langle\chi_{q}^{\beta}\left|\hat{\mathcal{J}}_{l^{\alpha}}\right| \chi_{q}^{\beta}\right\rangle
\end{aligned}
$$

aqui, os termos $\chi_{q}^{\alpha}$ estão associados aos spin-orbitais $\phi_{q}^{\alpha}\left(\mathbf{r}_{i}\right) \alpha(i)$, enquanto os termos $\chi_{q^{\beta}}^{\beta}$ estão associados aos spin-orbitais $\phi_{q}\left(\mathbf{r}_{i}\right) \beta(i)$. Os operadores $\hat{\mathcal{J}}_{l^{\xi}}$ e $\hat{\mathcal{K}}_{l^{\xi}}$, para $\xi=\alpha, \beta$, são definidos da seguinte maneira:

$$
\begin{gathered}
\hat{\mathcal{J}}_{q^{\xi}}(i)\left|\chi_{l \xi^{\prime}}^{(i)}\right\rangle=\left[\int \chi_{q^{\xi}}^{(n) *}\left(\mathbf{r}_{n}\right) \frac{1}{r_{i n}} \chi_{q^{\xi}}^{(n)} \mathrm{d} \mathbf{r}_{n}\right]\left|\chi_{l^{\xi}}^{(i)}\right\rangle \\
\hat{\mathcal{K}}_{q^{\xi}}(i)\left|\chi_{l \xi^{\xi}}^{(i)}\right\rangle=\left[\int \chi_{q^{\xi}}^{(n) *} \frac{1}{r_{i n}} \chi_{l \xi^{\xi}}^{(n)} \mathrm{d} \mathbf{r}_{n}\right]\left|\chi_{q^{\xi}}^{(i)}\right\rangle
\end{gathered}
$$

O procedimento a seguir consiste em minimizar o funcional (2.49) com os vínculos de ortonormalidade:

$$
\left\langle\chi_{q^{\xi}} \mid \chi_{l^{\xi}}\right\rangle=\delta_{q l} \delta_{\xi \xi}
$$

Utilizando os multiplicadores de Lagrange:

$$
\delta\left(E[\psi]-\sum_{q=1}^{n_{\alpha}} \varepsilon_{q}^{\alpha}\left(\left\langle\chi_{q^{\alpha}} \mid \chi_{q^{\alpha}}\right\rangle-1\right)-\sum_{q=1}^{n_{\beta}} \varepsilon_{q}^{\beta}\left(\left\langle\chi_{q^{\beta}} \mid \chi_{q^{\beta}}\right\rangle-1\right)\right)=0
$$

que, de maneira semelhante ao caso geral, resulta nas seguintes equações 
de auto-valores e auto-estados:

$$
\begin{aligned}
& \hat{\mathcal{F}}_{\alpha}(i)\left|\chi_{q^{\alpha}}^{(i)}\right\rangle=\varepsilon_{q}^{\alpha}\left|\chi_{q^{\alpha}}^{(i)}\right\rangle \\
& \hat{\mathcal{F}}_{\beta}(i)\left|\chi_{q^{\beta}}^{(i)}\right\rangle=\varepsilon_{q}^{\beta}\left|\chi_{q^{\beta}}^{(i)}\right\rangle
\end{aligned}
$$

com

$$
\begin{aligned}
& \hat{\mathcal{F}}_{\alpha}(i)=\hat{h}(1)+\sum_{l=1}^{n_{\alpha}}\left(\hat{\mathcal{J}}_{l^{\alpha}}(i)-\hat{\mathcal{K}}_{l^{\alpha}}(i)\right)+\sum_{l=1}^{n_{\beta}} \hat{\mathcal{J}}_{l^{\beta}}(i) \\
& \hat{\mathcal{F}}_{\beta}(i)=\hat{h}(1)+\sum_{l=1}^{n_{\beta}}\left(\hat{\mathcal{J}}_{l^{\beta}}(i)-\hat{\mathcal{K}}_{l^{\beta}}(i)\right)+\sum_{l=1}^{n_{\alpha}} \hat{\mathcal{J}}_{l^{\alpha}}(i)
\end{aligned}
$$

Como no caso anterior, os operadores de Fock dependem explicitamente de um conjunto de spin-orbitais, o que faz com que o sistema de equações (2.54) seja não-linear. Um ciclo auto-consistente SCF é então realizado a partir de dois conjuntos de spi-norbitais iniciais; um conjunto para cada estado de spin. Como a solução do sistema é distinta para cada estado de spin, o método UHF descrito acima é chamado também de método de spin polarizado.

Devemos notar que, uma vez que $n_{\alpha}$ e $n_{\beta}$ são números diferentes, a função de onda $\psi$, uma vez convergida, não é necessariamente um autoestado do operador $\hat{S}^{2}$. Portanto propriedades espectroscópicas devem ser analisadas com cautela.

\subsubsection{O Método de Hartree-Fock Roothaan}

Uma vez que o método de Hartree-Fock aplicado para sistemas atômicos se torna expressivamente simplificado, o uso do mesmo para o estudo de sistemas moleculares é um pouco mais complexo. A teoria de Hartree-Fock Roothaan para o estudo de sistemas moleculares se baseia na teoria do orbital molecular, onde os orbitais moleculares podem ser descritos como uma combinação linear de orbitais atômicos (LCAO - Linear Combination of Atomic Orbitals). Na prática, isso significa definir a priori um conjunto finito de $n$ orbitais atômicos $\left\{\varphi_{\mu}\right\}$ normalizados em que vamos expandir os 
orbitais moleculares:

$$
\left|\phi_{i}\right\rangle=\sum_{\mu=1}^{n} C_{i \mu}\left|\varphi_{\mu}\right\rangle
$$

em que

$$
\left\langle\varphi_{\mu} \mid \varphi_{\mu}\right\rangle=1
$$

Podemos escrever a equação (2.55) na forma matricial:

$$
\phi=\mathbf{C} \varphi
$$

onde definimos:

$$
\begin{gathered}
\phi=\left[\begin{array}{c}
\left|\phi_{1}\right\rangle \\
\vdots \\
\left|\phi_{N}\right\rangle
\end{array}\right] \\
\varphi=\left[\begin{array}{c}
\left|\varphi_{1}\right\rangle \\
\vdots \\
\left|\varphi_{N}\right\rangle
\end{array}\right] \\
\mathbf{C}=\left[\begin{array}{ccc}
C_{11} & \cdots & C_{1 n} \\
C_{21} & \cdots & C_{2 n} \\
\vdots & \ddots & \vdots \\
C_{N 1} & \cdots & C_{N n}
\end{array}\right]
\end{gathered}
$$

Substituindo na equação (2.55) em (2.44), e multiplicando à esquerda por $\left\langle\varphi_{\nu}\right|$, obtemos uma equação para os coeficientes $C_{i \mu}$, que na forma matricial é escrita como:

$$
\mathbf{F C}=\mathbf{S C} \varepsilon
$$

Em que $\varepsilon=\left(\varepsilon_{i j}\right)=\left(\varepsilon_{i} \delta_{i j}\right), \mathbf{F}=\left(F_{\mu \nu}\right)$ e $\mathbf{S}=\left(S_{\mu \nu}\right)$, sendo:

$$
\begin{gathered}
F_{\mu \nu}=\left\langle\varphi_{\mu}|\hat{F}| \varphi_{\nu}\right\rangle \\
S_{\mu \nu}=\left\langle\varphi_{\mu} \mid \varphi_{\nu}\right\rangle
\end{gathered}
$$


A equação (2.61) pode ser reescrita na forma:

$$
(\mathbf{F}-\varepsilon \mathbf{S}) \mathbf{C}=0
$$

que representa um conjunto de equações conhecidas como equações de Hartree-Fock Roothaan:

$$
\sum_{\mu=1}^{n}\left(F_{\nu \mu}-\varepsilon_{i} S_{\nu \mu}\right) C_{\mu i}=0
$$

para $i=1,2, \ldots, N$ e $\nu=1,2, \ldots, n$. Os auto-valores das equações de Hartree-Fock Roothaan são, portanto, raízes da equação secular:

$$
\operatorname{det}|\mathbf{F}-\varepsilon \mathbf{S}|=0
$$

Os termos $F_{\nu \mu}$ associados ao operador de Fock podem ser escritos como:

$$
F_{\mu \nu}=h_{\mu \nu}+\sum_{\rho, \lambda} P_{\rho \lambda}\left(\langle\mu \nu \mid \rho \lambda\rangle-\frac{1}{2}\langle\mu \lambda \mid \rho \nu\rangle\right)
$$

em que $h_{\mu \nu}=\left\langle\varphi_{\mu}|\hat{h}| \varphi_{\nu}\right\rangle$, e:

$$
\begin{gathered}
P_{\rho \lambda}=2 \sum_{i=1}^{N} C_{\rho i}^{*} C_{\lambda i} \\
\langle\mu \nu \mid \rho \lambda\rangle=\iint \varphi_{\mu}\left(\mathbf{r}_{i}\right) \varphi_{\nu}\left(\mathbf{r}_{j}\right) \frac{1}{r_{i j}} \varphi_{\rho}\left(\mathbf{r}_{i}\right) \varphi_{\lambda}\left(\mathbf{r}_{j}\right) \mathrm{d} \mathbf{r}_{i} \mathrm{~d} \mathbf{r}_{j} \\
\langle\mu \lambda \mid \rho \nu\rangle=\iint \varphi_{\mu}\left(\mathbf{r}_{i}\right) \varphi_{\lambda}\left(\mathbf{r}_{j}\right) \frac{1}{r_{i j}} \varphi_{\rho}\left(\mathbf{r}_{i}\right) \varphi_{\nu}\left(\mathbf{r}_{j}\right) \mathrm{d} \mathbf{r}_{i} \mathrm{~d} \mathbf{r}_{j}
\end{gathered}
$$

A equação (2.66) é então resolvida de maneira auto-consitente, com um ciclo SCF sujo critério de convergência foi pré-estabelecido. Os orbitais atômicos utilizados na expansão (2.55) são chamados funções base, e suas características serão discutidas adiante. 


\subsubsection{Correlação Eletrônica}

O método HF baseia-se na aproximação de partícula independente, onde as equações (2.44) para uma única partícula descreve um único elétron se movendo sob a influência de um campo eletrostático médio gerado pelos demais elétrons. O operador de Fock leva em consideração, além da energia cinética de um elétron, a interação coulombiana entre um elétron e os demais e a energia de troca (exchange).

Entretanto, o método HF não descreve as correlações dinâmicas associadas aos movimentos eletrônicos, que por sua vez possuem origem na repulsão eletrônica, exclusivamente. Portanto, é de se esperar que o método HF não descreva de maneira satisfatória propriedades físicas que envolvem termos de correlação. Apesar disso, o tratamento do método HF é muito utilizado, pois grande parte das propriedades físico-químicas sobrevivem, com boa aproximação, a essa limitação.

Não há uma maneira, nesse tratamento, de se obter o valor da energia de correlação eletrônica. Entretanto, há métodos para se obter a energia exata do problema eletrônico a partir do estado fundamental na aproximação de Hartree-Fock. Um desses métodos é conhecido como Interação de Configurações (CI).

O método HF constrói a função de onda eletrônica a partir de $N$ spinorbitais determinados pelas equações (2.44). Entretanto, o operador de Fock é hermitiano e portanto possui um número infinito de auto-valores e auto-funções. Os programas computacionais cujo método de HF está implementado determinam um número maior que $N$ de spin-orbitais, sendo que os $N$ primeiros associados aos menores auto-valores são chamados de spin-orbitais ocupados, enquanto que o restante são chamados de spinorbitais virtuais. Nessa abordagem, a função de onda eletrônica no método HF é obtida através do determinante de Slater (2.32) entre os spin-orbitais ocupados, que aqui chamaremos temporariamente de $\left|\psi_{0}\right\rangle$.

O método CI constrói a função de onda eletrônica como uma combinação linear entre diversos determinantes de Slater com spin-orbitais ocupados e 
virtuais:

$$
|\psi\rangle=\left|\psi_{0}\right\rangle+\sum_{a, r} C_{a}^{r}\left|\psi_{a}^{r}\right\rangle+\sum_{a, b, r, s} C_{a b}^{r s}\left|\psi_{a b}^{r s}\right\rangle+\sum_{a, b, c, r, s, t} C_{a b c}^{r s t}\left|\psi_{a b c}^{r s t}\right\rangle+\ldots
$$

em que a primeira soma é realizada sobre os estados determinantais $\left|\psi_{a}^{r}\right\rangle$ onde um spin-orbital ocupado $\left|\chi_{a}\right\rangle$ é substituído por um spin-orbital virtual $\left|\chi_{r}\right\rangle$ e são chamados mono-excitados, o segundo termo está associado ao estados determinantais $\left|\psi_{a b}^{r s}\right\rangle$ onde dois spin-orbitais ocupados $\left|\chi_{a}\right\rangle$ e $\left|\chi_{b}\right\rangle$ são substituídos por dois spin-orbitais virtuais $\left|\chi_{r}\right\rangle$ e $\left|\chi_{s}\right\rangle$ e são chamados duplamente excitados, e assim por diante.

O problema é então resolvido diagonalizando-se a matriz hamiltoniana eletrônica na base dos estados (2.71). O menor auto-valor é a energia exata não-relativística do problema eletrônico $E_{\text {exata }}$. A energia de correlação eletrônica, $E_{c o r r}$, portanto, pode ser definida como se segue:

$$
E_{\text {corr }}=E_{\text {exata }}-E_{H F}
$$

Em teoria, esse é um procedimento para se determinar a energia exata associada a função de onda eletrônica. Na prática, precisaríamos de uma base infinita de auto-estados do operador de Fock para construirmos infinitos termos na expansão (2.71). Um método conhecido como full-CI admite uma base finita de spin-orbitais e calcula uma aproximação para a energia exata utilizando essa base. Entretanto, esse método é computacionalmente muito caro, mesmo para bases finitas relativamente pequenas.

Outro problema da Interação de Configurações é a questão da extensividade, isto é, a proporcionalidade entre a energia $E$ e o número de elétrons $N$. Quando utilizamos uma base finita, a expansão (2.71) é truncada em um determinado termo, não satisfazendo, no geral, essa condição.

Outros métodos para se estimar a energia de correlação eletrônica estão implementados em muitos programas computacionais de química quântica, como métodos perturbativos. 


\subsection{Teoria do Funcional da Densidade}

A Teoria do Funcional da Densidade (DFT) se utiliza como variável do problema eletrônico a densidade eletrônica $\rho(\mathbf{r})$. A vantagem dessa abordagem é a que trocamos um problema de $N$ elétrons - com $3 N$ variáveis espaciais mais o estado de spin - para um problema de somente três variáveis. A ideia de se utilizar a densidade eletrônica como variável básica para o problema de muitos elétrons se iniciou com Drude no começo do século XX, entretanto a solução e desenvolvimento da teoria apenas se deu por Hohenberg e Kohn em 1964, rendendo à Walter Kohn o prêmio Nobel de Química em 1998. A teoria ainda sofreu um grande avanço e desenvolvimento em sua aplicabilidade no ano de 1965 devido aos trabalhhos de Kohn e Sham, e atualmente é largamente utilizada no estudo de propriedades eletrônicas de sistemas atômicos, moléculas e sólidos.

Em particular, a DFT é muito utilizada para o estudo de propriedades eletrônicas de biomoléculas e macromoléculas em geral (número de átomos > 20), devido a seu baixo custo computacional quando comparado a métodos ab initio, como o método Hartree-Fock discutido anteriormente.

A seguir apresentaremos os teoremas de Hohenberg e Kohn, teoremas centrais na DFT, seguido das equações de Kohn-Sham para a solução do problema eletrônico.

\subsubsection{Teoremas de Hohenberg e Kohn}

Os dois teoremas atribuídos à Hohenberg e Kohn (HK) são os pilares da Teoria do Funcional da Densidade, e serão discutidos a seguir. Primeiramente, considere um sistema com $N$ elétrons e, como usual, $\mathbf{r}_{i}$ sendo a posição do $i$-ésimo elétron. O hamiltoniano eletrônico é dado por:

$$
\hat{\mathcal{H}}_{\text {ele }}=\hat{T}_{e}+\hat{V}_{e}+\hat{U}
$$

em que os dois primeiros termos são os operadores associados à energia cinética dos elétrons e à energia potencial de interação entre os elétrons. 
O último termo $\hat{U}$ é entendido como um potencial externo, que no caso de uma molécula isolada, é exclusivamente o potencial sentido pelos elétrons devido aos núcleos. No espaço de posições, o operador $\hat{U}$ pode ser descrito com o uso de potenciais externos, da seguinte forma:

$$
\hat{U} \longmapsto \sum_{i=1}^{N} v\left(\mathbf{r}_{i}\right)
$$

onde $v\left(\mathbf{r}_{i}\right)$ é o potencial externo sentido pelo $i$-ésimo elétron. Além disso, podemos escrever a densidade eletrônica como:

$$
\rho(\mathbf{r})=\left\langle\psi\left|\sum_{i=1}^{N} \delta\left(\mathbf{r}-\mathbf{r}_{i}\right)\right| \psi\right\rangle
$$

em que, nessa seção, o vetor $\mathbf{r}$ é um ponto de observação no espaço tridimensional.

Assim, nota-se que podemos escrever o valor esperado do operador $\hat{U}$ em termos da densidade eletrônica da seguinte forma:

$$
\begin{aligned}
\langle\psi|\hat{U}| \psi\rangle & =\sum_{i=1}^{N} \int \mathrm{d} \mathbf{r}_{1} \cdots \int \mathrm{d} \mathbf{r}_{N} \psi^{*}\left(\mathbf{r}_{1}, \ldots, \mathbf{r}_{N}\right) v\left(\mathbf{r}_{i}\right) \psi\left(\mathbf{r}_{1}, \ldots, \mathbf{r}_{N}\right) \\
& =\sum_{i=1}^{N} \int \mathrm{d} \mathbf{r} \int \mathrm{d} \mathbf{r}_{1} \cdots \int \mathrm{d} \mathbf{r}_{i} v(\mathbf{r}) \delta\left(\mathbf{r}-\mathbf{r}_{i}\right) \cdots \int \mathrm{d} \mathbf{r}_{N} \psi^{*} \psi \\
& =\int \rho(\mathbf{r}) v(\mathbf{r}) \mathrm{d} \mathbf{r}
\end{aligned}
$$

A partir disso os teoremas de HK podem ser demonstrados de uma maneira simples[12].

Teorema $1(\mathrm{HK})$. O potencial externo $v(\mathbf{r})$ é um funcional único da densidade eletrônica $\rho(\mathbf{r})$.

Demonstração. Consideraremos como ponto de partida dois potenciais externos diferentes $v(\mathbf{r})$ e $v^{\prime}(\mathbf{r})$, relativos a dois operadores $\hat{U}$ e $\hat{U}^{\prime}$, que diferem entre si por mais do que uma constante aditiva. Como os dois operadores de energia potencial externa são distintos, teremos dois hamiltonianos 
distintos e, portanto, dois estados eletrônicos fundamentais diferentes $|\psi\rangle$ e $\left|\psi^{\prime}\right\rangle$. Consideremos agora, por hipótese, que os dois potenciais externos geram a mesma densidade eletrônica $\rho(\mathbf{r})$ do estado fundamental. Temos, pelo princípio variacional:

$$
E=\left\langle\psi\left|\hat{T}_{e}+\hat{V}_{e}+\hat{U}\right| \psi\right\rangle<\left\langle\psi^{\prime}\left|\hat{T}_{e}+\hat{V}_{e}+\hat{U}\right| \psi^{\prime}\right\rangle
$$

$\mathrm{e}$

$$
E^{\prime}=\left\langle\psi^{\prime}\left|\hat{T}_{e}+\hat{V}_{e}+\hat{U}^{\prime}\right| \psi^{\prime}\right\rangle<\left\langle\psi\left|\hat{T}_{e}+\hat{V}_{e}+\hat{U}^{\prime}\right| \psi\right\rangle
$$

Ou seja:

$$
\langle\psi|\hat{H}| \psi\rangle<\left\langle\psi^{\prime}\left|\hat{H}^{\prime}\right| \psi^{\prime}\right\rangle+\left\langle\psi^{\prime}\left|\hat{U}-\hat{U}^{\prime}\right| \psi^{\prime}\right\rangle
$$

$\mathrm{e}$

$$
\left\langle\psi^{\prime}\left|\hat{H}^{\prime}\right| \psi^{\prime}\right\rangle<\langle\psi|\hat{H}| \psi\rangle+\left\langle\psi\left|\hat{U}^{\prime}-\hat{U}\right| \psi\right\rangle
$$

Fazendo o uso de (2.76), as desigualdades acima podem ser reescritas da seguinte maneira

$$
\begin{aligned}
& E<E^{\prime}+\int\left(v(\mathbf{r})-v^{\prime}(\mathbf{r})\right) \rho(\mathbf{r}) \mathrm{d} \mathbf{r} \\
& E^{\prime}<E+\int\left(v^{\prime}(\mathbf{r})-v(\mathbf{r})\right) \rho(\mathbf{r}) \mathrm{d} \mathbf{r}
\end{aligned}
$$

Logo, somando-se as duas desigualdades acima:

$$
E+E^{\prime}<E^{\prime}+E
$$

Obtemos, portanto, um absurdo decorrente da hipótese de que dois potenciais externos distintos $v(\mathbf{r})$ e $v^{\prime}(\mathbf{r})$ geram uma mesma densidade $\rho(\mathbf{r})$. Concluimos que a unicidade de $\rho(\mathbf{r})$ exige considerar um único estado fundamental $|\psi\rangle=\left|\psi^{\prime}\right\rangle$.

Em outras palavras, a densidade eletrônica $\rho(\mathbf{r})$ deve conter satisfatoriamente toda a infromação contida na função de onda relativa a mesma. Isto é, qualquer obervável físico $\hat{O}$ possui um valor esperado dado como 
um funcional único da densidade eletrônica:

$$
\langle O\rangle=\langle\psi|\hat{O}| \psi\rangle=O[\rho(\mathbf{r})]
$$

Teorema 2 (HK). A energia do estado fundamental E $[\rho]$ é minima para a densidade $\rho(\mathbf{r})$ exata.

Demonstração. O segundo teorema de HK diz que a energia é um funcional único da densidade eletrônica $\rho(\mathbf{r})$ cujo valor minimo é obtido através da densidade eletrônica do estado fundamental, a quem chamaremos de $\rho_{0}(\mathbf{r})$.

O funcional $E[\rho]$ pode ser escrito da seguite maneira:

$$
\begin{aligned}
E[\rho] & =\left\langle\psi\left|\hat{\mathcal{H}}_{e l e}\right| \psi\right\rangle=\left\langle\psi\left|\hat{T}_{e}+\hat{V}_{e}\right| \psi\right\rangle+\langle\psi|\hat{U}| \psi\rangle \\
& =F[\rho]+\langle\psi|\hat{U}| \psi\rangle
\end{aligned}
$$

onde $F[\rho]$ é um funcional universal, isto é, se aplica da mesma maneira à qualquer sistema de $N$ elétrons independente do potencial externo. Considerando agora a densidade eletrônica do estado fundamental, temos, analogamente:

$$
E\left[\rho_{0}\right]=F\left[\rho_{0}\right]+\left\langle\psi_{0}|\hat{U}| \psi_{0}\right\rangle
$$

em que $\left|\psi_{0}\right\rangle$ é o estado eletrônico fundamental não degenerado associado à densidade $\rho_{0}$.

Como as densidades eletrônicas são univocamente determinadas através de um potencial externo e, além disso, cada densidade está associada a apenas um único estado eletrônico, podemos recorrer ao princípio variacional para concluir que:

$$
\begin{aligned}
\left\langle\psi_{0}\left|\hat{\mathcal{H}}_{\text {ele }}\right| \psi_{0}\right\rangle & <\left\langle\psi\left|\hat{\mathcal{H}}_{\text {ele }}\right| \psi\right\rangle \\
F\left[\rho_{0}\right]+\left\langle\psi_{0}|\hat{U}| \psi_{0}\right\rangle & <F[\rho]+\langle\psi|\hat{U}| \psi\rangle \\
E\left[\rho_{0}\right] & <E[\rho]
\end{aligned}
$$

para $\rho \neq \rho_{0}$.

Esse segundo teorema fornece uma maneira de buscar a densidade eletrônica 
do estado fundamental. Uma vez que qualquer aproximação para a densidade, $\rho^{\prime}(\mathbf{r})$, está associada a um único potencial externo $v^{\prime}(\mathbf{r})$ e, assim, a um hamiltoniano eletrônico $\hat{\mathcal{H}}_{\text {ele }}^{\prime}$ que possui um estado fundamental $\left|\psi^{\prime}\right\rangle$, esse mesmo pode ser utilizado como uma função tentativa para o sistema com o potencial externo real $v(\mathbf{r})$. Temos que:

$$
E_{0}=F[\rho]+\int \rho(\mathbf{r}) v(\mathbf{r}) \mathrm{d} \mathbf{r} \leq F\left[\rho^{\prime}\right]+\int \rho^{\prime}(\mathbf{r}) v(\mathbf{r}) \mathrm{d} \mathbf{r}
$$

\subsubsection{Equações de Kohn-Sham}

O funcional universal definido na equação (2.83) inclui o termo eletrostático, a energia cinética dos elétrons e um termo associado à energia de correlação e troca. O funcional pode ser escrito da seguinte maneira:

$$
F[\rho]=\frac{1}{2} \iint \frac{\rho(\mathbf{r}) \rho\left(\mathbf{r}^{\prime}\right)}{\left|\mathbf{r}-\mathbf{r}^{\prime}\right|} \mathrm{d} \mathbf{r} \mathrm{d} \mathbf{r}^{\prime}+G[\rho]
$$

em que o primeiro termo é a energia de interação coulombiana elétronelétron, e $G[\rho]$ também é um funcional universal. Dessa maneira, o funcional de energia eletrônica é dado por:

$$
E[\rho]=\int \rho(\mathbf{r}) v(\mathbf{r}) \mathrm{d} \mathbf{r}+\frac{1}{2} \iint \frac{\rho(\mathbf{r}) \rho\left(\mathbf{r}^{\prime}\right)}{\left|\mathbf{r}-\mathbf{r}^{\prime}\right|} \mathrm{d} \mathbf{r} \mathrm{d} \mathbf{r}^{\prime}+G[\rho]
$$

Em 1965, Kohn e Sham propuseram uma estratégia para se calcular a estrutura eletrônica através da densidade e do funcional acima definido. Em sua proposta, o funcional universal $G[\rho]$ pode ser escrito como uma contribuição de dois termos:

$$
G[\rho]=T[\rho]+E_{x c}[\rho]
$$

em que o primeiro termo $T[\rho]$ representa a energia cinética de $N$ elétrons não-interagentes num sistema de densidade $\rho(\mathbf{r})$, e o segundo termo contém a energia de troca (exchange) e o termo de correlação eletrônica, além da correção para a energia cinética. Obviamente, a expressão para $E_{x c}[\rho]$ não é nem um pouco simples, e podemos escrevê-la convenientemente da 
seguinte forma:

$$
E_{x c}[\rho]=\int \rho(\mathbf{r}) \epsilon_{x c}(\rho(\mathbf{r})) \mathrm{d} \mathbf{r}
$$

em que, agora, $\epsilon_{x c}(\rho(\mathbf{r}))$ é uma função da densidade eletrônica conhecida como termo de correlação e troca. Dessa maneira o funcional de energia pode ser escrito como:

$$
E[\rho]=\int \rho(\mathbf{r}) v(\mathbf{r}) \mathrm{d} \mathbf{r}+\frac{1}{2} \iint \frac{\rho(\mathbf{r}) \rho\left(\mathbf{r}^{\prime}\right)}{\left|\mathbf{r}-\mathbf{r}^{\prime}\right|} \mathrm{d} \mathbf{r} \mathrm{d} \mathbf{r}^{\prime}+T[\rho]+\int \rho(\mathbf{r}) \epsilon_{x c}(\rho(\mathbf{r})) \mathrm{d} \mathbf{r}
$$

Podemos aplicar agora o princípio variacional no funcional $E[\rho]$, com o vínculo de que a carga eletrônica total seja constante:

$$
\int \rho(\mathbf{r}) \mathrm{d} \mathbf{r}=N
$$

Fazendo o uso dos multiplicadores de Lagrange, a minimização se torna, portanto:

$$
\delta\left\{E[\rho]-\mu\left[\int \rho(\mathbf{r}) \mathrm{d} \mathbf{r}-N\right]\right\}=0
$$

obtemos, da condição (2.94):

$$
\int \delta \rho(\mathbf{r})\left\{\frac{\delta T[\rho]}{\delta \rho}+v(\mathbf{r})+\int \frac{\rho\left(\mathbf{r}^{\prime}\right)}{\left|\mathbf{r}-\mathbf{r}^{\prime}\right|} \mathrm{d} \mathbf{r}^{\prime}+v_{x c}[\rho]-\mu\right\} \mathrm{d} \mathbf{r}=0
$$

em que $v_{x c}[\rho]$ é o potencial de correlação e troca dado por:

$$
v_{x c}[\rho]=\frac{\delta E_{x c}}{\delta \rho}
$$

Como a densidade eletrônica é dada a partir da função de onda eletrônica (2.75), é importante definí-la a partir de funções de onda de uma partícula, $\psi_{i}(\mathbf{r})$. A função de uma partícula se relaciona com a função de onda eletrônica como um determinante de Slater conhecido como determinante 
de Kohn-Sham (KS).

$$
\psi\left(\mathbf{r}_{1}, \ldots, \mathbf{r}_{N}\right)=\frac{1}{\sqrt{N !}}\left|\begin{array}{ccc}
\psi_{i}\left(\mathbf{r}_{1}\right) & \cdots & \psi_{k}\left(\mathbf{r}_{1}\right) \\
\psi_{i}\left(\mathbf{r}_{2}\right) & \cdots & \psi_{k}\left(\mathbf{r}_{2}\right) \\
\vdots & \ddots & \vdots \\
\psi_{i}\left(\mathbf{r}_{N}\right) & \cdots & \psi_{k}\left(\mathbf{r}_{N}\right)
\end{array}\right|
$$

Utilizando as funções $\psi_{i}$, o primeiro termo do integrando em (2.94) referente ao funcional de energia cinética pode, por sua vez, ser reescrito como:

$$
\frac{\delta T[\rho]}{\delta \rho}=-\frac{1}{2} \frac{\delta}{\delta \rho}\left\{\sum_{i} \int \psi_{i}^{*}(\mathbf{r}) \nabla^{2} \psi_{i}(\mathbf{r}) \mathrm{d} \mathbf{r}\right\}
$$

com

$$
\rho(\mathbf{r})=\sum_{i}\left|\psi_{i}(\mathbf{r})\right|^{2}
$$

Substituindo (2.97) em (2.94), e fazendo o uso da densidade eletrônica (2.98), podemos obter uma equação de Schrödinger de uma partícula:

$$
\begin{aligned}
\left(-\frac{1}{2} \nabla^{2}+v^{K S}[\rho]\right) \psi_{i}(\mathbf{r}) & =\varepsilon_{i} \psi_{i}(\mathbf{r}) \\
\hat{h}^{K S} \psi_{i}(\mathbf{r}) & =\varepsilon_{i} \psi_{i}(\mathbf{r})
\end{aligned}
$$

As equações (2.98) são conhecidas como equações de Kohn-Sham, e o operador $\hat{h}^{K S}$ será definido como o hamiltoniano de Kohn-Sham. O termo $v^{K S}[\rho]$ é chamado potencial efetivo de Kohn-Sham, e é dado por:

$$
v^{K S}[\rho]=v(\mathbf{r})+\int \frac{\rho(\mathbf{r})}{\left|\mathbf{r}-\mathbf{r}^{\prime}\right|} \mathrm{d} \mathbf{r}^{\prime}+v_{x c}[\rho]
$$

É importante notar que as equações de Kohn-Sham (2.99) resolvem o problema eletrônico por meio da função de onda de uma partícula, o orbital $\psi_{i}(\mathbf{r})$ ao invés da densidade eletrônica, explicitamente.

O primeiro passo para se resolver as equações de Kohn-Sham é construir o funcional de correlação e troca, $E_{x c}[\rho]$. Muitos modelos foram propostos e atualmente muitos funcionais são largamente utilizados para descrever 
diversas propriedades eletrônicas de diversos sistemas moleculares. Alguns desses funcionais se utilizam de parametrizações semi-empíricas, e portanto são chamados de funcionais híbridos, como o caso do B3LYP, que será discutido a seguir. Uma vez que o funcional esteja bem estabelecido, um ciclo de auto-consistência SCF deve ser realizado nas equações de KS até a convergência pré-estabelecida ser atingida.

\section{Equações de KS para camada fechada}

Para sistemas de camada fechada (número de elétrons $N$ par), ou sistemas de spin compensado[15], a função de onda eletrônica é construída com um determinante de Slater semelhante à equação (2.24), mas com o uso de $N / 2$ orbitais.

$$
\psi^{K S}\left(\mathbf{r}_{1}, \ldots, \mathbf{r}_{N}\right)=\frac{1}{\sqrt{N !}}\left|\begin{array}{ccc}
\psi_{1}^{K S}\left(\mathbf{r}_{1}\right) & \cdots & \psi_{N / 2}^{K S}\left(\mathbf{r}_{1}\right) \\
\psi_{1}^{K S}\left(\mathbf{r}_{2}\right) & \cdots & \psi_{N / 2}^{K S}\left(\mathbf{r}_{2}\right) \\
\vdots & \ddots & \vdots \\
\psi_{1}^{K S}\left(\mathbf{r}_{N / 2}\right) & \cdots & \psi_{N / 2}^{K S}\left(\mathbf{r}_{N / 2}\right)
\end{array}\right|
$$

Cada orbital está duplamente ocupado com elétrons em diferentes estados de spin, e satisfazem as equações de KS.

$$
\hat{h}^{K S} \psi_{i}^{K S}(\mathbf{r})=\varepsilon_{i} \psi_{i}^{K S}(\mathbf{r}), \quad i=1,2, \ldots, \frac{N}{2}
$$

A densidade eletrônica é, nesse caso;

$$
\rho(\mathbf{r})=\sum_{i=1}^{N / 2} 2\left|\psi_{i}^{K S}(\mathbf{r})\right|^{2}
$$

e a energia eletrônica pode ser calculada da seguinte maneira:

$E[\rho]=\sum_{i=1}^{N / 2} 2 \varepsilon_{i}-\frac{1}{2} \iint \frac{\rho(\mathbf{r}) \rho\left(\mathbf{r}^{\prime}\right)}{\left|\mathbf{r}-\mathbf{r}^{\prime}\right|} \mathrm{d} \mathbf{r} \mathrm{d} \mathbf{r}^{\prime}+\int \rho(\mathbf{r})\left\{\epsilon_{x c}(\rho(\mathbf{r}))-v_{x c}(\rho(\mathbf{r}))\right\} \mathrm{d} \mathbf{r}$

que é a expressão da energia escrita em termos dos auto-valores das equações 
de KS.

\section{Equações de KS para camada aberta}

Para uma melhor descrição de sistemas de camada aberta, ou sistemas submetidos a campos magnéticos, utilizamos as equações de KS para spinpolarizado. Aqui, temos $n_{\alpha}$ elétrons cujo estado de spin $\alpha$ e $n_{\beta}$ elétrons no estado $\beta$, tais que $n_{\alpha}+n_{\beta}=N$. A densidade eletrônica pode ser escrita como uma soma:

$$
\rho(\mathbf{r})=\rho_{\alpha}(\mathbf{r})+\rho_{\beta}(\mathbf{r})=\sum_{i=1}^{n_{\alpha}}\left|\psi_{i^{\alpha}}(\mathbf{r})\right|^{2}+\sum_{i=1}^{n_{\beta}}\left|\psi_{i^{\beta}}(\mathbf{r})\right|^{2}
$$

em que o primeiro termo diz respeito apenas aos elétrons $\alpha$ e o segundo termo aos elétrons $\beta$.

Temos dois sistemas de equações de KS, um para cada estado de spin:

$$
\begin{aligned}
\left(-\frac{1}{2} \nabla^{2}+v_{\xi}^{K S}[\rho]\right) \psi_{i \xi}(\mathbf{r}) & =\varepsilon_{i \xi} \psi_{i \xi}(\mathbf{r}) \\
\hat{h}_{\xi} \psi_{i \xi}(\mathbf{r}) & =\varepsilon_{i \xi} \psi_{i \xi}(\mathbf{r})
\end{aligned}
$$

em que $\xi=\alpha, \beta$ e o potencial efetivo $v_{\xi}^{K S}[\rho]$ é dado por:

$$
v_{\xi}^{K S}[\rho]=v(\mathbf{r})+\int \frac{\rho\left(\mathbf{r}^{\prime}\right)}{\left|\mathbf{r}-\mathbf{r}^{\prime}\right|} \mathrm{d} \mathbf{r}^{\prime}+\frac{\delta E_{x c}\left[\rho_{\alpha}, \rho_{\beta}\right]}{\delta \rho_{\xi}}
$$

Ao se resolver as equações de KS para camada aberta através de um ciclo SCF, a função de onda eletrônica pode ser construída a partir de um determinante de Slater semelhante a (2.101), porém agora com $N$ spinorbitais de elétrons $\alpha$ e $\beta$.

\subsubsection{O funcional híbrido B3LYP}

O funcional B3LYP (Beck, 3-parameter, Lee-Yang-Parr)[16] é um dos mais usados atualmente no estudo de propriedades eletrônicas de macromoléculas de interesse biológico, pois descreve de maneira satisfatória muitas medidas experimentais e possui baixo custo computacional. Para 
descrever o funcional B3LYP, primeiramente descreveremos duas aproximações para o termo de correlação e troca conhecidas como Local Spin Density Approximation - LSDA - e Generalized Gradient Approximation GGA.

Na aproximação de densidade de spin local (LSDA), aproxima-se a energia de correlação de troca no ponto $\mathbf{r}$ como a energia de correlação e troca de um gás de elétrons homogêneo de densidade $\rho(\mathbf{r})$. Nessa aproximação supõe-se que a densidade eletrônica varie lentamente nas vizinhanças do ponto r. Assim,

$$
\begin{aligned}
E_{x c}\left[\rho^{\alpha}, \rho^{\beta}\right] & \simeq E_{x c}^{L S D A}\left[\rho^{\alpha}, \rho^{\beta}\right]=\int\left(\epsilon_{x}\left(\rho^{\alpha}(\mathbf{r})\right)+\epsilon_{c}\left(\rho^{\alpha}(\mathbf{r})\right)\right) \rho^{\alpha}(\mathbf{r}) \mathrm{d} \mathbf{r} \\
& +\int\left(\epsilon_{x}\left(\rho^{\beta}(\mathbf{r})\right)+\epsilon_{c}\left(\rho^{\beta}(\mathbf{r})\right)\right) \rho^{\beta}(\mathbf{r}) \mathrm{d} \mathbf{r}
\end{aligned}
$$

Podemos, de outra forma, escrever o termo $E_{x c}^{L S D A}\left[\rho^{\alpha}, \rho^{\beta}\right]$ como uma soma de dois termos:

$$
E_{x c}^{L S D A}\left[\rho^{\alpha}, \rho^{\beta}\right]=E_{x}^{L S D A}\left[\rho^{\alpha}, \rho^{\beta}\right]+E_{c}^{L S D A}\left[\rho^{\alpha}, \rho^{\beta}\right]
$$

em que

$$
E_{x}^{L S D A}\left[\rho^{\alpha}, \rho^{\beta}\right]=\int\left(\epsilon_{x}\left(\rho^{\alpha}(\mathbf{r})\right) \rho^{\alpha}(\mathbf{r})+\epsilon_{x}\left(\rho^{\beta}(\mathbf{r})\right) \rho^{\beta}(\mathbf{r})\right) \mathrm{d} \mathbf{r}
$$

e

$$
E_{c}^{L S D A}\left[\rho^{\alpha}, \rho^{\beta}\right]=\int\left(\epsilon_{c}\left(\rho^{\alpha}(\mathbf{r})\right) \rho^{\alpha}(\mathbf{r})+\epsilon_{c}\left(\rho^{\beta}(\mathbf{r})\right) \rho^{\beta}(\mathbf{r})\right) \mathrm{d} \mathbf{r}
$$

$\mathrm{Na}$ aproximação LSDA, uma expressão analítica para o termo (2.110) referente à energia de troca foi proposta diretamente da teoria quântica para gases de elétrons homogêneos:

$$
E_{x}^{L S D A}\left[\rho^{\alpha}, \rho^{\beta}\right]=2^{1 / 3} C_{x} \int\left\{\left(\rho^{\alpha}(\mathbf{r})\right)^{4 / 3}+\left(\rho^{\beta}(\mathbf{r})\right)^{4 / 3}\right\} \mathrm{d} \mathbf{r}
$$

onde

$$
C_{x}=\frac{3}{4}\left(\frac{3}{\pi}\right)^{1 / 3}
$$


Por outro lado, como não se obtém analiticamente uma expressão para o termo (2.111), existem diversas propostas parametrizadas que foram sendo calibradas ao longo dos anos. Alguns trabalhos sobre propostas e parametrizações para os termos de correlação podem ser encontradas na literatura.

A aproximação (GGA) pode ser entendida como um refinamento da aproximação LSDA, onde se considera o termo de correlação e troca como uma função do gradiente da densidade eletrônica no ponto r. Entende-se esse aproximação como uma correção à LSDA pois em sistemas físicos, no geral, a densidade eletrônica não varia lentamente entre um determinado ponto e sua vizinhança. O funcional assume a seguinte fórmula:

$$
E_{x c}^{G G A}[\rho]=\int f(\rho(\mathbf{r}), \nabla \rho(\mathbf{r})) \mathrm{d} \mathbf{r}
$$

Assim como na equação (2.109), esse termo pode ser entendido como uma contribuição de dois termos:

$$
E_{x c}^{G G A}[\rho]=E_{x}^{G G A}[\rho]+E_{c}^{G G A}[\rho]
$$

Para o termo de troca, obteve-se uma expressão analítica dada por:

$$
E_{x}^{G G A}[\rho]=-\frac{3}{4}\left(\frac{3}{\pi}\right)^{1 / 3} \int(\rho(\mathbf{r}))^{4 / 3} F(s(\mathbf{r})) \mathrm{d} \mathbf{r}
$$

onde $F(s(\mathbf{r}))$ é uma função cuja variável $s(\mathbf{r})$ indica a não-homogeneidade local da densidade eletrônica, e é dada por:

$$
s(\mathbf{r})=\frac{|\nabla \rho(\mathbf{r})|}{2 k_{F} \rho(\mathbf{r})}
$$

em que $k_{F}=\left(3 \pi^{2} \rho\right)^{1 / 3}$.

Note-se que, para $F(s(\mathbf{r}))=1$, obtemos um funcional de troca da mesma forma que o considerado na aproximação LSDA. Entretanto, muitas formas para a função $F$ foram propostas e diferentes funcionais de troca GGA foram criados.

Analogamente à aproximação LSDA, não há uma expressão analítica 
para o termo de correlação eletrônica $E_{c}^{G G A}[\rho]$, e muitos trabalhos referentes às propostas e parametrizações podem ser encontrados nas referências.

A partir das aproximações LSDA e GGA, alguns funcionais foram construídos considerando combinações entre os funcionais de correlação e troca da teoria do funcional da densidade (DFT) com o termo de troca (exchange) da teoria Hartree-Fock (2.37). Esse funcionais foram batizados de funcionais híbridos, e o B3LYP é um dos funcionais mais populares dessa classe. O funcional B3LYP é dado pela seguinte combinação de funcionais:

$$
\begin{gathered}
E_{x c}^{B 3 L Y P}[\rho]=E_{x}^{L S D A}[\rho]+a_{0}\left(E_{x}^{H F}[\rho]-E_{x}^{L S D A}[\rho]\right)+ \\
a_{x}\left(E_{x}^{G G A}[\rho]-E_{x}^{L S D A}[\rho]\right)+a_{c}\left(E_{c}^{G G A}[\rho]-E_{c}^{L S D A}[\rho]\right)
\end{gathered}
$$

em que os parâmetros possuem os valores $a_{0}=0.20, a_{x}=0.72$ e $a_{c}=0.81$.

Muitos outros funcionais híbridos foram propostos e são largamente utilizados, como o funcional PBE0, o funcional HSE, os funcionais híbridos meta-GGA, entre outros. Uma discussão sobre os funcionais pode ser encontrada na referência, e não serão discutidos aqui.

\subsection{Energia Livre}

A energia eletrônica algumas vezes não é uma grandeza conveniente para descrever alguns fenômenos físico-químicos, precisando-se frequentemente recorrer à energia livre do sistema. A energia livre é uma medida associada à reatividade de um determinado sistema com relação a um determinado processo químico, e leva em conta correções térmicas correspondentes a seus possíveis movimentos. Para se obter a energia livre de uma molécula, consideramos que a mesma encontra-se em um sistema gasoso à temperatura e pressão constante. Nesse regime, a energia livre pode ser escrita como[17]:

$$
G=E_{t o t}+k_{B} T-T S_{t o t}
$$

em que $E_{\text {tot }}=E+E_{v}+E_{r}+E_{t}$ e $S_{t o t}=S_{e}+S_{v}+S_{r}+S_{t}$. Cada termo das duas somas anteriores se refere a uma contribuição em particular. $E$ 
é a energia eletrônica, $E_{v}$ é a contribuição vibracional da energia, $E_{r}$ é a contribuição rotacional e $E_{t}$ é a contribuição translacional (a mesma notação vale para os termos de entropia). Cada um desses termos é obtido através da mecânica estatística com o uso da função de partição de cada contribuição.

Dessa forma, podemos calcular energias livres e diferenças de energia livre entre dois estados:

$$
\Delta G_{A B}=G_{B}-G_{A}=\Delta E_{t o t}-T \Delta S_{t o t}
$$

\subsection{Otimização de Geometria}

Os métodos de estrutura eletrônica, dos quais dois foram discutidos anteriormente, são utilizados para cálculos de energia em geometrias nucleares bem definidas, assim como são úteis para otimizá-las, isto é, encontrar geometrias de sistemas as quais as energias são mínimas. Além disso, é possível obter geometrias associadas a reagentes, produtos e estados de transição de reações químicas.

Na aproximação de Born-Oppenheimer, a energia eletrônica de um certo estado eletrônico, como função da geometria nuclear $\mathbf{R}$, é descrita por uma hipersuperfície (2.7). Nas vizinhanças de uma dada geometria $\mathbf{R}_{0}$, a energia pode ser expandida numa série de Taylor:

$$
E(\mathbf{R})=E\left(\mathbf{R}_{0}\right)+\nabla E \cdot\left(\mathbf{R}-\mathbf{R}_{0}\right)+\frac{1}{2} \sum_{i=1}^{3 M} \sum_{j=1}^{3 M} \frac{\partial^{2} E}{\partial R_{i} \partial R_{j}}\left(R_{i}-R_{0 i}\right)\left(R_{j}-R_{0 j}\right)+\ldots
$$

em que todas as derivadas são avaliadas na geometria $\mathbf{R}_{0}$.

Em notação matricial, podemos escrever a expansão acima como:

$$
E(\mathbf{R})=E\left(\mathbf{R}_{0}\right)+\mathbf{g}_{0}^{T} \Delta \mathbf{R}+\frac{1}{2} \Delta \mathbf{R}^{T} \mathbf{H}_{0} \Delta \mathbf{R}+\ldots
$$

em que, aqui, $\mathbf{g}_{0}$ é um vetor representado por uma matriz coluna cujas componentes são as mesmas do gradiente de $E(\mathbf{R})$ calculado em $\mathbf{R}_{0}, \Delta \mathbf{R}=$ 
$\mathbf{R}-\mathbf{R}_{0}$ e $\mathbf{H}_{0}$ é a matriz hessiana calculada em $\mathbf{R}_{0}$. A matriz $\mathbf{g}$ pode ser escrita como:

$$
\mathbf{g}=\mathbf{g}_{0}+\mathbf{H}_{0} \Delta \mathbf{R}
$$

Em processos de otimização de geometria, busca-se uma configuração $\mathbf{R}$ tal que $\mathbf{g}=0$. Isto é,

$$
\Delta \mathbf{R}=-\mathbf{H}_{0}^{-1} \mathbf{g}_{0}
$$

Outra condição para geometrias de mínima energia é a de que todas as componentes da matriz hessiana devem ser positivas. Ou seja, devemos encontrar em um ponto cuja aproximação harmônica da hipersuperfície de energia eletrônica gere frequências de vibrações reais.

Para processos onde há interesse em estados de transição entre uma espécie reagente e uma espécie produto, busca-se uma configuração que respeite a condição (2.124), mas cuja matriz hessiana possua uma, e somente uma, componente negativa. A saber, tal componente deve corresponder à coordenada de reação previamente definida pela reação em questão. A implementação desse método utilizada no presente trabalho se chama STQN (Synchronous Transit-Guided Quasi-Newton Method)[18, 19].

Métodos de resolução da equação (2.124) para estados otimizados, assim como para estados de transição, encontram-se na referência[20] e não serão discutidos em detalhe.

\subsection{Funções Base}

Nessa seção descreveremos os conjuntos de funções base utilizados em métodos de mecânica quântica[21] e, em particular, o conjunto utilizado no presente trabalho. Métodos de estrutura eletrônica, tais como o método de Hartree-Fock ou a Teoria do Funcional da Densidade, são formulados para um conjunto infinito de funções base na expansão (2.55), embora considerar um conjunto finito de funções seja uma aproximação irremediável.

Há um enorme número de conjuntos de funções base na literatura, como os STOs (Slater Type Orbitals) ou as GTOs (Gaussian Type Orbitals) como 
os conjuntos 3-21G, 6-31G, 6-311G, entre outros muitos.

Devido ao menor custo computacional para se calcular integrais de 2 elétrons, como (2.69) e (2.70), as bases GTOs são as mais utilizadas e estão implementadas em grande parte dos programas computacionais de química quântica. A expressão dos orbitais gaussianos possui a seguinte forma:

$$
\varphi_{\zeta, n, l, m}^{G T O}(\mathbf{r})=N Y_{l, m}(\theta, \varphi) r^{2 n-2-l} e^{-\zeta r^{2}}
$$

em que $Y_{l, m}(\theta, \varphi)$ são os harmônicos esféricos escritos em coordenadas esféricas usuais e $N$ é uma constante de normalização, como requerido em (2.56). O parâmetro $\zeta$ é o expoente. Se ele for pequeno, a função representa um orbital difuso, enquanto que se for grande, a função representa um orbital localizado. Cada orbital atômico (2.125) está centrado em um determinado sítio atômico, escrito em termos de coordenadas esféricas cuja origem coincide com a posição desse sítio em particular.

Para uma descrição mais refinada da estrutura eletrônica, algumas bases consideram, para cada orbital atômico $n, l, m$ de um determinado sítio, uma combinação de funções gaussianas ao invés de uma única função. Esse procedimento é conhecido como CGTOs (Contracted Gaussian Types Orbitals)

$$
\varphi_{\zeta, n, l, m}^{C G T O}(\mathbf{r})=N \sum_{k=1}^{n} c_{k} Y_{l, m}(\theta, \varphi) r^{2 n-2-l} e^{-\zeta_{k} r^{2}}
$$

As constantes c's são chamadas de coeficientes de contração da base. O número $n$ de gaussianas para descrever um determinado orbital atômico pode variar de átomo para átomo, assim como de orbital para orbital. Algumas bases conhecidas utilizam, por exemplo, de $n=1$ para todos os orbitais atômicos. Outras se utilizam de $n=2$ para todos os orbitais, e são conhecidas como bases double-zeta (DZ), ou $n=3$ (TZ), e assim por diante. Algumas também usam diferentes contrações para orbitais de caroço e orbitais de valência.

Podemos também incluir funções de polarização na descrição dos orbitais. Isso significa adicionar ao conjunto base funções relacionadas a 
momentos angulares maiores que os orbitais da camada de valência. Isso permite que os orbitais possuam mais flexibilidade e possam assim descrever de maneira mais acurada algumas espécies, como ânions ou radicais livres.

Além disso, há a possibilidade de incluir funções gaussianas no conjunto de base pré-estabelecido. Isso é, adicionar a cada tipo atômico um conjunto extra de funções. Isso é de grande utilidade quando queremos descrever, por exemplo, algum orbital de valência com melhor detalhamento, ou um orbital difuso em uma determinada localização, entre outros fenômenos de interesse.

Do ponto de vista computacional, grande parte dos softwares de mecânica quântica implementam as gaussianas da expansão (2.126) escritas em coordenadas cartesianas, e são assim chamadas de gaussianas cartesianas (GCs).

\subsubsection{A Base Schaefer}

No fim da década de 1980, Schaefer e colaboradores começaram a trabalhar no desenvolvimento de funções de base para descrever melhor orbitais de valência e difusos em diversas espécies. Entre as espécies químicas de estudo se encontravam biomoléculas como aminoácidos, bases nitrogenadas e nucleotídeos. Os estudos buscavam incrementar a base full-DZ com um conjunto de bases calibrado para descrever as espécies em questão. Em 2002[22], Schaefer apresentou um conjunto de bases extra apresentado na Tabela 2.1 para os átomos que constituem a molécula 3'-dGMP.

No presente estudo, fez-se o uso da base Schaefer como uma base extra, afim de descrevermos de maneira mais acurada as espécies 3'-dGMP e $3^{\prime}$-dGMP ${ }^{-}$. 
Tabela 2.1: Base proposta por Schaefer para os átomos H, C, N, O e P.

\begin{tabular}{|cc|cc|}
\hline & Tipo & $\zeta$ & $c$ \\
\hline $\mathrm{H}$ & & & \\
& $\mathrm{S}$ & 0.0441500 & 1.000000 \\
\hline $\mathrm{C}$ & & & \\
& $\mathrm{S}$ & 0.0430200 & 1.000000 \\
& $\mathrm{P}$ & 0.0362900 & 1.000000 \\
\hline $\mathrm{N}$ & & & \\
& $\mathrm{S}$ & 0.0602900 & 1.000000 \\
& $\mathrm{P}$ & 0.0514800 & 1.000000 \\
\hline $\mathrm{O}$ & & & \\
& $\mathrm{S}$ & 0.0822700 & 1.000000 \\
& $\mathrm{P}$ & 0.0650800 & 1.000000 \\
\hline $\mathrm{P}$ & & & \\
& $\mathrm{S}$ & 0.0344800 & 1.000000 \\
& $\mathrm{P}$ & 0.0334600 & 1.000000 \\
\hline
\end{tabular}

\subsection{Aplicações}

O presente trabalho aborda o problema da captura eletrônica da molécula $3^{\prime}$-dGMP do ponto de vista de estrutura eletrônica. Para estudarmos a estrutura eletrônica das espécies 3'dGMP e 3'-dGMP- ${ }^{-}$, utilizou-se a teoria do funcional da densidade com o funcional híbrido B3LYP e a base D95 (full double-zeta - proposta por Huzinaga-Dunning[23, 24]) acrescidas de funções de polarização e do conjunto extra de funções base proposta por Schaefer.

É importante salientar que a proposta do projeto não é discutir detalhadamente a validade e as limitações dos métodos ou da base utilizada.

Todos os cálculos foram realizados com o uso dos softwares gaussian 09[25] e gaussian03[26]. 


\section{Capítulo 3}

\section{Métodos Teóricos II - Efeitos do Solvente}

Muitos processos de interesse físico-químico ocorrem em solução, e por isso muitos métodos foram, e estão sendo, desenvolvidos para estudar como a solvatação pode afetar um determinado fenômeno. O projeto discute como a solvatação influencia a estrutura eletrônica do ânion transiente $3^{\prime}$-dGMP ${ }^{-}$, além de buscar estimativas da barreira de energia livre associada à dissociação $\mathrm{C}_{3^{\prime}}-\mathrm{O}_{3^{\prime}}$ em solução.

Sistemas moleculares em solução são extremamente complexos e, por isso, os efeitos de solvente que buscamos estudar estão relacionados diretamente com o modelo de solvatação. O solvente de uma solução é no geral entendido como um líquido capaz de dissolver um material de interesse ou, neste caso particular, nucleotídeos.

No caso de solvatação de biomoléculas o solvente de maior interesse é a água, visto que o material biológico é constituído essencialmente por soluções aquosas. A água possui um comportamento complexo e curioso, por possuir certas propriedades que desafiam os modelos teóricos. Um exemplo dessas propriedades é a grande capacidade da água líquida de formar ligações de hidrogênio, explicando seus altos pontos de fusão e ebulição, quando comparados a outros solventes polares. Assim, pode-se dizer que uma descrição detalhada de solução aquosa possui importância central na compreensão da dinâmica, propriedades eletrônicas, propriedades espec- 
troscópicas de sistemas moleculares em solução, entre outras.

O entendimento adequado de solvatação se dá por meio de uma quantidade conhecida como energia livre de solvatação, $\Delta G_{\text {solv }}$, que, a grosso modo, está associada ao trabalho necessário para deslocar a molécula de soluto, inicialmente no infinito, para uma determinada posição dentro do solvente, por sua vez mantido à temperatura e pressão constantes. Isso significa que a energia livre de solvatação carrega informações sobre a energia de interação soluto - solvente, solvente - solvente (eletrostáticas), e o trabalho associado às mudanças estruturais realizadas no solvente ao "acomodar" o soluto.

Entende-se, portanto, que a energia de solvatação possui componentes de naturezas eletrostáticas e não-eletrostáticas, as quais chamaremos de $\Delta G_{e l}$ e $\Delta G_{n e l}$, respectivamente. A primeira contribuição diz respeito à interação entre cargas. Ou seja, é a interação eletrostática entre a distribuição de cargas do soluto e do solvente. Essa interação pode ser entendida também da seguinte forma: é a energia necessária para que a distribuição de cargas que o soluto possuía no vácuo seja deslocada para o meio solvente, acrescida da energia gasta para o solvente polarizar essa distribuição. A contribuição não-eletrostática, por sua vez, está relacionada à energia necessária para criar, no solvente, uma cavidade de tamanho suficiente para acomodar aprorpiadamente o soluto, além de uma contribuição devido ao termo de ven der Waals entre o soluto e o solvente. O primeiro termo é denominado energia de cavitação $\Delta G_{c a v}$ e é, no geral, um termo desfavorável no processo de solvatação (isto é, $\Delta G_{\text {cav }}>0$ ). O segundo termo, por sua vez, usualmente contribui favoravelmente para o processo $\left(\Delta G_{v d W}<0\right)$.

A energia livre pode ser interpretada como uma medida da espontaneidade de um processo físico-químico. Um processo de solvatação no qual $\Delta G_{\text {solv }}<0$ implica que a solvatação ocorre de maneira espontânea. A energia livre é largamente utilizada no estudo da estabilidade de isômeros de uma determinada espécie molecular, além do estudo de suas concentrações em uma dada solução. No nosso caso, queremos estimar uma barreira de 
energia livre associada a uma dissociação em meio solvatado, e compará-la com a obtida em fase gasosa. Nesse trabalho essa barreira de energia livre será chamada de energia livre de ativação.

Neste capítulo serão descritos os métodos de solvatação utilizados no trabalho.

\subsection{Modelos de solvatação}

\subsubsection{Solvatação implícita - Modelos contínuos}

Os modelos de solvatação implícita, ou modelos contínuos, levam em consideração contribuições eletrostáticas através de um meio contínuo - sem a necessidade de tratar o solvente como um sistema molecular. Geralmente esse meio é descrito por um dielétrico cuja constante dielétrica é $\epsilon$, e isto significa que o solvente pode ser caracterizado, a priori, por um único parâmetro. Esses modelos de solvatação foram inicialmente propostos na década de 1930[27, 28, 29] e ainda hoje estão sendo desenvolvidos.

A principal característica das solvatações implícitas é o tratamento de interações eletrostáticas e contribuições de longo alcance, além de incluírem efeitos de polarização do soluto devido à presença do solvente. Na aproximação Born-Oppenheimer, o hamiltoniano eletrônico do sistema é dado por:

$$
\hat{\mathcal{H}}_{\text {ele }}=\hat{\mathcal{H}}_{S}^{(0)}+\hat{V}_{i}
$$

em que $\hat{\mathcal{H}}_{S}^{(0)}$ é o operador hamiltoniano eletrônico do soluto e $\hat{V}_{i}$ é o operador que descreve a interação soluto-solvente. Essa energia potencial de interação é tradicionalmente modelada como:

$$
\hat{V}_{i}=\hat{V}_{i}\left(\mathbf{r}, \mathbf{R}, \rho_{S} ; \epsilon\right)
$$

em que $\rho_{S}$ é a densidade de cargas induzidas na superfície da cavidade, $\epsilon$ é a constante dielétrica do solvente e, nessa seção, $\mathbf{r}=\left\{\mathbf{r}_{1}, \ldots, \mathbf{r}_{N}\right\}$ e $\mathbf{R}=\left\{\mathbf{R}_{1}, \ldots, \mathbf{R}_{N}\right\}$ são as posições dos elétrons e núcleos do soluto, respec- 
tivamente. A energia do sistema é dada por:

$$
E=\left\langle\psi\left|\hat{\mathcal{H}}_{\text {ele }}\right| \psi\right\rangle=\left\langle\psi\left|\hat{\mathcal{H}}_{S}^{(0)}\right| \psi\right\rangle+\left\langle\psi\left|\hat{V}_{i}\right| \psi\right\rangle=E^{(0)}+W
$$

na qual $W$ é o valor da energia de interação soluto-solvente. É importante notar que $\hat{V}_{i}$ é um operador de um elétron, e portanto, o cálculo de $W$ não necessita de um acréscimo de custo computacional significativo.

A proposta dos modelos contínuos é partir da interação $\hat{V}_{i}$, escrita em termos de um potencial eletrostático gerado pela distribuição de cargas do soluto. Esse potencial polariza o solvente, que por sua vez gera um potencial eletrostático sobre o soluto, também induzindo sua polarização. O resultado é que, ao longo das iterações, o potencial eletrostático converge para $\Phi$. Uma vez que o potencial $\Phi$ e a interação $\hat{V}_{i}$ dependem da densidade $\rho_{S}$, temos um problema não linear e, assim, sua solução requer um ciclo adicional de auto-consistência. A saber, há um ciclo de auto-consistência para se determinar a distribuição $\rho_{S}$ através de cálculos quânticos, enquanto simultaneamente há um ciclo de auto-consistência para a determinação do potencial $\Phi$ através do problema eletrostático (equação de Poisson). Esse método é conhecido como Campo de Reação Auto-Consistente, ou SCRF (Self Consistent Reaction Field) [30, 31].

Muitos modelos contínuos foram propostos diferindo essencialmente na descrição do potencial eletrostático e na construção da cavidade que acomoda o soluto. Dentre todos os modelos hoje aceitos, o mais utilizado é o modelo contínuo polarizável, PCM (Polarizable Continuum Model).

\section{PCM - Modelo contínuo polarizável}

No atual modelo contínuo polarizável, a cavidade do solvente é construída sobrepondo-se cavidades esféricas centradas nos sítios atômicos do soluto, isto é, para cada átomo do soluto forma-se uma cavidade esférica cujo centro coincide com o centro do sítio atômico. A primeira proposta 
foi utilizar os raios de van der Waals para as cavidades:

$$
R_{\alpha}=R_{\alpha}^{v d W}
$$

Entretanto, alguns resultados experimentais sugeriram que para alguns sistemas a cavidade deveria ser ajustada de forma que os raios $R_{\alpha}$ fossem cerca de 20\% maior do que os respectivos raios de van der Waals para que o modelo conseguisse descrever bem algumas propriedades. Assim, podemos escrever

$$
R_{\alpha}=f R_{\alpha}^{v d W}
$$

em $f$ é um fator de ajuste e seu valor depende do modelo da construção da cavidade. Alguns desses modelos serão brevemente discutidos a seguir.

Tabela 3.1: Raios de van der Waals - VdW - dos átomos constituintes da molécula $3^{\prime}$-dGMP, em $\AA$

\begin{tabular}{|cc|}
\hline Átomo & $R_{\alpha}(\AA)$ \\
\hline $\mathrm{H}$ & 1.20 \\
$\mathrm{C}$ & 1.85 \\
$\mathrm{~N}$ & 1.54 \\
$\mathrm{O}$ & 1.40 \\
$\mathrm{P}$ & 1.90 \\
\hline
\end{tabular}

O problema a ser resolvido é do tipo SCRF e, em um determinado passo $j$ do ciclo de auto-consistência, o potencial eletrostático $\Phi^{(j)}=\Phi^{(j)}(\mathbf{x})$ é dado pela equação de Poisson (em unidades gaussianas):

$$
\nabla^{2} \Phi^{(j)}(\mathbf{x})=\left\{\begin{array}{cl}
-4 \pi \rho_{S}^{(j)}, & \text { se } \mathbf{x} \in \Omega \\
0, & \text { se } \mathbf{x} \notin \Omega
\end{array}\right.
$$

em que $\Omega$ é o volume coompreendido pela cavidade. A determinação do potencial $\Phi^{(j)}(\mathbf{x})$ nos permite escrever o potencial $V_{i}^{(j)}$, que por sua vez é utilizado para resolver a equação de Schrödinger independente do tempo:

$$
\left\{\hat{\mathcal{H}}_{S}^{(0)}+\hat{V}_{i}^{(j)}\left(\mathbf{r}, \mathbf{R}, \rho_{S}^{(j)} ; \epsilon\right)\right\}\left|\psi^{(j)}\right\rangle=E^{(j)}\left|\psi^{(j)}\right\rangle
$$

em que $\left|\psi^{(j)}\right\rangle$ é o estado do sistema no $j$-ésimo passo do ciclo de auto- 
consistência, e $E^{(j)}$ é a energia associada a esse estado. Resolvida essa equação para o estado $\left|\psi^{(j)}\right\rangle$, obtém-se a densidade de cargas do soluto $\rho_{S}^{(j+1)}$ do passo seguinte, iniciando-se assim uma nova iteração. Ao longo do ciclo SCRF, o potencial converge para $\Phi^{(j)}(\mathbf{x}) \rightarrow \Phi(\mathbf{x})$, ao passo que a energia, a densidade de cargas e a função de onda também convergem para a solução de interesse.

Um dos modelos mais utilizados de PCM é chamado de UFF (Universal Force Field)[32], no qual a cavidade é formada sobrepondo-se esferas em todos os átomos cujo raio é dado por (3.4) com $f=1.1$. Nesse modelo, a equação (3.5) é resolvida com o método de integração IEF (Integral Equation Formalism)[33].

Outro modelo muito utilizado, em especial para o cálculo de energia livre de solvatação, é o modelo UAHF (United Atom Topological Model - Hartree-Fock)[34]. Nesse modelo, a cavidade é constituída por esferas centradas apenas em átomos pesados, excluindo hidrogênios (que por sua vez possuem uma cavidade própria). Além disso, o modelo UAHF computa o fator de escala $f$ através da otimização da estrutura eletrônica de cada átomo com o método $\mathrm{HF} / 6-31 \mathrm{G}(\mathrm{d})$. O método UAHF também utiliza a integração IEF.

Um outro modelo mais recente permite construir a cavidade e descrever a interação soluto-solvente com base na densidade eletrônica do soluto, sem a necessidade de definir uma carga efetiva em cada sítio atômico na integração da equação (3.5), chamado de SMD (Solvation Model Density). O procedimento foi proposto em 2009 por Truhlar e colaboradores e possui constantes parametrizadas que dizem respeito às cavidades de cada sítio atômico, considerando o elemento e a carga efetiva, além de constantes relacionadas às tensões superficiais na superfície da cavidade. Esse método está descrito com detalhes na referência[35].

O modelo PCM nos permite obter a energia livre de solvatação, $\Delta G_{\text {solv }}$ através da seguinte expressão:

$$
\Delta G_{\text {solv }}=\Delta G_{\text {ele }}+\Delta G_{\text {cav }}+\Delta G_{R D}
$$


O termo $\Delta G_{\text {ele }}$ é a contribuição eletrostática da energia livre, relacionada com a interação eletrostática entre o soluto e o solvente mais a energia de polarização do soluto. Esse termo pode ser obtido através da seguinte relação:

$$
\Delta G_{\text {ele }}^{(j)}=\frac{1}{2}\left\langle\psi^{(j)}\left|\hat{V}_{i}^{(j)}\right| \psi^{(j)}\right\rangle=\frac{1}{2} W^{(j)}
$$

que, por sua vez, deve convergir ao longo do ciclo. O termo $\Delta G_{c a v}$ é a energia de cavitação, relacionada com o trabalho realizado para construir a cavidade no dielétrico. Por último, o termo $\Delta G_{R D}$ é a energia de repulsão e dispersão, e pode ser escrita como uma contribuição de dois termos:

$$
\Delta G_{R D}=\Delta G_{r e p}+\Delta G_{d i s p}
$$

Mais detalhes sobre a formulação do meio contínuo polarizável encontrase nas referências[15, 36, 37, 38].

Embora os modelos contínuos sejam muito utilizados devido a seus baixos custos computacionais, eles se mostram ineficientes na investigação de certos fenômenos que necessitam de modelos solvatação explícita, por exemplo, a descrição da primeira camada de solvatação associada à solução. Outro fenômeno que podemos citar são as ligações de hidrogênio entre o soluto e as moléculas do solvente. Essas ligações podem explicar diversos comportamentos em solução e não são levados em conta nos modelos contínuos.

\subsubsection{Simulação Computacional}

A simulação computacional de líquidos moleculares e soluções é uma ferramenta que descreve de maneira sofisticada fenômenos de solvatação, podendo investigar comportamentos que foram desprezados em modelos contínuos, como o PCM. A simulação computacional trata as moléculas do soluto e do solvente explicitamente e suas técnicas se baseiam tradicionalmente em duas metodologias: o método de Monte Carlo e a Dinâmica Molecular. As simulações em ambas metodologias são computacionalmente 
muito mais caras que os modelos contínuos, e geralmente requerem uma série de parâmetros numéricos associados ao sistema em particular.

No presente trabalho, utilizou-se exclusivamente o método de Monte Carlo nas simulações [39, 40].

\section{O método de Monte Carlo}

O método de Monte Carlo é uma técnica relativamente eficaz para se tratar problemas de alta complexidade. De modo geral, o método de Monte Carlo é todo e qualquer método que se utiliza de números aleatórios para cálculos como estimativas ou geração de configurações. O uso de números aleatórios na ciência existe desde a primeira metade do século XX, mas ganhou força e popularidade apenas com o desenvolvimento de recursos computacionais.

No caso de sistemas moleculares, mais particularmente para líquidos moleculares, o método de Monte Carlo se baseia em tratar as moléculas como consituintes rígidos (movimentos internos de vibração desconsiderados) formando um sistema cuja energia é descrita por um hamiltoniano clássico. Isto é, o hamiltoniano é uma função das posições $\mathbf{x}_{i}$ e dos momentos $\mathbf{p}_{i}$ de cada sítio dos constituintes.

$$
H(\mathbf{x}, \mathbf{p})=\sum_{i=1}^{6 N} \frac{\mathbf{p}_{i}^{2}}{2 m_{i}}+U(\mathbf{x})
$$

Em que $N$ é o número total de moléculas do sistema, e a soma é feita sobre os $3 N$ graus de liberdade translacionais e $3 N$ graus de liberdade configuracionais dos constituintes e o termo $U(\mathbf{x})$ é o potencial de interação intermolecular.

Além disso, o método consiste no uso de números aleatórios para a produção de configurações termodinamicamente estáveis. Ou seja, buscase obter um conjunto de configurações que satisfaçam a distribuição de 
probabilidades de Boltzmann.

$$
\begin{gathered}
\rho_{N V T}(\Gamma)=\frac{e^{-\frac{U(\Gamma)}{k_{B} T}}}{Z_{N V T}} \\
\rho_{N P T}(\Gamma)=\frac{e^{-\frac{U(\Gamma)+P V}{k_{B} T}}}{Z_{N P T}}
\end{gathered}
$$

Na qual $\Gamma$ é um vetor multidimensional que representa a configuração do sistema, isto é, para $N$ átomos, temos que $\Gamma=\left(\mathbf{x}_{1}, \mathbf{x}_{2}, \ldots, \mathbf{x}_{N}\right), U(\Gamma)$ é a energia potencial associada a essa configuração, $T$ é a temperatura absoluta, $k_{B}$ é a constante de Boltzmann e $Z$ é a função de partição configuracional.

$$
\begin{gathered}
Z_{N V T}=\int e^{-\frac{U\left(\mathbf{x}_{1}, \mathbf{x}_{2}, \ldots, \mathbf{x}_{N}\right)}{k_{B} T}} \mathrm{~d}^{N} \mathbf{x}=\int e^{-\frac{U(\Gamma)}{k_{B} T}} \mathrm{~d} \Gamma \\
Z_{N P T}=\iint e^{-\frac{U\left(\mathbf{x}_{1}, \mathbf{x}_{2}, \ldots, \mathbf{x}_{N}\right)+P V}{k_{B} T}} \mathrm{~d}^{N} \mathbf{x} \mathrm{d} V=\iint e^{-\frac{U(\Gamma)+P V}{k_{B} T}} \mathrm{~d} \Gamma \mathrm{d} V
\end{gathered}
$$

O procedimento para a geração de tais configurações segue o algoritmo de Metrópolis, que funciona de maneira ligeiramente diferente para cada ensemble em questão, e pode ser descrito da seguinte maneira.

\section{Ensemble NVT}

Nesse ensemble o número de consituintes, o volume do sistema e sua temperatura são mantidos constantes. Inicialmente, cria-se uma caixa de simulação, e gera-se uma configuração aleatória com a molécula do soluto e $N$ moléculas do solvente $\Gamma_{i}$, cuja energia associada é $U\left(\Gamma_{i}\right) \equiv$ $U_{i}$.

Em seguida sorteia-se uma das $N+1$ moléculas do sistema. A molécula sorteada terá seu centro de massa deslocado de uma quantidade, também sorteada, $\delta \mathbf{x}$, além de ser reorientada angularmente por uma quantidade angular também aleatória. O sistema então atinge uma nova configuração $\Gamma_{j}$, cuja nova energia é $U\left(\Gamma_{j}\right) \equiv U_{j}$.

Após isso calcula-se a seguinte quantidade

$$
\pi_{i j} \equiv e^{-\frac{U\left(\Gamma_{j}\right)-U\left(\Gamma_{i}\right)}{k_{B} T}}=e^{-\frac{\Delta U_{i j}}{k_{B} T}}
$$


e:

- Se $U_{j} \leq U_{i}$, a nova configuração é aceita.

- Se $U_{j}>U_{i}$, sorteia-se um número aleatório $p \in[0,1]$ e o comparamos com $\pi_{i j}$. Caso $p<\pi_{i j}$, a nova configuração é aceita. Caso contrário, a nova configuração é rejeitada.

Essa repetição é realizada $N+1$ vezes a cada ciclo. Assim, depois de um número suficiente $n$ de ciclos Monte Carlo (um total de $n_{T}=$ $n \times(N+1)$ passos $)$, o sistema atinge o equilíbrio termodinâmico e passa a construir configurações que satisfazem a distribuição de Boltzmann nesse ensemble.

\section{Ensemble NPT}

Nesse ensemble o número de constituintes, a pressão do sistema e sua temperatura são mantidos constantes. Assim como no ensemble NVT, inicialmente cria-se uma caixa de simulação e gera-se uma configuração inicial aleatória com a molécula de soluto e $N$ moléculas do solvente.

Em seguida sorteia-se uma das moléculas que terá seu centro de massa deslocado de uma quantidade, também sorteada, $\delta \mathbf{x}$, além de ser reorientada angularmente por uma quantidade angular também aleatória.

Após isso calcula-se a quantidade

$$
\pi_{i j}=e^{-\frac{U\left(\Gamma_{j}\right)-U\left(\Gamma_{i}\right)}{k_{B} T}}=e^{-\frac{\Delta U_{i j}}{k_{B} T}}
$$

e:

- Se $U_{j} \leq U_{i}$, a nova configuração é aceita.

- Se $U_{j}>U_{i}$, sorteia-se um número aleatório $p \in[0,1]$ e o comparamos com $\pi_{i j}$. Caso $p<\pi_{i j}$, a nova configuração é aceita. Caso contrário, a nova configuração é rejeitada. 
Essa repetição é realizada $n$ vezes.

Em seguida sorteia-se uma quantidade $\delta L$ para que cada lado da caixa seja modificado, mudando assim o volume do sistema. Após isso, calcula-se:

$$
\Pi_{i j} \equiv e^{-\frac{U\left(\Gamma_{j}\right)-U\left(\Gamma_{i}\right)+P\left(V_{j}-V_{i}\right)}{k_{B} T}}=e^{-\frac{\Delta U_{i j}+P \Delta V_{i j}}{k_{B} T}}
$$

e:

- Se $U_{j}+P V_{j} \leq U_{i}+P V_{i}$, a nova configuração é aceita.

- Se $U_{j}+P V_{j}>U_{i}+P V_{i}$, sorteia-se um número aleatório $p$, tal que $0<p<1$, e o comparamos com $\Pi_{i j}$. Caso $p<\Pi_{i j}$, a nova configuração é aceita. Caso contrário, a nova configuração é rejeitada.

Essa repetição é realizada $n_{V}$ vezes, sendo que a cada repetição se realiza $n$ ciclos descritos anteriormente, totalizando $n \times n_{V}$ ciclos. Isto é, $n_{T}=n \times n_{V} \times(N+1)$ passos ao longo da simulação.

Assim como no ensemble anterior, após um número suficiente de ciclos o sistema atinge o equilíbrio termodinâmico, gerando configurações que satisfazem a distribuição de Boltzmann nesse ensemble.

Para se obter médias de grandezas termodinâmicas, a princípio definiríamos a grandeza de interesse $A$ em cada configuração $A=A(\Gamma)$, e faríamos:

$$
\langle A\rangle=\frac{1}{Z} \int_{\{\Gamma\}} A(\Gamma) \rho(\Gamma) \mathrm{d} \Gamma
$$

Onde a integral é realizada sobre todas as possíveis configurações termodinamicamente acessíveis do sistema. A função de partição $Z$ e a distribuição $\rho$ são características do ensemble em que se está trabalhando.

Independente do ensemble em questão, a simulação gerará um conjunto de $n_{T}$ configurações $\{\Gamma\}=\left\{\Gamma_{1}, \Gamma_{2}, \ldots, \Gamma_{n_{T}}\right\}$. Então a média de uma gran- 
deza termodinâmica $A$ pode ser calculada da seguinte maneira:

$$
\langle A\rangle=\frac{1}{n_{T}} \sum_{i=1}^{n_{T}} A\left(\Gamma_{i}\right)
$$

Em que $A\left(\Gamma_{i}\right)$ é a própria grandeza avaliada em cada configuração $\Gamma_{i}$ gerada.

\section{O Potencial de Interação}

Uma vez que não há um potencial intermolecular clássico único, as simulações dependem diretamente de um potencial efetivo conveniente para aquele tipo de sistema. O potencial de interação intermolecular clássico utilizado foi o potencial de Lennard-Jones (LJ) acrescido do termo de Coulomb:

$$
U(\Gamma)=\sum_{(i, j)}\left\{4 \epsilon_{i j}\left[\left(\frac{\sigma_{i j}}{r_{i j}}\right)^{12}-\left(\frac{\sigma_{i j}}{r_{i j}}\right)^{6}\right]+\frac{1}{4 \pi \epsilon_{0}} \frac{q_{i} q_{j}}{r_{i j}}\right\}
$$

Em que $r_{i j}=\left|\mathbf{x}_{j}-\mathbf{x}_{i}\right|$ é a distância entre o sítio atômico $i$ e o sítio atômico $j, \epsilon_{i j}=\sqrt{\epsilon_{i} \epsilon_{j}}$ e $\sigma_{i j}=\sqrt{\sigma_{i} \sigma_{j}}$ onde $\epsilon_{i}$ e $\sigma_{i}$ são os parâmetros de LJ associados ao sítio atômico $i, q_{i}$ é a carga desse sítio, $\epsilon_{j}$ e $\sigma_{j}$ são os parâmetros de LJ associados ao sítio atômico $j$ e $q_{j}$ é a carga desse sítio. Vemos assim que, se tratando da simulação computacional, a molécula (tanto do soluto quanto do solvente) pode ser caracterizada apenas por uma geometria e pelo conjunto de parâmetros $\{q, \epsilon, \sigma\}$.

O conjunto de parâmetros utilizados, combinados ao potencial de interação, definem o campo de força utilizado na simulação computacional. Para os parâmetros $\epsilon$ 's e $\sigma$ 's dos sítios atômicos, há hoje em dia uma série de campos de força parametrizados na literatura, como o OPLS (Optimized Parameters for Liquid Simulations)[41], o AMBER (Assisted Model Building with Energy Refinement)[42], entre outros. Com relação às cargas, alguns campos de força possuem valores parametrizados de $q$ 's, como os citados anteriormente. Entretanto, uma maneira conveniente de se de- 
terminar as cargas efetivas de cada sítio atômico é através de um cálculo quântico sob a metodologia CHELPG[43]. Essa metodologia obtém o potencial eletrostático no espaço devido ao estado do sistema calculado quanticamente. Em seguida o método ajusta uma carga efetiva em cada sítio atômico para melhor descrever o potencial gerado.

\subsubsection{Análise da Simulação - Erros e Distribuição Radial de Pa- res}

\section{Erros estatísticos}

Vimos que uma grandeza física pode ser calculada como uma média sobre configurações (3.18). O erro associado a essa grandeza é dado por:

$$
\operatorname{err}(\langle A\rangle)=\sqrt{\frac{\langle\delta A\rangle^{2}}{n}}=\frac{\langle\delta A\rangle}{\sqrt{n}}
$$

em que:

$$
\langle\delta A\rangle^{2}=\left\langle A^{2}\right\rangle-\langle A\rangle^{2}
$$

e $n$ é o número de configurações utilizadas para o cálculo da média.

Em geral, a expressão (3.20) é válida quando as configurações são independentes, isto é, estatisticamente descorrelacionadas (ver sç. 3.1.5).

\section{Distribuição radial de pares}

A distribuição radial de pares (RDF) é uma função associada a um par de átomos ou moléculas $i j$ que nos fornece a probabilidade de encontrar esse par a uma distância entre $r$ e $r+\mathrm{d} r$. A função, portanto, carrega informações sobre a estrutura e disposição das moléculas dentro do sistema, e experimentalmente tais informações podem ser obtidas através de difração de raios-X e difração de nêutrons[44, 45].

A RDF, $G(r)$, deve ser tal que o número total de moléculas é dado por:

$$
N=\frac{4 \pi}{V} \int G(r) r^{2} \mathrm{~d} r
$$


ou seja, a função $G(r)$ deve ser devidamente normalizada. Para um par de elementos em específico, podemos escrever a RDF como:

$$
G_{i j}(r)=\frac{n_{i j}(r, r+\mathrm{d} r)}{n_{0}(r, r+\mathrm{d} r)}
$$

em que o numerador $n_{i j}(r, r+\mathrm{d} r)$ é o número de pares $i j$ separados por uma distância entre $r$ e $r+\mathrm{d} r$, e o denominador $n_{0}(r, r+\mathrm{d} r)$ é o número de pares $i j$ separados por uma distância entre $r$ e $r+\mathrm{d} r$ caso o sistema fosse homogêneo de densidade $\rho$. Ou, de outra forma, $n_{0}$ é o número de pares associado a um gás ideal de mesma densidade.

$$
n_{0}(r, r+d r)=\frac{4 \pi}{3} \rho\left[(r+\mathrm{d} r)^{3}-r^{3}\right] \simeq 4 \pi \rho r^{2} \mathrm{~d} r
$$

Podemos, evidentemente, calcular a função $G(r)$ de diversas maneiras, visto que há diversos modos de definir distâncias entre pares de moléculas. Uma das maneiras mais convencionais de gerar a RDF é definindo $r$ como a distância entre os centros de massa $(\mathrm{CM})$ das moléculas, conveniente quando a molécula do soluto é pequena ou cuja estrutura é aproximadamente esférica. Nesse caso, a RDF de centros de massa fornece satisfatoriamente informações sobre camadas de solvatação, concentrações de moléculas de solvente, entre outras. Caso o soluto possua dimensões muito diferentes, como uma molécula alongada em uma certa direção, a RDF de centros de massa deixa de ser conveniente. A partir disso, desenvolveuse outra função $G(r)$ dada pela minima distância entre duas moléculas (MDDF)[46, 47], que permite melhor descrição da estrutura do solvente em torno do soluto.

\subsubsection{O Método QM/MM}

O método QM/MM (Quantum Mechanics/Molecular Mechanics) é um procedimento eficiente para tratar sistemas de alto número de graus de liberdade quando estamos interessados em uma determinada propriedade quântica local (do soluto ou na interação entre o soluto e o solvente), como 
a estrutura eletrônica de uma molécula em meio a um sistema líquido. A metodologia considera o sistema divido em uma parte quântica e uma clássica, tratando o hamiltoniano do sistema como uma soma de um termo puramente quântico, um termo puramente clássico e um termo de interação entre as duas partes:

$$
\mathcal{H}=\mathcal{H}_{Q M}+\mathcal{H}_{M M}+\mathcal{H}_{Q M / M M}
$$

em que o primeiro termo se refere à parte quântica, o segundo à parte clássica e o terceiro à interação entre ambas. A vantagem do procedimento é o baixo custo computacional, em vista da possibilidade de tratar um número muito grande de moléculas explicitamente. A ideia central do método quando aplicado a soluções consiste em dividir o sistema físico em soluto - a parte quântica - e o solvente - parte clássica.

A parte clássica pode ser tratada através de uma simulação computacional como descrita na seção 3.1.2, gerando-se as configurações de equilíbrio termodinâmico. A cada passo da simulação clássica, realiza-se um cálculo quântico da propriedade desejada. $\mathrm{O}$ que difere os diferentes métodos QM/MM é o modo como acoplar a parte quântica e a parte clássica, isto é, como descrever de maneirda adequada o termo $\mathcal{H}_{Q M / M M}$ da equação (3.25). Uma das maneiras, por exemplo, seria tratar as moléculas de solvente como cargas pontuais e, consequentemente, a interação solutosolvente de maneira puramente eletrostática. Nesse caso os sítios atômicos das moléculas do solvente são substituídos por cargas cujo valor corresponde aos parâmetros $q$ do campo de força utilizado na simulação.

\subsubsection{O Método s-QM/MM}

O método s-QM/MM (sequential-Quantum Mechanics/Molecular Mechanics) foi proposto por Canuto e Coutinho[37] como uma alternativa ao QM/MM convencional. Nessa abordagem utiliza-se um conjunto particular de configurações dentre as geradas na simulação computacional e realizam-se cálculos quânticos das propriedades desejadas em cada uma de- 
las, tomando-se uma média ao fim do processo. A dificuldade do método é selecionar, dentre as configurações geradas, as que serão efetivamente utilizadas nos cálculos quânticos. Esse aspecto da metodologia faz com que consigamos obter propriedades quânticas devidamente convergidas com um número relativamente baixo de cálculos.

Para selecionar as configurações de interesse, define-se primeiramente uma função de autocorrelação de energia, $C(t)$, dada por:

$$
C(t)=\frac{\left\langle\delta E_{i} \delta E_{i+t}\right\rangle}{\left\langle\delta E^{2}\right\rangle}=\frac{\sum_{i}\left(E_{i}-\langle E\rangle\right)\left(E_{i+t}-\langle E\rangle\right)}{\sum_{i}\left(E_{i}-\langle E\rangle\right)^{2}}
$$

em que $E_{i}$ é a energia total da configuração no $i$-ésimo passo de Monte Carlo, e $\langle E\rangle$ é o valor médio da mesma sobre todas as configurações geradas.

Precisamos obter configurações estatisticamente descorrelacionadas. Para isso, realiza-se um ajuste da expressão (3.28) da seguinte forma:

$$
C(t)=\sum_{j} c_{j} e^{-t / \tau_{j}}
$$

onde $c_{j}$ e $\tau_{j}$ são as constantes do ajuste. Na prática, é suficiente considerar apenas dois termos da expressão acima:

$$
C(t) \simeq c_{1} e^{-t / \tau_{1}}+c_{2} e^{-t / \tau_{2}}
$$

Considera-se, aqui, que as configurações descorrelacionadas são aquelas cuja separação (em passos de MC) nos fornece uma correlação menor que cerca de $\sim 13 \%$. Após definida a separação necessária para a descorrelação, seleciona-se um conjunto relativamente pequeno de configurações descorrelacionadas para se realizar cálculos quânticos e tomar médias das propriedades de interesse. Esse número de configurações necessárias para obter médias de propriedades quânticas devidamente convergidas é tipicamente da ordem de 100.

Uma outra maneira de tratar o solvente como um campo de cargas pontuais é o ASEC (Average Solvent Eletrostatic Configuration)[48] em que sobrepõe-se todas as $n_{T}$ configurações geradas em uma única configuração. 
Todas as moléculas agora são substituídas por cargas pontuais cujo valor é dado pelas cargas admitidas na simualçao computacional divididas por $n_{T}$. Assim, realiza-se um único cálculo quântico da propriedade desejada.

\subsubsection{Energia Livre de Solvatação - Teoria da Perturbação Ter- modinâmica}

Em sistemas solvatados, a energia livre é uma grandeza muito mais adequada para se estudar fenômenos físico-químicos quando comparada à energia total, como foi discutido no início do capítulo 3. Alguns métodos foram desenvolvidos para se obter a diferença de energia livre entre dois estados de um determinado sistema, tanto na abordagem de modelos contínuos quanto em simulações computacionais.

Como já foi discutido anteriormente, modelos contínuos (particularmente PCM) nos permite obter a energia livre de solvatação (eq. (3.8)) diretamente. Entretanto, a maneira de obtê-la em modelos de solvatação explícita é um pouco mais complexa. O procedimento adotado para se obter energias livres de solvatação com o método de Monte Carlo foi a Teoria da Perturbação Termodinâmica, do inglês FEP (Free-Energy Perturbation $)[49,50]$.

\section{Teoria da Perturbação Termodinâmica}

A função de partição configuracional de um sistema $\mathcal{A}$ definido por um determinado potencial $U_{\mathcal{A}}$ é dada pelas expressões (3.12) ou (3.13), dependendo do ensemble em questão. A energia livre associada a esse sistema é dada por:

$$
A_{\mathcal{A}}=-k_{B} T \ln Z_{\mathcal{A}}
$$

A energia livre $A$ representa a energia livre de Helmholtz, caso o ensemble em questão seja o ensemble NVT, enquanto que a mesma representa a energia livre de Gibbs, caso o ensemble seja o NPT.

Assim, a diferença de energia livre entre dois sistemas $\mathcal{A}$ e $\mathcal{B}$ é dada 
por:

$$
\Delta A_{\mathcal{A B}}=A_{\mathcal{B}}-A_{\mathcal{A}}=-k_{B} T \ln \frac{Z_{\mathcal{B}}}{Z_{\mathcal{A}}}
$$

no caso do ensemble NPT;

$$
\Delta G_{\mathcal{A B}}=-k_{B} T \ln \frac{Z_{\mathcal{B}}}{Z_{\mathcal{A}}}
$$

em que as funções de partição são dadas por (3.13).

A razão entre as funções de partição que aparece no logaritmando pode ser reescrita da seguinta maneira:

$$
\begin{aligned}
\frac{Z_{\mathcal{B}}}{Z_{\mathcal{A}}} & =\frac{1}{Z_{\mathcal{A}}} \iint e^{-\frac{U_{\mathcal{B}}(\Gamma)+P V}{k_{B} T}} \mathrm{~d} \Gamma \mathrm{d} V \\
& =\frac{1}{Z_{\mathcal{A}}} \iint e^{-\frac{H_{\mathcal{B}}(\Gamma)}{k_{B} T}} \mathrm{~d} \Gamma \mathrm{d} V \\
& =\frac{1}{Z_{\mathcal{A}}} \iint e^{-\frac{H_{\mathcal{B}}(\Gamma)-H_{\mathcal{A}}(\Gamma)}{k_{B} T}} e^{-\frac{H_{\mathcal{A}}(\Gamma)}{k_{B} T}} \mathrm{~d} \Gamma \mathrm{d} V \\
& =\left\langle e^{-\frac{\Delta H_{\mathcal{A} \mathcal{B}}}{k_{B} T}}\right\rangle_{\mathcal{A}}
\end{aligned}
$$

onde a função de partição está expressa em termos da entalpia $H=U+P V$, e a média da última expressão é realizada sobre a amostragem do sistema A. Logo,

$$
\Delta G_{\mathcal{A B}}=-k_{B} T \ln \left\langle e^{-\frac{\Delta H_{\mathcal{A B}}}{k_{B} T}}\right\rangle_{\mathcal{A}}
$$

Em princípio, esta expressão para $\Delta G_{\mathcal{A B}}$ é exata. Porém, precisamos que o sistema $\mathcal{A}$ amostre satisfatoriamente o sistema $\mathcal{B}$, o que no caso geral não é satisfeito. Em casos de cálculos de $\Delta G$ de soltavação, por exemplo, em que um dos sistemas é constituído pela molécula isolada e um sistema líquido infinitamente separados e o outro sistema é a molécula solvatada, essa condição claramente não se satisfaz.

Assim, criou-se o método perturbativo FEP, em que se conecta os sistemas $\mathcal{A}$ e $\mathcal{B}$ por um caminho de $N-2$ sistemas intermediários $\left\{\lambda_{i}\right\}$ tal que:

$$
\Delta G_{\mathcal{A B}}=-k_{B} T \sum_{i=1}^{N-1} \ln \left\langle e^{-\frac{\Delta H_{\lambda_{i} \lambda_{i+1}}}{k_{B} T}}\right\rangle_{\lambda_{i}}
$$


de modo que $\lambda_{1}$ representa o estado $\mathcal{A}, \lambda_{N}$ representa o estado $\mathcal{B}$ e que em todos os termos da soma, a equação (3.33) deve ser uma aproximação satisfatória. Do ponto de vista computacional, para obter $\Delta G_{\mathcal{A B}}$ devemos realizar $N-1$ simulações cuja amostragem de configurações é feita sobre um sistema $\lambda_{i}$ e o termo exponencial em (3.34) é calculado para um sistema $\lambda_{i+1}$. Ao final das simulações, soma-se todas as variações de energia livre.

Para se obter a energia livre de solvatação $\Delta G_{\text {solv }}$ o procedimento é partir do sistema solvatado, com o soluto e o solvente sendo caracterizados pelos parâmetros $\{q, \epsilon, \sigma\}$, como descrito anteriormente. Em seguida, considera-se uma série de sistemas em que os parâmetros do soluto $(S)$ vão percentualmente para zero, fazendo-se o soluto "desaparecer" do sistema. Isto é, para cada um dos parâmetros $\alpha=q, \epsilon, \sigma$ as simulação perturbativas são realizadas com os valores $\alpha_{\lambda_{i}}=\lambda_{i} \alpha$, com $i=1,2, \ldots, N-1$ e $0<\lambda_{i}<1$. Em seguida, fazendo uso do ciclo termodinâmico da Fig. 3.1, temos:

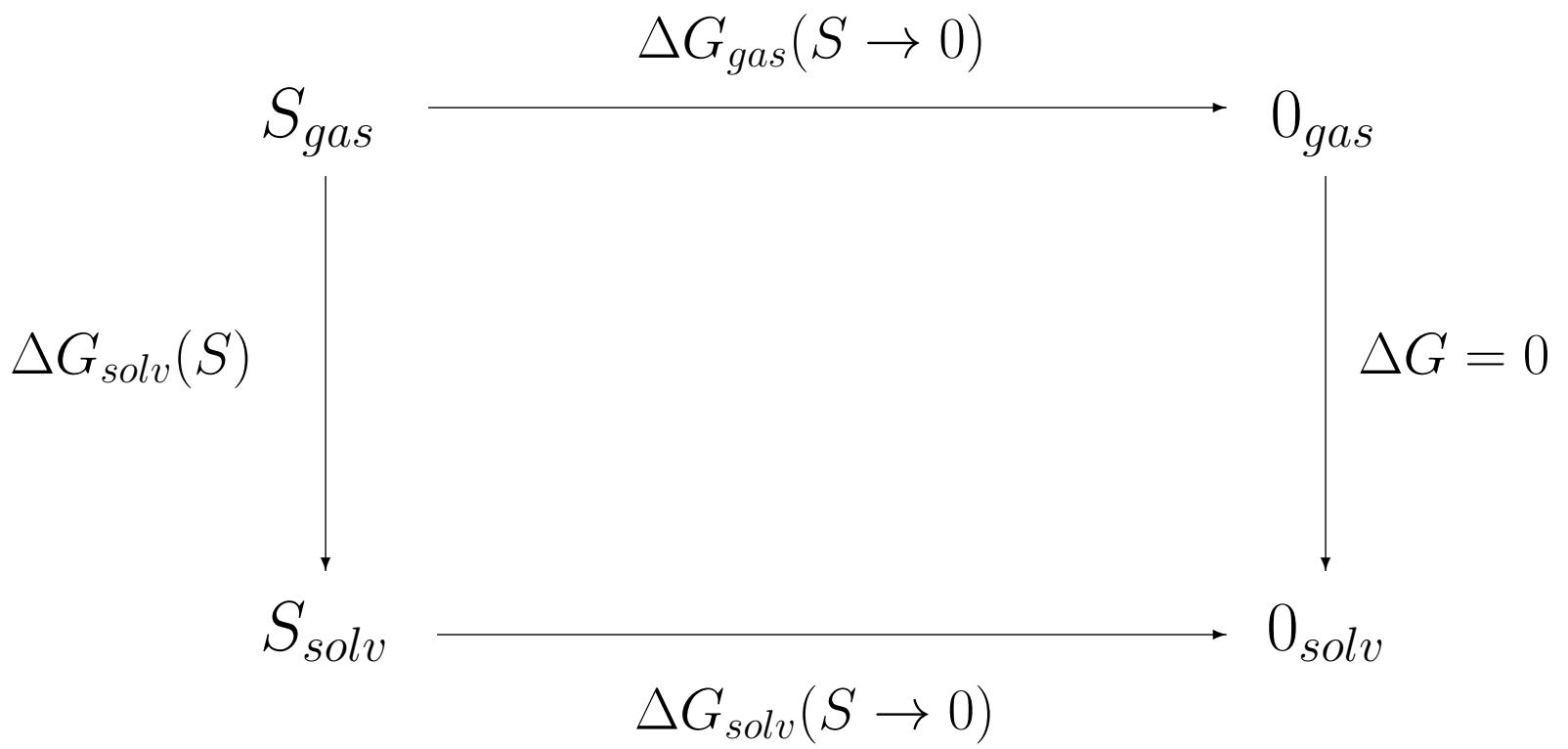

Figura 3.1: Ciclo termodinâmico para a determinação da energia livre de solvatação. Na notação adotada, $S$ representa a geometria e o conjunto de parâmetros do campo de força do soluto.

$$
\Delta G_{\text {ciclo }}=0 \Rightarrow \Delta G_{\text {solv }}(S)=\Delta G_{\text {gas }}(S \rightarrow 0)-\Delta G_{\text {solv }}(S \rightarrow 0)
$$

em que $\Delta G_{\text {gas }}(S \rightarrow 0)$ é a energia livre da molécula em fase gasosa, e 
$\Delta G_{\text {solv }}(S \rightarrow 0)$ é obtida com o uso da expressão (3.25) através da simulação computacional.

Esse procedimento também é útil para se calcular barreiras de energia livre de uma reação em solução. No presente trabalho, obtivemos a variação de energia livre entre o estado otimizado e o estado de transição da molécula 3'-dGMP ${ }^{-}$em solução. Para isso, utilizou-se o ciclo termodinâmico da Fig. 3.2. Temos:

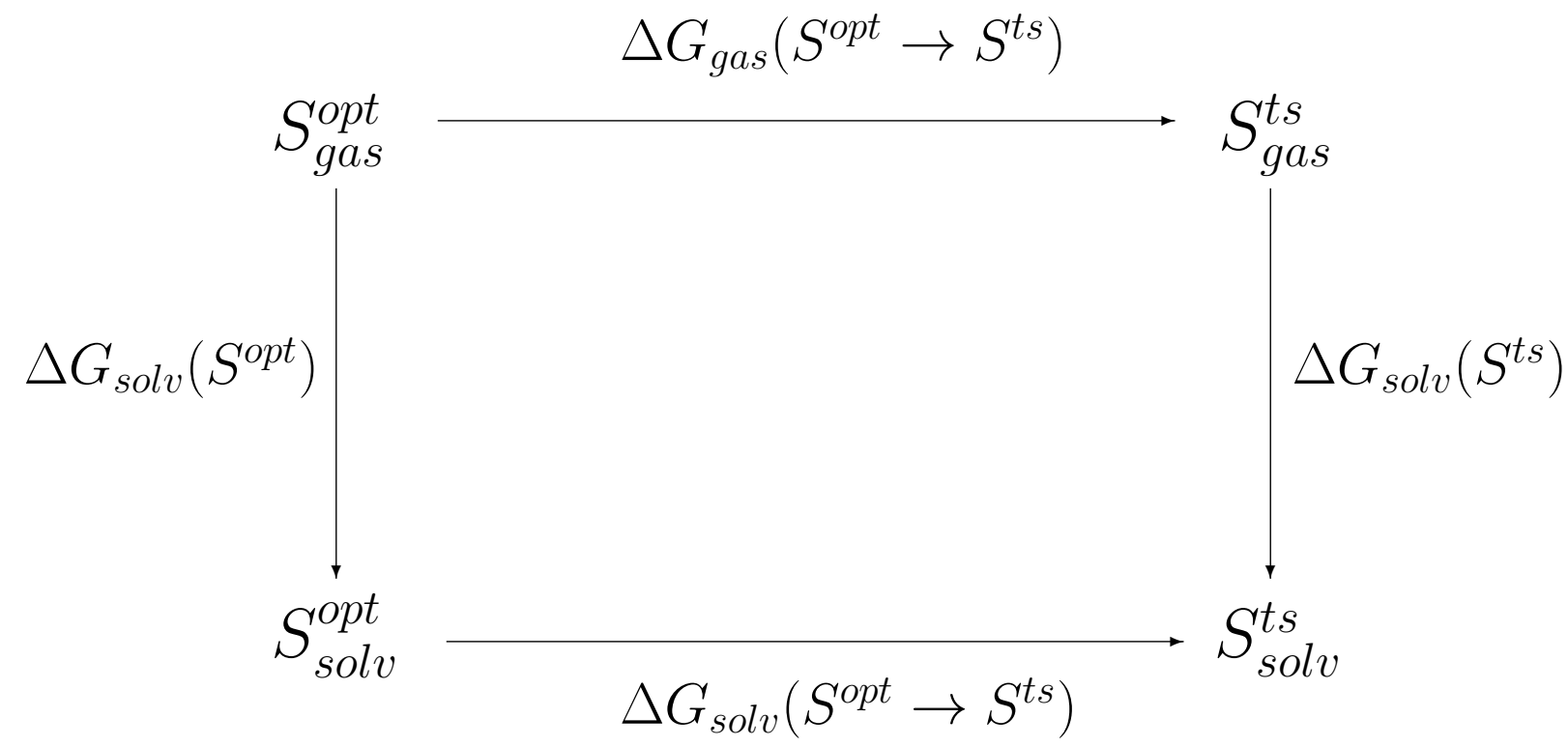

Figura 3.2: Ciclo termodinâmico para a determinação da barreira de energia livre. Na notação adotada, $S^{\text {opt }}$ e $S^{t s}$ representam as geometrias otimizadas e de transição do soluto, e os respectivos conjuntos de parâmetros do campo de força.

$$
\begin{aligned}
\Delta G_{\text {ciclo }} & =0 \Rightarrow \Delta G_{\text {solv }}\left(S^{o p t} \rightarrow S^{t s}\right)=\Delta G_{\text {gas }}\left(S^{o p t} \rightarrow S^{t s}\right) \\
& +\Delta G_{\text {solv }}\left(S^{t s}\right)-\Delta G_{\text {solv }}\left(S^{\text {opt }}\right)
\end{aligned}
$$

em que o primeiro termo é a barreira de energia livre da reação no vácuo, e os dois útlimos termos são as energias livres de solvatação do estado transição e otimizado, respectivamente[51, 52, 53].

\subsection{Aplicações}

Estudou-se os efeitos de solvatação em meio aquoso através de modelos contínuos (PCM) e simulações computacionais. Nos modelos contínuos, 
utilizou-se os três métodos de contrução de cavidade no dielétrico citadas na seção 3.1.1 (UFF, UAHF e SMD). Os programas utilizados foram o gaussian09, para os métodos UFF e SMD, e o gaussian03 para o método UAHF. Quanto à simulação computacional, utilizou-se o programa DICE[54], e o campo de força adotado foi o OPLS. Para a água, o campo de força utilizado foi o SPC[39], e os parâmetros estão dispostos na tabela abaixo:

Tabela 3.2: Geometria da água no modelo SPC, os valores estão em A.

\begin{tabular}{|c|ccc|}
\hline & $\mathrm{x}$ & $\mathrm{y}$ & $\mathrm{z}$ \\
\hline $\mathrm{O}$ & 0.000 & 0.000 & 0.000 \\
$\mathrm{H}$ & 0.577 & 0.817 & 0.000 \\
$\mathrm{H}$ & 0.577 & -0.817 & 0.000 \\
\hline
\end{tabular}

Tabela 3.3: Valores dos parâmetros OPLS da água. Os valores de $q$ estão dados em termos da carga elementar, os valores de $\epsilon$ estão em $\mathrm{kcal} / \mathrm{mol}$ e os valores de $\sigma$ estão em $\AA$.

\begin{tabular}{|c|ccc|}
\hline & $q$ & $\epsilon$ & $\sigma$ \\
\hline $\mathrm{O}$ & -0.82 & 0.155 & 3.165 \\
$\mathrm{H}$ & 0.41 & 0.000 & 0.000 \\
$\mathrm{H}$ & 0.41 & 0.000 & 0.000 \\
\hline
\end{tabular}




\section{Capítulo 4}

\section{Análise dos Resultados}

O projeto busca investigar a captura eletrônica pelo nucleotídeo 3'-dGMP, estudando aspectos fenomenológicos acerca das estruturas eletrônicas envolvidas. O nucleotídeo é a menor unidade molecular capaz de simular o mecanismo de dissociação de fita simples do DNA, e a motivação na escolha da base $\mathrm{G}$ se deve ao fato dela estar associada à menor energia de ativação do processo de ruptura[10], além de possuir o maior momento de dipolo entre as outras nucleobases, desafiando assim a descrição das estruturas eletrônicas envolvidas.

Neste capítulo, apresentaremos os resultados obtidos, tanto em fase gasosa quanto em solução aquosa. Todas as geometrias obtidas estão dispostas no Apêndice A.

\subsection{Moléculas Isoladas}

\subsubsection{3'-dGMP}

Primeiramente, o estado fundamental da molécula 3'-dGMP foi otimizado, utilizando-se DFT com o funcional híbrido B3LYP. A base utilizada foi a D95 com função de polarização acrescida da base Schaefer (D95*-Sch) (Sç. 2.7.1). A molécula 3'-dGMP neutra possui 37 átomos e 180 elétrons, sendo assim um sistema de camada fechada. A molécula pertence ao grupo pontual de simetria $C_{1}$. O resultado obtido está disposto a seguir. A coordenada da reação (1.4) é a distância entre os átomos $\mathrm{O}(2)$ e $\mathrm{C}(8)$, a qual 


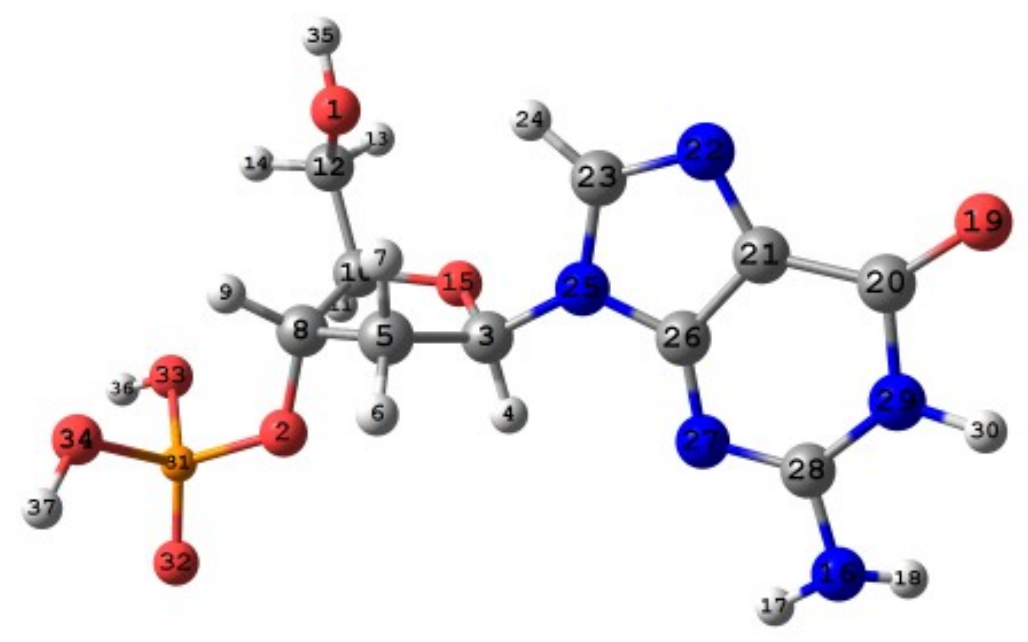

Figura 4.1: Geometria otimizada da molécula 3'-dGMP e a numeração dos sítios atômicos. O código de cores segue a seguinte relação: H - branco; C - cinza; N - azul; O - vermelho; $\mathrm{P}$ - laranja.

chamaremos de $R(\mathrm{C}, \mathrm{O})$. Na geometria otimizada da molécula 3'-dGMP neutra, $\mathbf{R}_{n}$, o comprimento de ligação $R(\mathrm{C}, \mathrm{O})$ vale $1.460 \AA$. Os orbitais HOMO (Highest Occupied Molecular Orbital) e LUMO (Lowest Unoccupied Molecular Orbital) estão dipostos ma Fig. $4.2^{1}$.

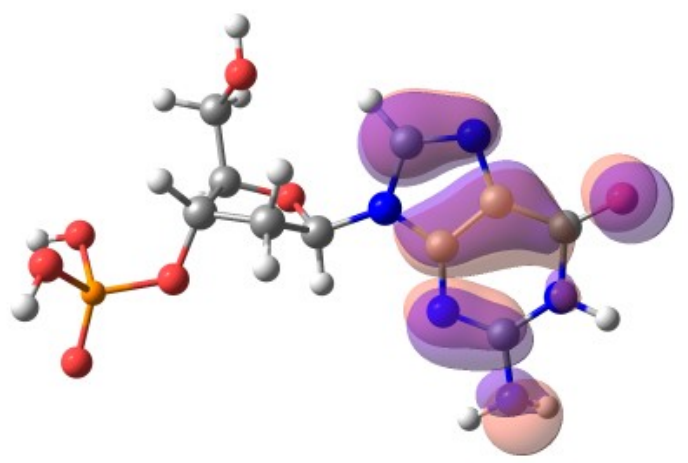

(a) HOMO

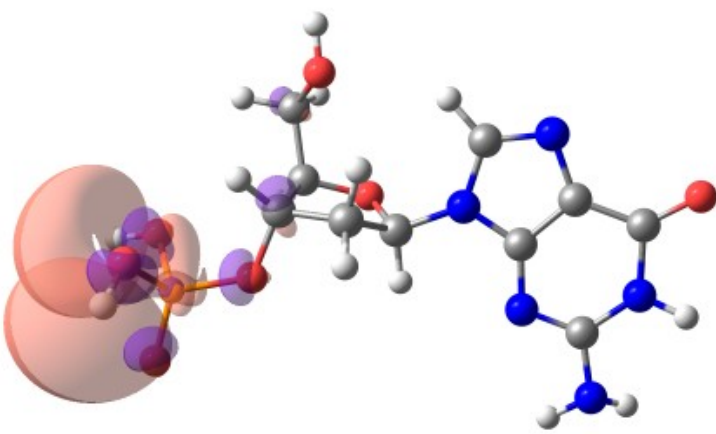

(b) LUMO

Figura 4.2: (a) O orbital HOMO e (b) LUMO da molécula dGMP neutra, na geometria otimizada com o método B3LYP.

Como podemos observar, o orbital ocupado de mais alta energia possui caráter $\pi^{*}$ localizado sobre a base nitrogenada. O orbital desocupado de menor energia, por sua vez, possui caráter de estado ligado por dipolo, com uma densidade eletrônica significativa sobre o grupo fosfato. A carac-

\footnotetext{
${ }^{1}$ Todos os orbitais representados graficamente foram gerados a partir de uma superfície com isovalor de módulo 0.03 .
} 


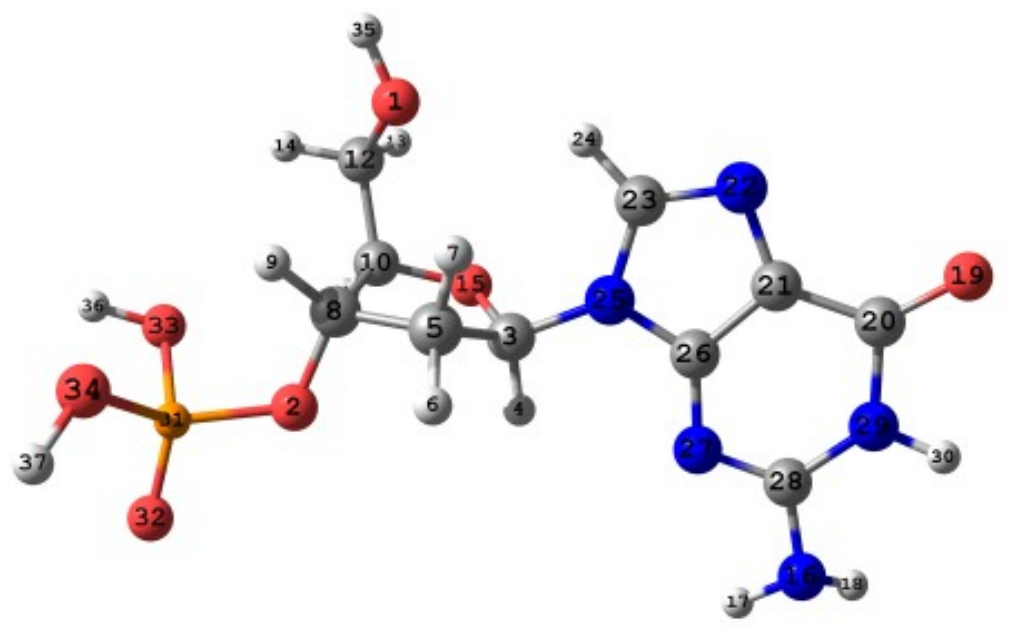

Figura 4.3: Geometria otimizada da molécula $3^{\prime}$-dGMP ${ }^{-}$e a numeração dos sítios atômicos. O código de cores segue a seguinte relação: H - branco; $\mathrm{C}$ - cinza; N - azul; O - vermelho; P - laranja.

terística dipolar do orbital LUMO é esperada, pois a dGMP neutra possui um alto momento de dipolo ( $\mu=6.39 \mathrm{D}$ pelo método B3LYP/D95*-Sch).

\subsection{2 Ânion $3^{\prime}-\mathrm{dGMP}^{-}$}

Em seguida, repetiu-se o procedimento para a espécie carregada com carga -1. O ânion $3^{\prime}$-dGMP ${ }^{-}$naturalmente possui 37 átomos, como a espécie neutra, mas é um sistema de camada aberta, visto que possui 181 elétrons. A numeração dos átomos está disposta na Figura 4.3 e é equivalente à adotada na espécie neutra. A coordenada de reação na geometria otimizada vale $R(\mathrm{C}, \mathrm{O})=1.451 \AA$.

O orbital SOMO (Singly Occupied OMolecular Orbital) do ânion está disposto na Fig. 4.4. Como observa-se, o orbital SOMO possui um caráter de dipolo com densidades localizadas no grupo fosfato e na base nitrogenada, sendo portanto semelhante ao orbital LUMO da espécie neutra disposto na Figura 4.2(b). O momento de dipolo não é um parâmetro físico conveniente em espécies carregadas, visto que sua magnitude, assim como o valor de suas componentes tridimensionais, dependem da origem do sistema de coordenadas. É importante notar que o orbital LUMO da espécie neutra (Fig. 4.2 (b)) possui um caráter de dipolo semelhante ao do orbital SOMO 


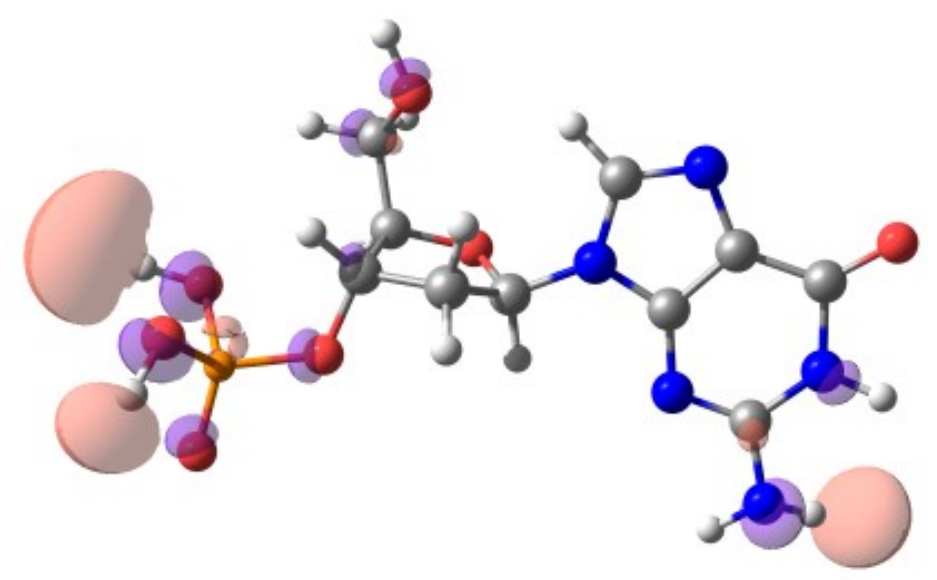

Figura 4.4: O orbital SOMO da molécula $3^{\prime}-\mathrm{dGMP}^{-}$, na geometria otimizada com o método B3LYP.

da espécie carregada (Fig. 4.4). É usual esperar que em vácuo ambos os orbitais de fato possuam uma estrutura de caráter semelhante.

Podemos realizar uma comparação entre os sistemas neutro e carregado com o uso das seguintes definições:

$$
\begin{aligned}
& V A E=E_{a}\left(\mathbf{R}_{n}\right)-E_{n}\left(\mathbf{R}_{n}\right) \\
& V D E=E_{n}\left(\mathbf{R}_{a}\right)-E_{a}\left(\mathbf{R}_{a}\right) \\
& A E A=E_{n}\left(\mathbf{R}_{n}\right)-E_{a}\left(\mathbf{R}_{a}\right)
\end{aligned}
$$

em que VAE, VDE e AEA significam vertical attachment energy, vertical detachment energy e adiabatic electron affinity, respectivamente. O termo $E_{n}\left(\mathbf{R}_{n}\right)$ é a energia eletrônica da espécie neutra calculada na geometria otimizada da molécula neutra, $E_{a}\left(\mathbf{R}_{n}\right)$ é a energia eletrônica do ânion calculada na geometria otimizada da molécula neutra, $E_{n}\left(\mathbf{R}_{a}\right)$ é a energia eletrônica da molécula neutra calculada na geometria otimizada da molécula carregada e $E_{a}\left(\mathbf{R}_{a}\right)$ é a energia eletrônica da molécula carregada calculada na geometria otimizada da molécula carregada. Para a obtenção dessas grandezas realizou-se cálculos single points (SP) das espécies nas respectivas geometrias. O índice $Z P E$ na última coluna da Tabela 4.3 indica a correção de ponto zero na $A E A$.

O termo $V A E$ indica o quão energeticamente abaixo do neutro se en- 
Tabela 4.1: Valores de $V A E$ (4.1), $V D E$ (4.2) e $A E A$ (4.3) em fase gasosa.

\begin{tabular}{|c|cccc|}
\hline & $V A E$ & $V D E$ & $A E A$ & $A E A_{Z P E}$ \\
\hline (Hartree) & -0.0050 & 0.0100 & 0.0079 & 0.0123 \\
$(\mathrm{kcal} / \mathrm{mol})$ & -3.14 & 6.27 & 4.96 & 7.72 \\
$(\mathrm{eV})$ & -0.1360 & 0.2721 & 0.2150 & 0.3347 \\
\hline
\end{tabular}

contra a espécie carregada. O termo $V D E$ nos mostra a diferença de energia com relação à relaxação do ânion. A afinidade eletrônica $A E A=$ $4.96 \mathrm{kcal} / \mathrm{mol}\left(A E A_{Z P E}=7.72 \mathrm{kcal} / \mathrm{mol}\right)$ nos mostra que o ânion é ligado com relação à espécie neutra. Isto é, a energia do ânion em sua geometria otimizada é cerca de $5 \mathrm{kcal} / \mathrm{mol}$ menor do que a energia do neutro em sua respectiva geometria otimizada (eq. (4.3)).

Em seguida buscou-se o estado de transição associado à reação (1.4). O estado de transição no caso da dissociação da $3^{\prime}$-dGMP ${ }^{-}$através da ligação $\mathrm{C}(8)-\mathrm{O}(2)$ é o ponto de sela na hipersuperfície de energia eletrônica entre o estado estado reagente (otimizado) e produto (dissociado). Esse ponto de sela é equivalente ao ponto de máximo local da projeção da hipersuperfície ao longo da coordenada de reação. Como citado no capítulo 2, utilizou-se o método STQN para a determinação desse estado.

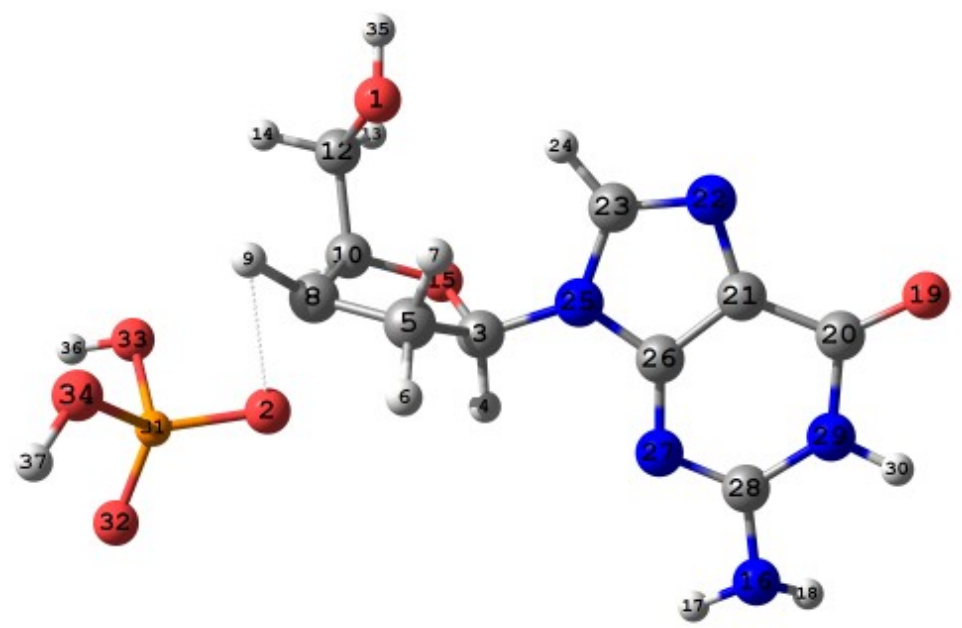

Figura 4.5: Geometria do estado de transição da molécula $3^{\prime}-\mathrm{dGMP}^{-}$e a numeração dos sítios atômicos. O código de cores segue a seguinte relação: H - branco; C - cinza; N azul; O - vermelho; P - laranja.

No estado de transição, a coordenada de reação vale $R(\mathrm{C}, \mathrm{O})=1.74 \AA$ e o orbital SOMO possui um caráter $\sigma^{*}$ sobre a ligação $\mathrm{C}(8)-\mathrm{O}(2)$, como 


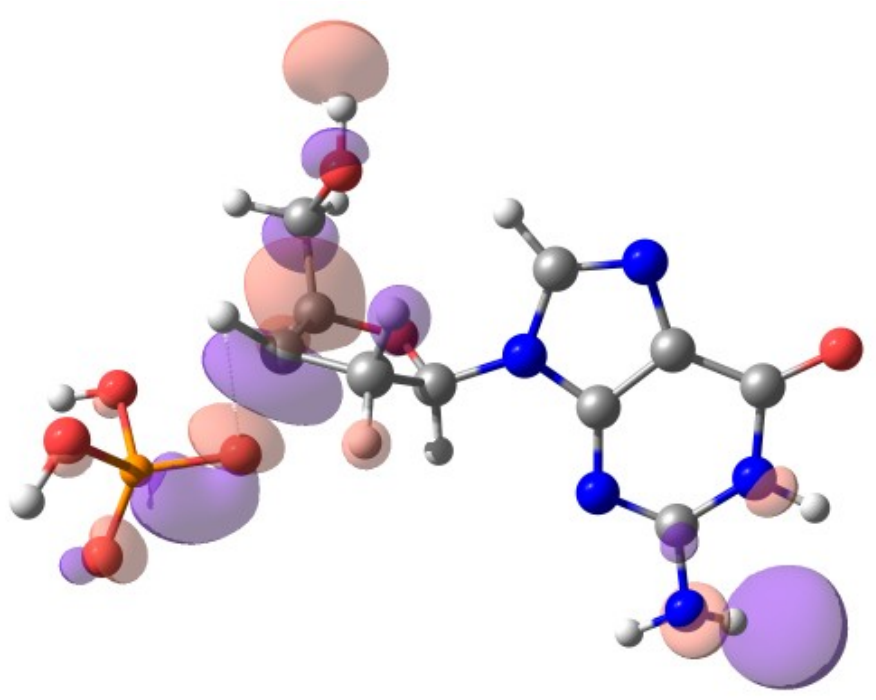

Figura 4.6: Orbital SOMO do estado de transição.

previsto no mecanismo de dissociação. Um cálculo de frequências nos permite verificar a validade do estado de transição. Esse estado possui um único modo de vibração cuja frequência é imaginária. A saber, esse modo está associado ao estiramento entre os átomos $\mathrm{C}(8)$ e $\mathrm{O}(2)$ e a frequência imaginária obtida é $821.55 \mathrm{icm}^{-1}$.

Podemos, agora, determinar a barreira de energia potencial da reação (1.4). O cálculo é realizado através da fórmula (4.4) e os resultados obtidos estão dispostos na Tabela 4.5.

$$
\Delta E_{g a s}=E_{a}\left(\mathbf{R}_{a}^{T S}\right)-E_{a}\left(\mathbf{R}_{a}\right)
$$

A correção de ponto zero na energia de ativação foi obtida desconsideradoTabela 4.2: Barreira de energia potencial $\Delta E_{\text {gas }}$, em fase gasosa, obtida através do método DFT/B3LYP. Os valores entre parêntesis estão corrigidos com a energia de ponto zero.

\begin{tabular}{|ccc|}
\hline$\Delta E_{\text {gas }}($ Hartree $)$ & $\Delta E_{\text {gas }}(\mathrm{kcal} / \mathrm{mol})$ & $\Delta E_{\text {gas }}(\mathrm{eV})$ \\
\hline $0.0195(0.0171)$ & $12.24(10.72)$ & $0.5362(0.4649)$ \\
\hline
\end{tabular}

se o modo de vibração associado ao estiramento da coordenada de reação, nas duas geometrias. O cálculo foi realizado deixando fixo o valor de $R(\mathrm{C}, \mathrm{O})$. Um esquema do comportamento do $\mathrm{SOMO}$ da molécula $3^{\prime}$-dGMP ${ }^{-}$ ao longo da reação está representado na Fig. 4.7.

Considerando as correções de ponto zero, correções entrópicas e entálpicas 


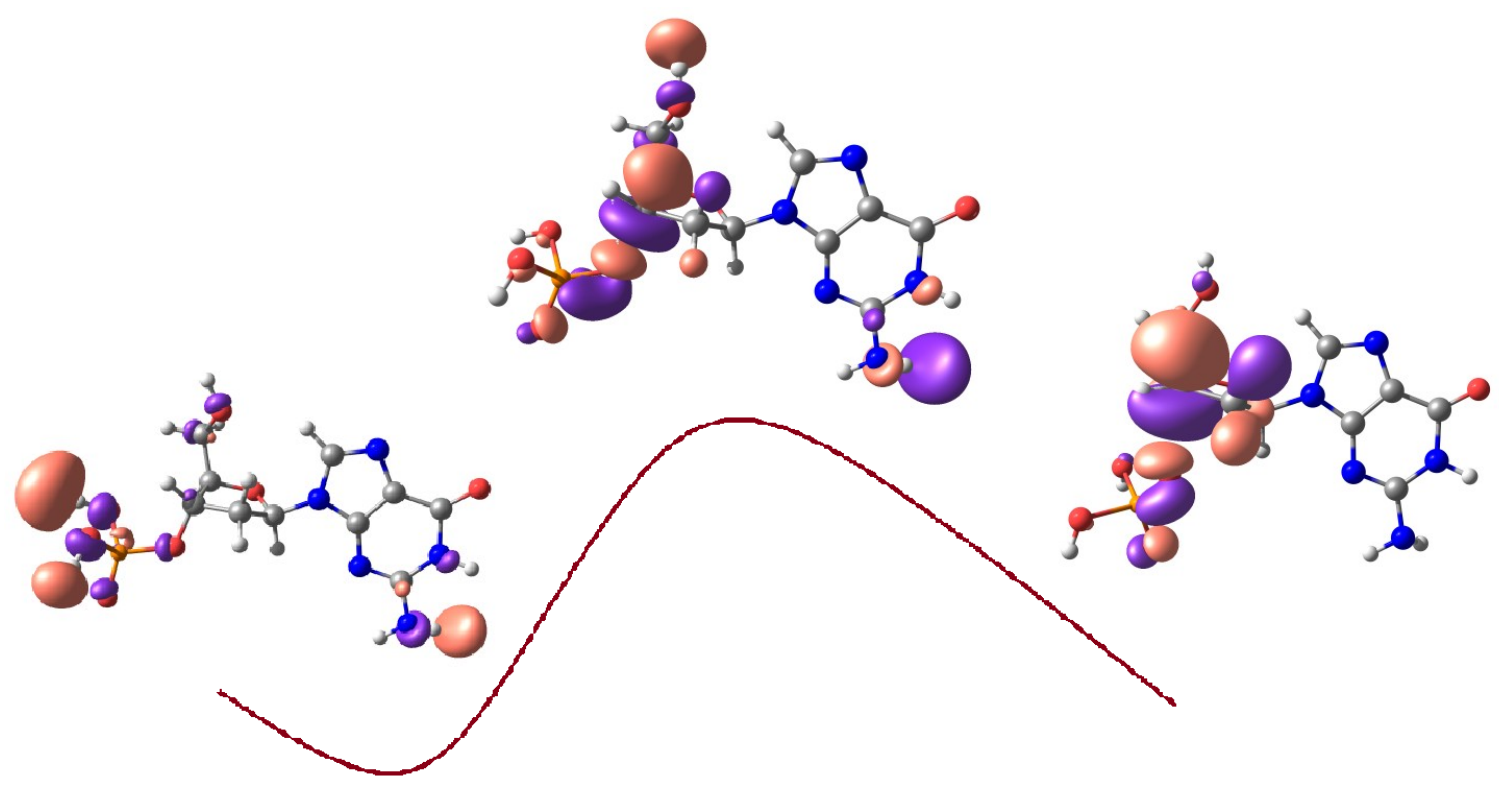

Figura 4.7: Orbital SOMO ao longo da reação (1.4).

(2.119)-(2.120) (Sç. 2.5) à temperatura de $T=298,10 \mathrm{~K}$ na energia de cada uma das duas geometrias (otimizada e de transição), podemos corrigir cada um dos dois termos na equação (4.4) estimar uma barreira de energia livre associada à reação. $\mathrm{O}$ valor obtido foi:

$$
\Delta G_{\text {gas }}=9.94 \mathrm{kcal} / \mathrm{mol}
$$

De uma maneira geral, o método/conjunto de funções base utilizado prediz uma barreira de energia potencial cuja ordem de grandeza está satisfatoriamente de acordo com a literatura ( $10 \mathrm{kcal} / \mathrm{mol})[10,11]$. Porém, conclui-se que o elétron capturado pelo nucleotídeo se aloca em um orbital sustentado por momento de dipolo, ao invés de um orbital $\pi^{*}$ localizado na base nitrogenada. Devido a isso, a estrutura eletrônica associada ao mecanismo esquematizado na Fig. 1.4 não é observada. Esse resultado semelhante (dipolo) foi obtido para espécies associadas à base $\mathrm{G}$ em diversos estudos anteriores que consideraram modelos em fase gasosa, com PCM e microssolvatação[10, 8] 


\subsection{Moléculas Solvatadas - Solvatação Implícita}

O primeiro passo no estudo dos efeitos do solvente foi submeter a molécula à solvatação implícita com o modelo PCM. Realizaram-se cálculos das estruturas eletrônicas em PCM das espécies neutra e carregada nas geometrias obtidas em fase gasosa e, analogamente ao que foi feito para moléculas isoladas, otimizou-se a geometria da molécula $3^{\prime}$-dGMP e $3^{\prime}$-dGMP ${ }^{-}$através de 3 métodos de construção da cavidade; UFF, UAHF e SMD. Nessa seção serão discutidas as geometrias otimizadas, as estruturas eletrônicas e as barreiras de energia potencial e energia livre do mecanismo de dissociação.

Para os métodos de cavitação UFF e SMD, os cálculos de estruturas eletrônicas e otimizações foram realizadas com DFT/B3LYP/D95*-Sch. No caso do método UAHF, os cálculos de estruturas e otimizações foram realizados com o método $\mathrm{HF} / 6-31 \mathrm{G}(\mathrm{d})$.

\subsubsection{3'-dGMP}

Primeiramente, estudou-se como o PCM afeta a estrutura eletrônica da espécie neutra, na geometria otimizada em fase gasosa. Para isso, efetuouse cálculos na geometria $\mathbf{R}_{n}$ (Tabela A.1). As estruturas eletrônicas dos orbitais HOMO e LUMO estão esquematizadas nas Fig. 4.8 e 4.9.

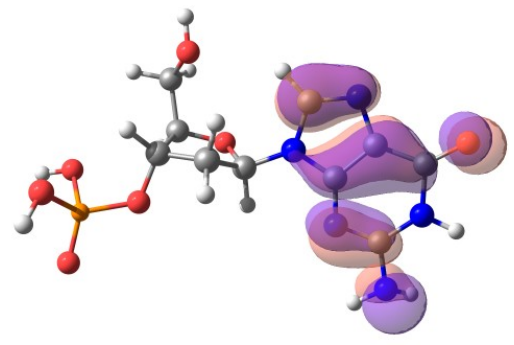

(a) UFF

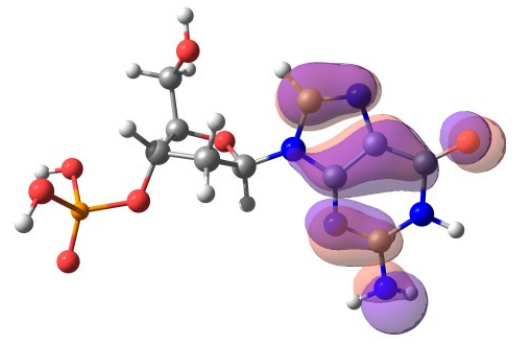

(b) SMD

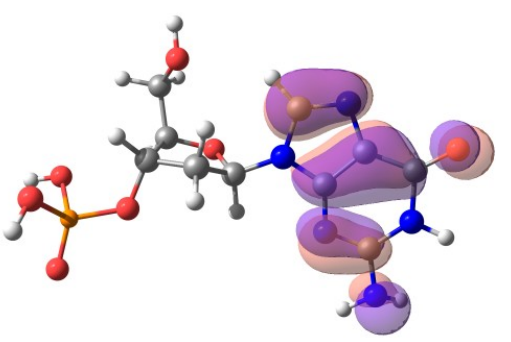

(c) UAHF

Figura 4.8: O orbital HOMO da molécula 3'-dGMP neutra, na geometria $\mathbf{R}_{n}$, em PCM cuja cavidade foi construída pela metodologia (a) UFF (DFT/B3LYP/D95*-Sch) (b) SMD (DFT/B3LYP/D95*-Sch) (c) UAHF (HF/6-31G(d)).

Em seguida, realizou-se otimizações de geometria em PCM. A numeração dos sítios atômicos é equivalente à utilizada nas otimizações em vácuo 


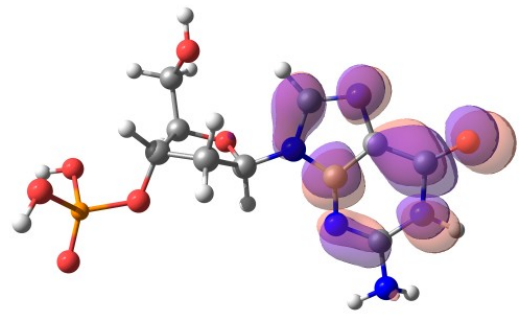

(a) UFF

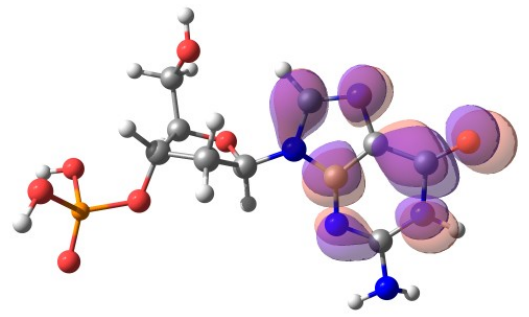

(b) SMD

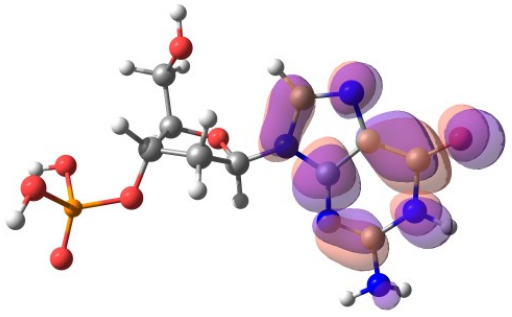

(c) UAHF

Figura 4.9: O orbital LUMO da molécula 3'-dGMP neutra, na geometria $\mathbf{R}_{n}$, em PCM cuja cavidade foi construída pela metodologia (a) UFF (DFT/B3LYP/D95*-Sch) (b) SMD (DFT/B3LYP/D95*-Sch) (c) UAHF (HF/6-31G(d)).

(Apêncie A). Com as geometrias otimizadas, pode-se analisar os orbitais HOMO e LUMO em cada um dos métodos. Comparando-se os orbitais

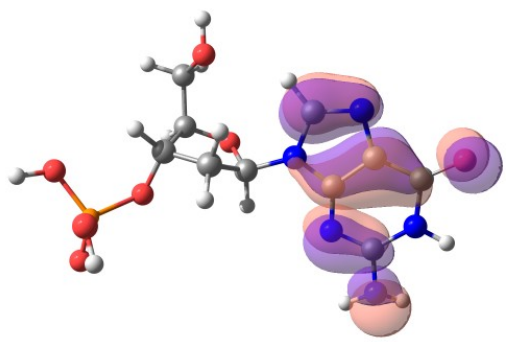

(a) UFF

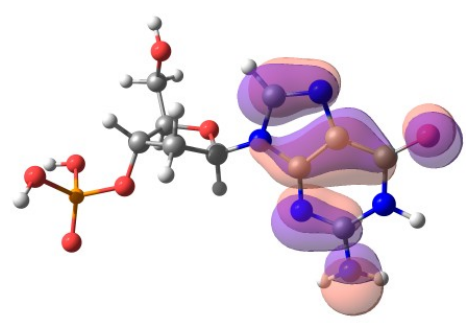

(b) SMD

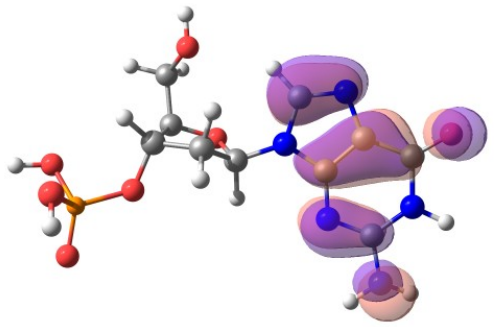

(c) UAHF

Figura 4.10: O orbital HOMO da molécula 3'-dGMP neutra, na geometria otimizada em PCM cuja cavidade foi construída pela metodologia (a) UFF (DFT/B3LYP/D95*-Sch) (b) SMD (DFT/B3LYP/D95*-Sch) (c) UAHF (HF/6-31G(d)).

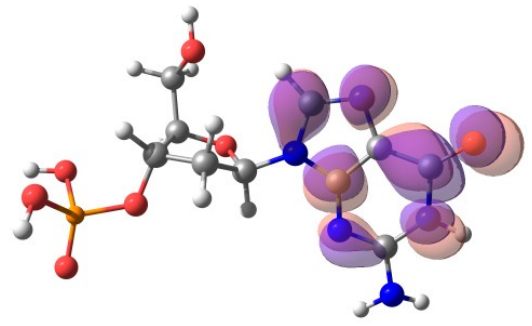

(a) UFF

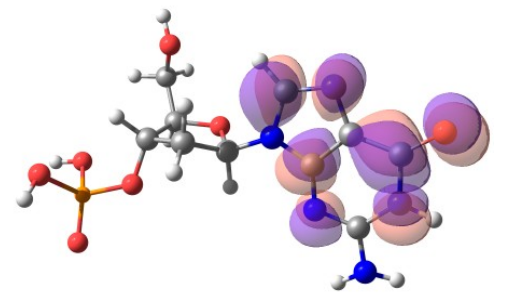

(b) SMD

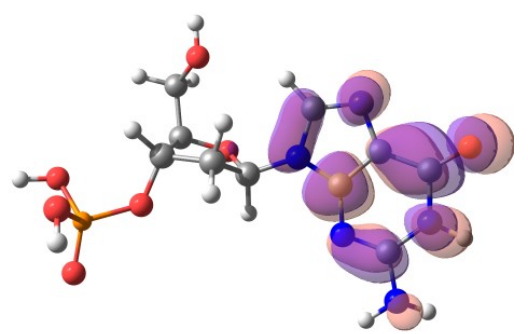

(c) UAHF

Figura 4.11: O orbital LUMO da molécula 3'-dGMP neutra, na geometria otimizada em PCM cuja cavidade foi construída pela metodologia (a) UFF (DFT/B3LYP/D95*-Sch) (b) SMD (DFT/B3LYP/D95*-Sch) (c) UAHF (HF/6-31G(d)).

das figuras 4.8 e 4.9 com os orbitais das figuras 4.10 e 4.11, conclui-se que a pequena mudança na geometria causada pela otimização em cada método não é suficiente para alterar o caráter dos orbitais de fronteira. Nos três 
métodos de cavitação, o orbital LUMO possui caráter $\pi^{*}$ localizado sobre a base nitrogenada, sugerindo que este seja o orbital responsável pela captura eletrônica. Além disso, comparando-se todas as estruturas HOMO e LUMO obtidas em PCM com as previamente obtidas com cálculos em vácuo, vemos que a solvatação implícita não altera de maneira significativa a estrutura eletrônica do orbital HOMO da espécie neutra. Entretanto, para o orbital LUMO, comparando a Fig. 4.2(b) com as Fig. 4.9 e 4.11 observa-se a mudança de um orbital sustentado por momento de dipolo para um orbital $\pi^{*}$. Supondo que o LUMO descreva o orbital responsável pelo aprisionamento do elétron, a solvatação implícita seria suficiente para descrever o mecanismo de dissociação. Para investigarmos essa hipótese, estudaram-se as estruturas da molécula carregada.

\subsection{2 Ânion $3^{\prime}-\mathrm{dGMP}^{-}$}

Foram analisadas as espécies carregadas $3^{\prime}-\mathrm{dGMP}^{-}$, inicialmente na geometria do mínimo de energia. Analogamente ao que foi realizado para espécie neutra, foram realizados cálculos da estrutura eletrônica em PCM do ânion $3^{\prime}$-dGMP ${ }^{-}$na geometria otimizada em fase gasosa $\mathrm{R}_{a}$. Os orbitais SOMO obtidos estão esquematizados na Fig. 4.12.

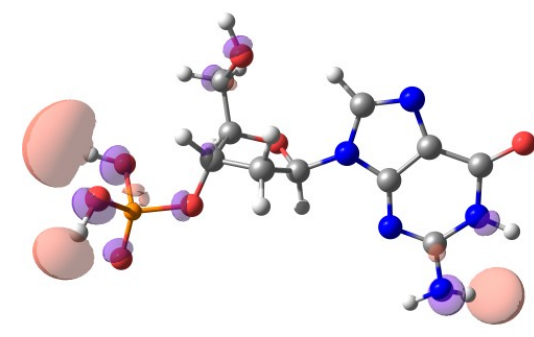

(a) UFF

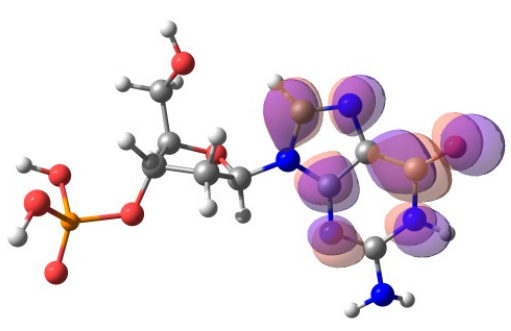

(b) SMD

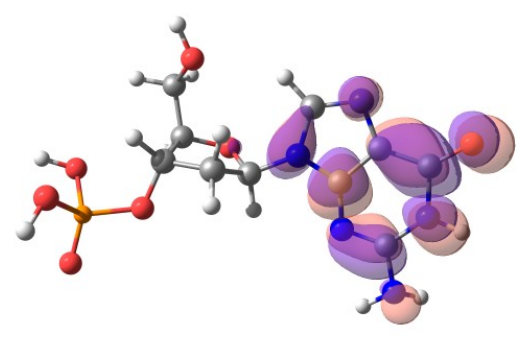

(c) UAHF

Figura 4.12: O orbital SOMO da molécula $3^{\prime}-\mathrm{dGMP}^{-}$, na geometria $\mathbf{R}_{a}$, em PCM cuja cavidade foi construída pela metodologia (a) UFF (DFT/B3LYP/D95*_Sch) (b) SMD (DFT/B3LYP/D95*-Sch) (c) UAHF (HF/6-31G(d)).

Observamos aqui que os orbitais obtidos por diferentes métodos de cavitação não são compatíveis. O uso do método UFF (Fig. 4.12(a)) na construção da cavidade gera um SOMO com caráter de dipolo, semelhante 
ao obtido em fase gasosa, que por sua vez foi questionado frente ao mecanismo de dissociação usualmente aceito. As metodologias SMD e UAHF fornecem orbitais $\pi^{*}$ sobre as bases nitrogenadas. Concluímos assim que esses métodos de cavitação são capazes, a princípio, de descrever corretamente o mecanismo (1.4) sob um modelo de solvatação implícita.

Em seguida, para fim de comparação, otimizou-se o ânion $3^{\prime}$-dGMP ${ }^{-}$ com as três diferentes metodologias. As geometrias obtidas se encontram no Apêndice A e os orbitais SOMO obtidos estão representados na Fig. 4.13. Com esses resultados em mãos, podemos comparar os efeitos de

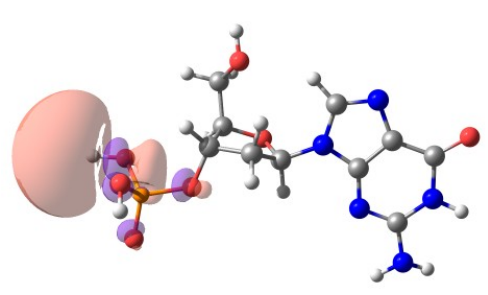

(a) UFF

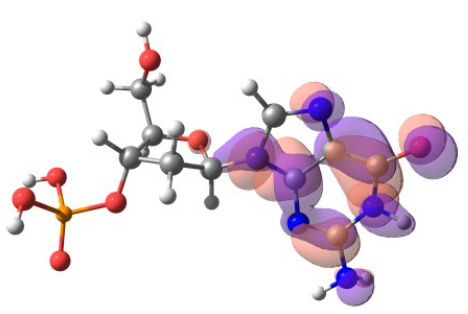

(b) SMD

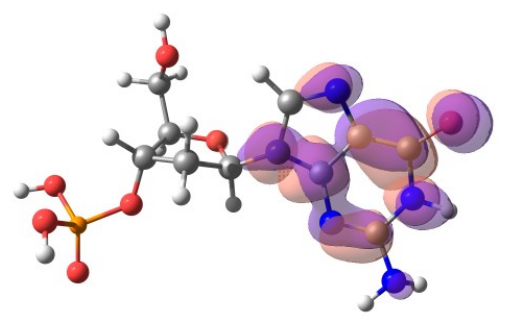

(c) UAHF

Figura 4.13: O orbital SOMO da molécula $3^{\prime}-\mathrm{dGMP}^{-}$, na geometria otimizada em PCM cuja cavidade foi construída pela metodologia (a) UFF (DFT/B3LYP/D95*-Sch) (b) SMD (DFT/B3LYP/D95*-Sch) (c) UAHF (HF/6-31G(d)).

solvatação implícita sobre a geometria e a estrutura eletrônica. De outra forma, podemos investigar como a otimização de geometria em PCM altera a natureza da estrutura eletrônica, quando a comparamos com a obtida sem otimização. Nas Tabelas 4.12 e 4.13 estão resumidos os dados referentes às energias e aos comprimentos da ligação $R(\mathrm{C}, \mathrm{O})$, das espécies neutra e carregada.

Tabela 4.3: Comparação entre os efeitos da solvatação implícita nas geometrias otimizadas no vácuo, $\mathbf{R}_{n}$, e em PCM, $\mathbf{R}_{n}^{P C M}$, da molécula 3'-dGMP neutra.

\begin{tabular}{|c|cc|}
\hline Método & $R(\mathrm{C}, \mathrm{O})(\AA)$ & $E_{n}$ (Hartree) \\
\hline B3LYP/UFF $\left(\mathbf{R}_{n}\right)$ & 1.460 & -1531.5444 \\
B3LYP $/$ UFF $\left(\mathbf{R}_{n}^{P C M}\right)$ & 1.462 & -1531.5464 \\
\hline B3LYP/SMD $\left(\mathbf{R}_{n}\right)$ & 1.460 & -1531.5711 \\
B3LYP/SMD $\left(\mathbf{R}_{n}^{P C M}\right)$ & 1.467 & -1531.5767 \\
\hline $\mathrm{HF} / \mathrm{UAHF}\left(\mathbf{R}_{n}\right)$ & 1.460 & -1524.0153 \\
$\mathrm{HF} / \mathrm{UAHF}\left(\mathbf{R}_{n}^{P C M}\right)$ & 1.440 & -1524.0369 \\
\hline
\end{tabular}


Tabela 4.4: Comparação entre os efeitos da solvatação implícita nas geometrias otimizadas no vácuo, $\mathbf{R}_{a}$, e em PCM, $\mathbf{R}_{a}^{P C M}$, da molécula $3^{\prime}-\mathrm{dGMP}^{-}$carregada.

\begin{tabular}{|c|cc|}
\hline Método & $R(\mathrm{C}, \mathrm{O})(\AA)$ & $E_{a}$ (Hartree) \\
\hline $\mathrm{B} 3 L Y P / \mathrm{UFF}\left(\mathbf{R}_{a}\right)$ & 1.451 & -1531.5929 \\
$\mathrm{~B} 3 L Y \mathrm{UPF}\left(\mathbf{R}_{a}^{P C M}\right)$ & 1.453 & -1531.5974 \\
\hline $\mathrm{B} 3 \mathrm{ULP} / \mathrm{SMD}\left(\mathbf{R}_{a}\right)$ & 1.451 & -1531.5750 \\
$\mathrm{~B} 3 \mathrm{LYP} / \mathrm{SMD}\left(\mathbf{R}_{a}^{P C M}\right)$ & 1.466 & -1531.5811 \\
\hline $\mathrm{HF} / \mathrm{UAHF}\left(\mathbf{R}_{a}\right)$ & 1.451 & -1524.0026 \\
$\mathrm{HF} / \mathrm{UAHF}\left(\mathbf{R}_{a}^{P C M}\right)$ & 1.444 & -1524.0373 \\
\hline
\end{tabular}

É imediato concluir que a otimização de geometria em PCM não muda significativamente a geometria dos sítios atômicos nem altera essencialmente a fenomenologia da estrutura eletrônica, em todos os casos de cavitação. A diferença entre as energias obtidas através dos cálculos quânticos em PCM com a geometria otimizada em vácuo e em PCM é da ordem de $\sim 2 \mathrm{kcal} / \mathrm{mol}$, enquanto que a diferença na coordenada de reação $R(\mathrm{C}, \mathrm{O})$ não passa de dois centésimos de Ångstrom. Isso sugere ser razoável estudar a reação de dissociação por captura eletrônica assumindo que o estado reagente possui a geometria $\mathbf{R}_{a}$ (Tabela 4.2 ) e o estado de transição possui a geometria $\mathbf{R}_{a}^{T S}$ (Tabela 4.3 ).

Dessa maneira, calculou-se a energia livre de solvatação da molécula $3^{\prime}$-dGMP ${ }^{-}$na geometria $\mathbf{R}_{a}$. As energias livres $\Delta G_{\text {solv }}$ com os métodos UFF e UAHF foram realizadas com o software gaussian03, e cada um dos termos da equação (3.7). Quanto ao método SMD, usou-se o software gaussian09 e, para estimar a barreira de energia livre da dissociação, realizou-se cálculos de energia livre em vácuo e em PCM e tomou-se a diferença. Os resultados estão na Tabela 4.5. Parte do termo $\Delta G_{e l}$ é

Tabela 4.5: Energia livre de solvatação da molécula $3^{\prime}-\mathrm{dGMP}^{-}$, com PCM.

\begin{tabular}{|c|ccc|}
\hline Método & $\Delta G_{e l}(\mathrm{kcal} / \mathrm{mol})$ & $\Delta G_{\text {nel }}(\mathrm{kcal} / \mathrm{mol})$ & $\Delta G_{\text {sol }}(\mathrm{kcal} / \mathrm{mol})$ \\
\hline B3LYP $/$ UFF & -79.51 & 17.52 & -61.99 \\
B3LYP $/$ SMD & -206.49 & 7.21 & -199.28 \\
HF $/$ UAHF & -99.65 & 6.75 & -92.90 \\
\hline
\end{tabular}

devido à energia de polarização do soluto. Esse termo nos mostra a energia necessária para polarizar a estrutura eletrônica sob a ação do campo 
de reação do PCM. A Tabela 4.6 mostra as energias de polarização do soluto, nos dois casos. Obteve-se, em seguida, a estrutura eletrônica da

Tabela 4.6: Energia de polarização do soluto na geometria otimizada.

\begin{tabular}{|c|c|}
\hline Método & $\Delta G_{\text {pol }}(\mathrm{kcal} / \mathrm{mol})$ \\
\hline B3LYP/UFF & 21.10 \\
B3LYP/SMD & 59.06 \\
HF $/$ UAHF & 15.33 \\
\hline
\end{tabular}

molécula 3'-dGMP ${ }^{-}$na geometria $\mathbf{R}_{a}^{T S}$. Os orbitais SOMO estão representados nas figuras abaixo. Onde observamos que, independente do método

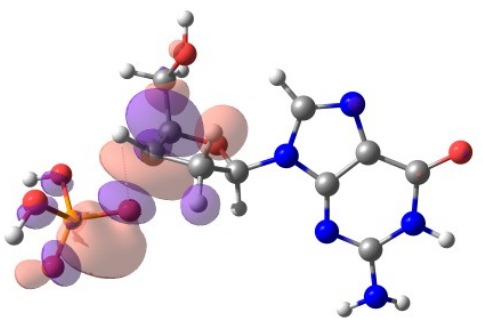

(a) UFF

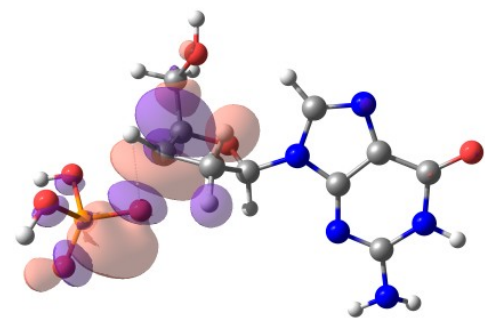

(b) SMD

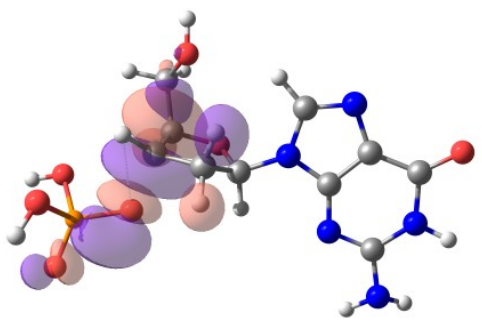

(c) UAHF

Figura 4.14: O orbital SOMO da molécula $3^{\prime}$-dGMP ${ }^{-}$, na geometria de transição em PCM cuja cavidade foi construída pela metodologia (a) UFF (DFT/B3LYP/D95*_Sch) (b) SMD (DFT/B3LYP/D95*-Sch) (c) UAHF (HF/6-31G(d)).

de cavitação, o orbital SOMO possui um caráter $\sigma^{*}$ semelhante nos três casos.

As energias livres de solvatação do estado de transição, para os métodos UFF e UAHF estão na Tabela 4.7, e as energias de polarização se encontram na Tabela 4.8 .

Tabela 4.7: Energia livre de solvatação do estado de transição da molécula $3^{\prime}-$ dGMP $^{-}$, com PCM.

\begin{tabular}{|c|cc|c|}
\hline Método & $\Delta G_{e l}(\mathrm{kcal} / \mathrm{mol})$ & $\Delta G_{n e l}(\mathrm{kcal} / \mathrm{mol})$ & $\Delta G_{\text {sol }}(\mathrm{kcal} / \mathrm{mol})$ \\
\hline B3LYP $/$ UFF & -69.88 & 18.02 & -51.86 \\
B3LYP $/$ SMD & -212.62 & 7.32 & -205.30 \\
HF $/$ UAHF & -82.23 & 7.18 & -75.04 \\
\hline
\end{tabular}

Assim, podemos estimar uma barreira de energia livre associada a reação de dissociação. Para isso utilizamos um ciclo termodinâmico semelhante 
Tabela 4.8: Polarização do soluto no estado de transição.

\begin{tabular}{|c|c|}
\hline Método & $\Delta G_{\text {pol }}(\mathrm{kcal} / \mathrm{mol})$ \\
\hline B3LYP $/$ UFF & 8.37 \\
B3LYP $/$ SMD & 23.09 \\
HF $/$ UAHF & 8.19 \\
\hline
\end{tabular}

ao da Figura 3.2. Obtemos do ciclo a fórmula:

$$
\Delta G=\Delta \Delta G_{\text {solv }}+\Delta G_{\text {gas }}
$$

em que $\Delta \Delta G_{\text {solv }}=\Delta G_{\text {solv }}^{T S}-\Delta G_{\text {solv }}^{O P T}$ e $\Delta G_{\text {gas }}$ é a barreira de energia livre em fase gasosa (eq. 4.5). Os resultados estão na Tabela 4.9.

Tabela 4.9: Barreira de energia livre.

\begin{tabular}{|c|c|}
\hline Método & $\Delta G(\mathrm{kcal} / \mathrm{mol})$ \\
\hline B3LYP $/$ UFF & 20.07 \\
B3LYP $/$ UFF & 3.92 \\
HF $/$ UAHF & 27.80 \\
\hline
\end{tabular}

\subsection{Moléculas Solvatadas - Solvatação Explícita}

Como dito no capítulo 3, a solvatação explícita foi tratada através de simulações computacionais pelo método de Monte Carlo, e foi empregada no estudo do ânion $3^{\prime}$-dGMP ${ }^{-}$. As moléculas de soluto e de água foram mantidas rígidas (isto é, sem graus de liberdade internos), com o potencial intermolecular LJ acrescido do termo de Coulomb (3.19). O campo de força utilizado foi o OPLS[55, 56, 57], e os parâmetros $\epsilon$ e $\sigma$ dos sítios atômicos estão representados na Tabela 4.10. Os valores das cargas $q$, por sua vez, foram obtidos através de cálculos quânticos em PCM, com o ajuste de cargas CHELPG. Obtiveram-se assim três conjuntos de cargas associados às diferentes metodologias de cavitação, para a geometria otimizada (OPT) e de transição (TS) (Tabela 4.11).

Vemos algumas mudanças apreciáveis ao comparar cargas de diferentes grupos. Entre elas observa-se que a carga do átomo H(36) é negativa sob o método UFF, enquanto que é positivo nos outros métodos. Isso signi- 
Tabela 4.10: Valores dos parâmetros OPLS do soluto $3^{\prime}$-dGMP ${ }^{-}$. Os valores de $\epsilon$ estão em $\mathrm{kcal} / \mathrm{mol}$ e os valores de $\sigma$ estão em $\AA$.

\begin{tabular}{|c|cc|}
\hline Átomo & $\epsilon$ & $\sigma$ \\
\hline $\mathrm{O}(1)$ & 0.170 & 3.120 \\
$\mathrm{O}(2)$ & 0.140 & 2.900 \\
$\mathrm{C}(3)$ & 0.066 & 3.500 \\
$\mathrm{H}(4)$ & 0.030 & 2.500 \\
$\mathrm{C}(5)$ & 0.066 & 3.500 \\
$\mathrm{H}(6)$ & 0.030 & 2.500 \\
$\mathrm{H}(7)$ & 0.030 & 2.500 \\
$\mathrm{C}(8)$ & 0.066 & 3.500 \\
$\mathrm{H}(9)$ & 0.030 & 2.500 \\
$\mathrm{C}(10)$ & 0.066 & 3.500 \\
$\mathrm{H}(11)$ & 0.030 & 2.500 \\
$\mathrm{C}(12)$ & 0.066 & 3.500 \\
$\mathrm{H}(13)$ & 0.030 & 2.500 \\
$\mathrm{H}(14)$ & 0.030 & 2.500 \\
$\mathrm{O}(15)$ & 0.140 & 2.900 \\
$\mathrm{~N}(16)$ & 0.170 & 3.250 \\
$\mathrm{H}(17)$ & 0.000 & 0.000 \\
$\mathrm{H}(18)$ & 0.000 & 0.000 \\
$\mathrm{O}(19)$ & 0.210 & 2.960 \\
$\mathrm{C}(20)$ & 0.105 & 3.750 \\
$\mathrm{C}(21)$ & 0.080 & 3.500 \\
$\mathrm{~N}(22)$ & 0.170 & 3.250 \\
$\mathrm{C}(23)$ & 0.080 & 3.500 \\
$\mathrm{H}(24)$ & 0.050 & 2.500 \\
$\mathrm{~N}(25)$ & 0.170 & 3.250 \\
$\mathrm{C}(26)$ & 0.080 & 3.500 \\
$\mathrm{~N}(27)$ & 0.170 & 3.250 \\
$\mathrm{C}(28)$ & 0.080 & 3.500 \\
$\mathrm{~N}(29)$ & 0.170 & 3.250 \\
$\mathrm{H}(30)$ & 0.000 & 0.000 \\
$\mathrm{P}(31)$ & 0.200 & 3.740 \\
$\mathrm{O}(32)$ & 0.200 & 3.150 \\
$\mathrm{O}(33)$ & 0.140 & 2.900 \\
$\mathrm{O}(34)$ & 0.140 & 2.900 \\
$\mathrm{H}(35)$ & 0.000 & 0.000 \\
$\mathrm{H}(36)$ & 0.000 & 0.000 \\
$\mathrm{H}(37)$ & 0.000 & 0.000 \\
\hline & & \\
\hline
\end{tabular}


Tabela 4.11: Valores das cargas $q$ do soluto $3^{\prime}$-dGMP ${ }^{-}$na geometria otimizada. Os valores das cargas estão dados em termos da carga elementar.

\begin{tabular}{|c|ccc|}
\hline Átomo & $q(\mathrm{UFF})$ & $q$ (SMD) & $q$ (UAHF) \\
\hline $\mathrm{O}(1)$ & -0.699 & -0.644 & -0.698 \\
$\mathrm{O}(2)$ & -0.697 & -0.538 & -0.606 \\
$\mathrm{C}(3)$ & 0.644 & 0.652 & 0.742 \\
$\mathrm{H}(4)$ & 0.012 & -0.006 & -0.005 \\
$\mathrm{C}(5)$ & -0.286 & -0.357 & -0.403 \\
$\mathrm{H}(6)$ & 0.101 & 0.120 & 0.119 \\
$\mathrm{H}(7)$ & 0.066 & 0.066 & 0.072 \\
$\mathrm{C}(8)$ & 0.476 & 0.377 & 0.473 \\
$\mathrm{H}(9)$ & -0.004 & 0.058 & 0.029 \\
$\mathrm{C}(10)$ & 0.293 & 0.358 & 0.320 \\
$\mathrm{H}(11)$ & -0.036 & 0.043 & 0.046 \\
$\mathrm{C}(12)$ & 0.117 & -0.009 & 0.144 \\
$\mathrm{H}(13)$ & 0.065 & 0.085 & 0.052 \\
$\mathrm{H}(14)$ & 0.020 & 0.065 & 0.011 \\
$\mathrm{O}(15)$ & -0.629 & -0.666 & -0.701 \\
$\mathrm{~N}(16)$ & -0.989 & -0.968 & -1.087 \\
$\mathrm{H}(17)$ & 0.450 & 0.419 & 0.430 \\
$\mathrm{H}(18)$ & 0.458 & 0.415 & 0.427 \\
$\mathrm{O}(19)$ & -0.820 & -0.831 & -0.825 \\
$\mathrm{C}(20)$ & 0.828 & 0.386 & 0.514 \\
$\mathrm{C}(21)$ & 0.076 & 0.026 & -0.022 \\
$\mathrm{~N}(22)$ & -0.787 & -0.721 & -0.718 \\
$\mathrm{C}(23)$ & 0.399 & 0.147 & 0.348 \\
$\mathrm{H}(24)$ & 0.095 & 0.075 & 0.070 \\
$\mathrm{~N}(25)$ & -0.261 & -0.211 & -0.317 \\
$\mathrm{C}(26)$ & 0.421 & 0.315 & 0.244 \\
$\mathrm{~N}(27)$ & -0.829 & -0.824 & -0.833 \\
$\mathrm{C}(28)$ & 0.999 & 0.872 & 0.977 \\
$\mathrm{~N}(29)$ & -0.846 & -0.760 & -0.898 \\
$\mathrm{H}(30)$ & 0.520 & 0.442 & 0.449 \\
$\mathrm{P}(31)$ & 1.596 & 1.298 & 1.413 \\
$\mathrm{O}(32)$ & -0.936 & -0.743 & -0.774 \\
$\mathrm{O}(33)$ & -0.306 & -0.710 & -0.747 \\
$\mathrm{O}(34)$ & -0.803 & -0.699 & -0.742 \\
$\mathrm{H}(35)$ & 0.487 & 0.464 & 0.471 \\
$\mathrm{H}(36)$ & -0.723 & 0.512 & 0.521 \\
$\mathrm{H}(37)$ & 0.529 & 0.493 & 0.505 \\
\hline & & & \\
\hline
\end{tabular}


fica que esse conjunto de cargas descreve uma densidade eletrônica sobre o grupo fosfato que nao se observa nos outros conjuntos. Podemos reforçar que a construção da cavidade na solvatação implícita é significativa na descrição do ânion em meio aquoso, como já se havia apontado nas Fig. 4.12 e 4.13. Já no estado de transição, não se observam mudanças apreciáveis entre os conjuntos de cargas. É importante enfatizar que os conjuntos de cargas UFF e SMD foram obtidos com o método DFT/B3LYP/D95*-Sch, enquanto que as cargas UAHF foram obtidas com o método HF/6-31G(d) (como a própria construção da cavitação exige que o seja).

As primeiras simulações foram feitas com o soluto $3^{\prime}-\mathrm{dGMP}^{-}$na geometria otimizada e com 1000 moléculas de solvente a uma temperatura de $T=298.15 \mathrm{~K}$ e à pressão de $p=1.0 \mathrm{~atm}$. A caixa inicial de simulação era cúbica de lado $31.197 \AA$. O número de ciclos de MC foi de 200000 na termalização e 400000 na produção. Salvaram-se 4000 configurações da amostragem.

A entalpia por molécula ao longo da amostragem, assim como a densidade, estão esquematizadas nos gráficos das Fig. 4.15, 4.16 e 4.17.

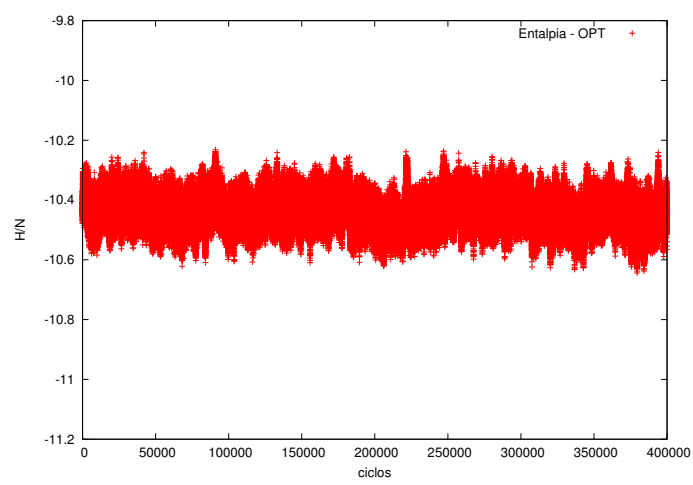

(a) Entalpia

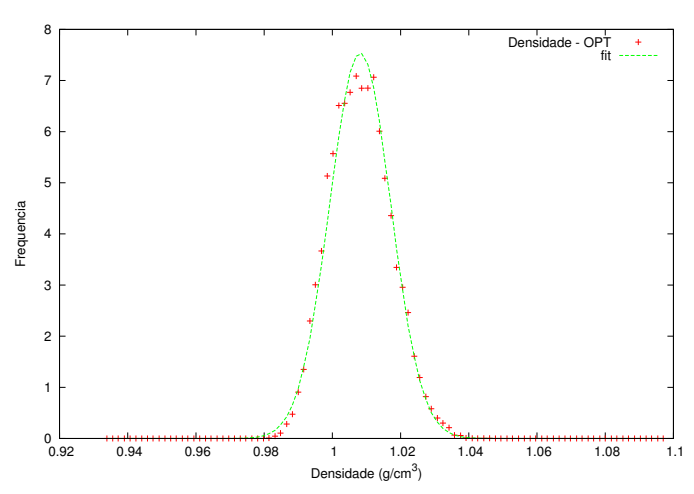

(b) Densidade

Figura 4.15: Simulação com o conjunto de cargas UFF: (a) A entalpia por molécula e (b) a densidade obtida ao longo da amostragem. A entalpia média obtida foi $\langle H / N\rangle=$ $-10.44 \pm 0.04 \mathrm{kcal} / \mathrm{mol}$ e a densidade média obtida foi $\langle\rho\rangle=1.008 \pm 0.007 \mathrm{~g} / \mathrm{cm}^{3}$.

Como vemos, ambas as simulações geram um resultado para a densidade da solução compatível com a densidade experimental da água líquida. Além disso, vemos que as entalpias médias por molécula são compatíveis entre si. 
Tabela 4.12: Valores das cargas $q$ do soluto $3^{\prime}$-dGMP ${ }^{-}$na geometria de transição. Os valores das cargas estão dados em termos da carga elementar.

\begin{tabular}{|c|ccc|}
\hline Átomo & $q(\mathrm{UFF})$ & $q(\mathrm{SMD})$ & $q$ (UAHF) \\
\hline $\mathrm{O}(1)$ & -0.742 & -0.728 & -0.790 \\
$\mathrm{O}(2)$ & -0.883 & -0.827 & -0.907 \\
$\mathrm{C}(3)$ & 0.760 & 0.602 & 0.672 \\
$\mathrm{H}(4)$ & -0.057 & 0.020 & 0.027 \\
$\mathrm{C}(5)$ & -0.497 & -0.414 & -0.413 \\
$\mathrm{H}(6)$ & 0.116 & 0.107 & 0.078 \\
$\mathrm{H}(7)$ & 0.040 & 0.033 & 0.017 \\
$\mathrm{C}(8)$ & 0.859 & 0.372 & 0.468 \\
$\mathrm{H}(9)$ & -0.092 & -0.014 & -0.066 \\
$\mathrm{C}(10)$ & 0.183 & 0.389 & 0.369 \\
$\mathrm{H}(11)$ & 0.037 & -0.017 & -0.034 \\
$\mathrm{C}(12)$ & 0.116 & -0.059 & 0.108 \\
$\mathrm{H}(13)$ & 0.064 & 0.093 & 0.042 \\
$\mathrm{H}(14)$ & 0.000 & 0.057 & 0.003 \\
$\mathrm{O}(15)$ & -0.656 & -0.667 & -0.708 \\
$\mathrm{~N}(16)$ & -0.894 & -0.925 & -1.032 \\
$\mathrm{H}(17)$ & 0.397 & 0.421 & 0.443 \\
$\mathrm{H}(18)$ & 0.408 & 0.426 & 0.452 \\
$\mathrm{O}(19)$ & -0.698 & -0.675 & -0.704 \\
$\mathrm{C}(20)$ & 0.692 & 0.634 & 0.840 \\
$\mathrm{C}(21)$ & 0.126 & 0.052 & -0.059 \\
$\mathrm{~N}(22)$ & -0.716 & -0.674 & -0.690 \\
$\mathrm{C}(23)$ & 0.315 & 0.250 & 0.314 \\
$\mathrm{H}(24)$ & 0.116 & 0.128 & 0.141 \\
$\mathrm{~N}(25)$ & -0.178 & -0.172 & -0.232 \\
$\mathrm{C}(26)$ & 0.287 & 0.365 & 0.425 \\
$\mathrm{~N}(27)$ & -0.699 & -0.756 & -0.861 \\
$\mathrm{C}(28)$ & 0.874 & 0.891 & 1.108 \\
$\mathrm{~N}(29)$ & -0.742 & -0.747 & -0.937 \\
$\mathrm{H}(30)$ & 0.441 & 0.460 & 0.496 \\
$\mathrm{P}(31)$ & 1.024 & 1.279 & 1.402 \\
$\mathrm{O}(32)$ & -0.908 & -0.863 & -0.880 \\
$\mathrm{O}(33)$ & -0.760 & -0.750 & -0.767 \\
$\mathrm{O}(34)$ & -0.722 & -0.740 & -0.771 \\
$\mathrm{H}(35)$ & 0.474 & 0.491 & 0.500 \\
$\mathrm{H}(36)$ & 0.467 & 0.487 & 0.475 \\
$\mathrm{H}(37)$ & 0.448 & 0.469 & 0.471 \\
& & & \\
\hline
\end{tabular}




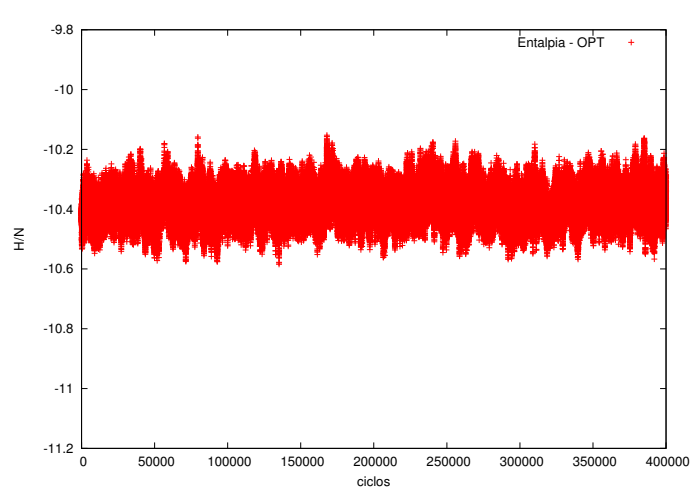

(a) Entalpia

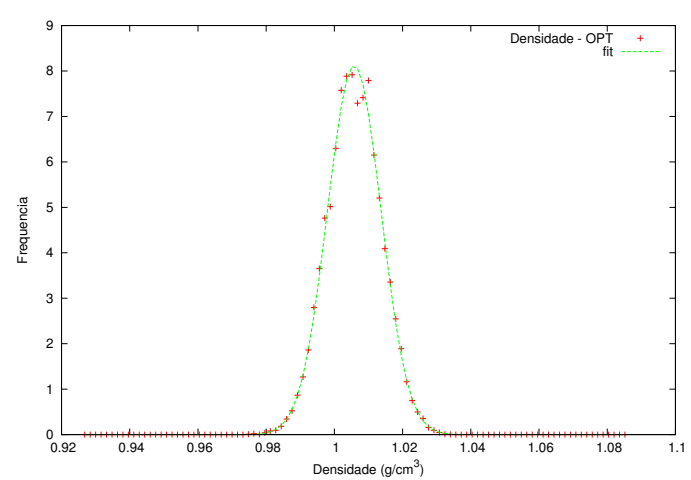

(b) Densidade

Figura 4.16: Simulação com o conjunto de cargas SMD: (a) A entalpia por molécula e (b) a densidade obtida ao longo da amostragem. A entalpia média obtida foi $\langle H / N\rangle=$ $-10.38 \pm 0.05 \mathrm{kcal} / \mathrm{mol}$ e a densidade média obtida foi $\langle\rho\rangle=1.006 \pm 0.008 \mathrm{~g} / \mathrm{cm}^{3}$.

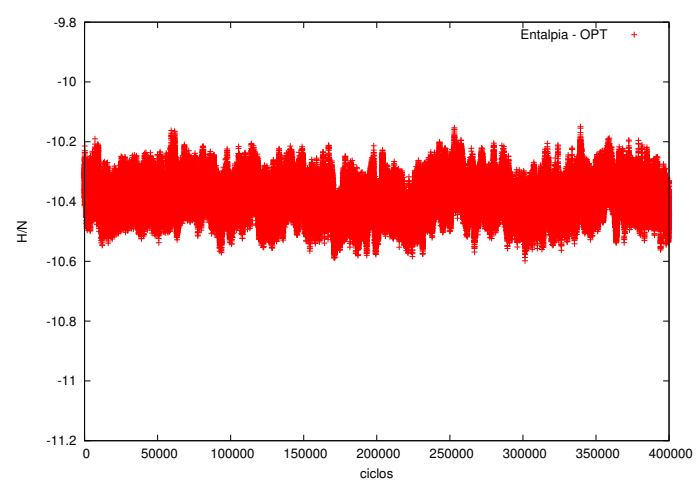

(a) Entalpia

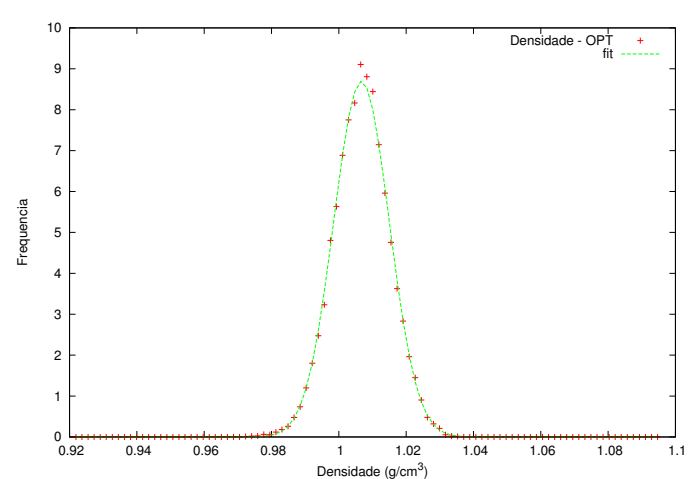

(b) Densidade

Figura 4.17: Simulação com o conjunto de cargas UAHF: (a) A entalpia por molécula e (b) a densidade obtida ao longo da amostragem. A entalpia média obtida foi $\langle H / N\rangle=$ $-10.39 \pm 0.05 \mathrm{kcal} / \mathrm{mol}$ e a densidade média obtida foi $\langle\rho\rangle=1.007 \pm 0.008 \mathrm{~g} / \mathrm{cm}^{3}$.

O próximo passo foi realizar as mesmas simulações para o soluto na geometria de transição. A entalpia por molécula ao longo da simulação, assim como a densidade, estão respresentadas nos gráficos das Fig. 4.18, 4.19 e 4.20. Assim como no caso da geometria otimizada, as simulações com o soluto na geometria de transição nos gera uma densidade média compatível com o valor experimental da densidade da água, e as entalpias por molécula de todos os métodos são compatíveis entre si. Isso justifica $a$ posteriori a escolha do campo de força OPLS.

Então, as primeiras camadas de solvatação foram estudadas em todos os casos. Para isso utilizou-se a distribuição de pares de mínima distância 


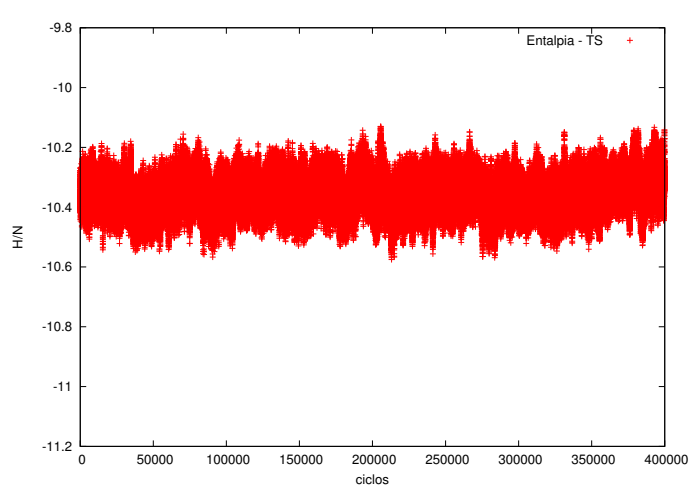

(a) Entalpia

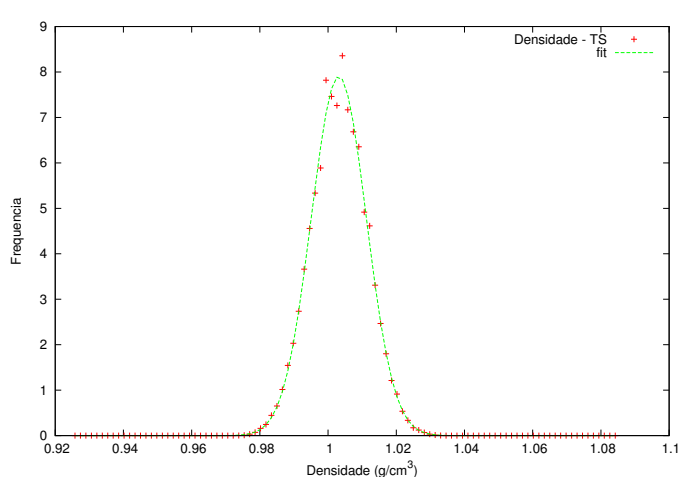

(b) Densidade

Figura 4.18: Simulação com o conjunto de cargas UFF: (a) A entalpia por molécula e (b) a densidade obtida ao longo da amostragem. A entalpia média obtida foi $\langle H / N\rangle=$ $-10.35 \pm 0.03 \mathrm{kcal} / \mathrm{mol}$ e a densidade média obtida foi $\langle\rho\rangle=1.007 \pm 0.007 \mathrm{~g} / \mathrm{cm}^{3}$.

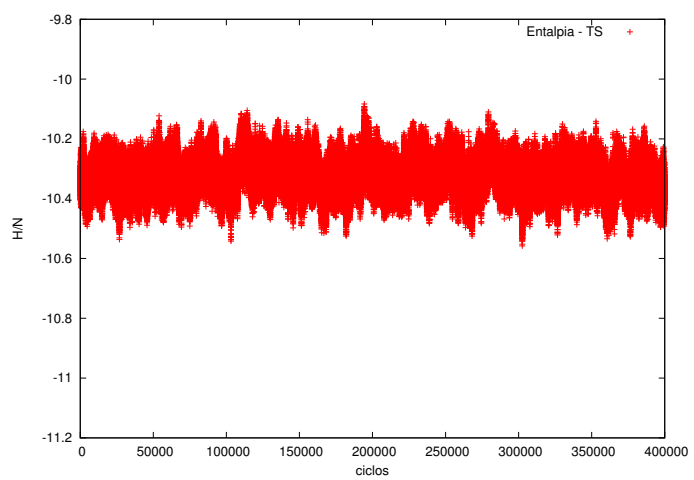

(a) Entalpia

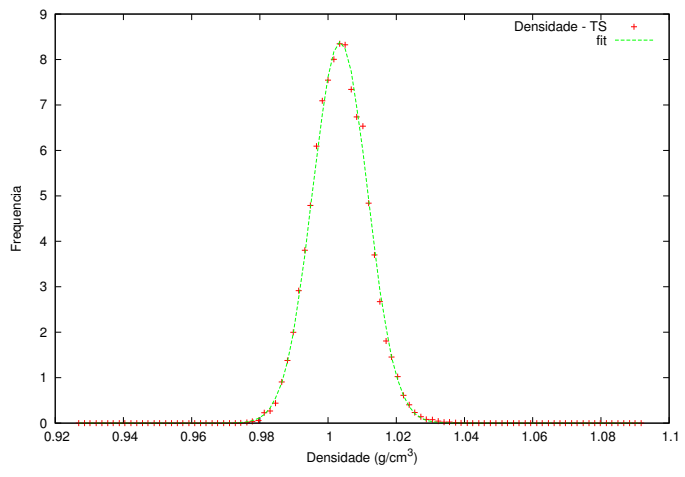

(b) Densidade

Figura 4.19: Simulação com o conjunto de cargas SMD: (a) A entalpia por molécula e (b) a densidade obtida ao longo da amostragem. A entalpia média obtida foi $\langle H / N\rangle=$ $-10.32 \pm 0.05 \mathrm{kcal} / \mathrm{mol}$ e a densidade média obtida foi $\langle\rho\rangle=1.003 \pm 0.008 \mathrm{~g} / \mathrm{cm}^{3}$.

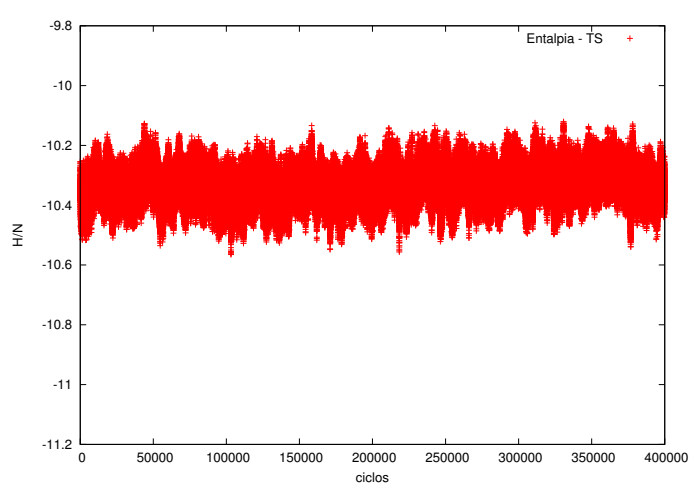

(a) Entalpia

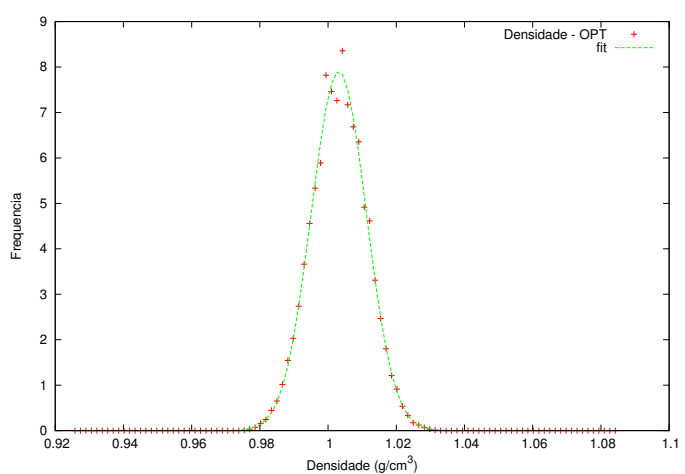

(b) Densidade

Figura 4.20: Simulação com o conjunto de cargas UAHF: (a) A entalpia por molécula e (b) a densidade obtida ao longo da amostragem. A entalpia média obtida foi $\langle H / N\rangle=$ $-10.33 \pm 0.05 \mathrm{kcal} / \mathrm{mol}$ e a densidade média obtida foi $\langle\rho\rangle=1.003 \pm 0.008 \mathrm{~g} / \mathrm{cm}^{3}$. 
devidamente normalizada. As MDDF obtidas se encontram nos gráficos das Fig. 4.21, 4.22 e 4.23. Determinou-se o número de moléculas de água

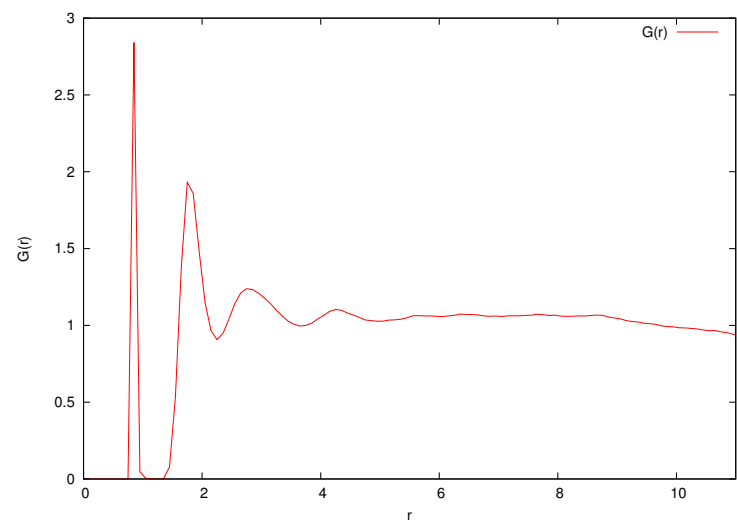

(a) MDDF - OPT (UFF)

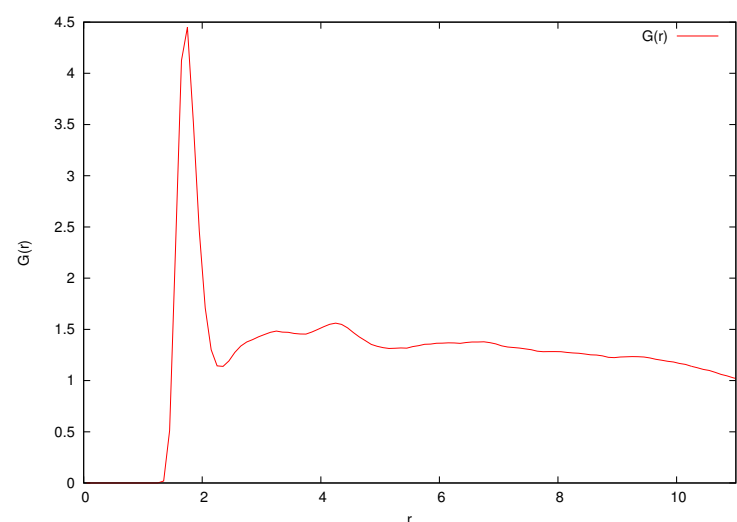

(b) MDDF - TS (UFF)

Figura 4.21: Distribuição de pares da simulação com o conjunto de cargas UFF: (a) OPT (b) TS.

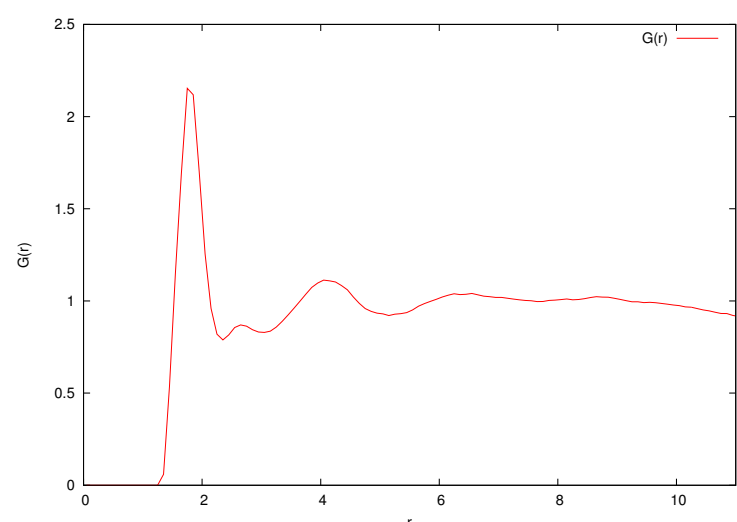

(a) MDDF - OPT (SMD)

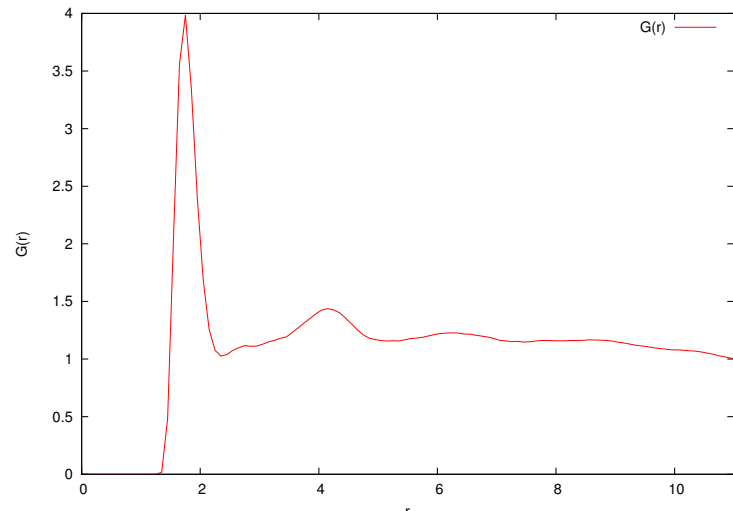

(b) MDDF - TS (SMD)

Figura 4.22: Distribuição de pares da simulação com o conjunto de cargas SMD: (a) OPT (b) TS.

na primeira camada de solvatação como sendo a integral da função MDDF até o ponto de mínimo local relativo a primeira camada de solvatação. Com exceção da distribuição de pares da Fig. 4.29 (a), que possui um mínimo associado a ligações de hidrogênio, todas as outras distribuições possuem a primeira camada de solvatação no primeiro mínimo local. O número de moléculas de solvente na primeira camada em cada uma das simulações está disposto na Tabela 4.13. Vemos, aqui, que os conjuntos de cargas SMD e UAHF no campo de força utilizado geram o mesmo número 


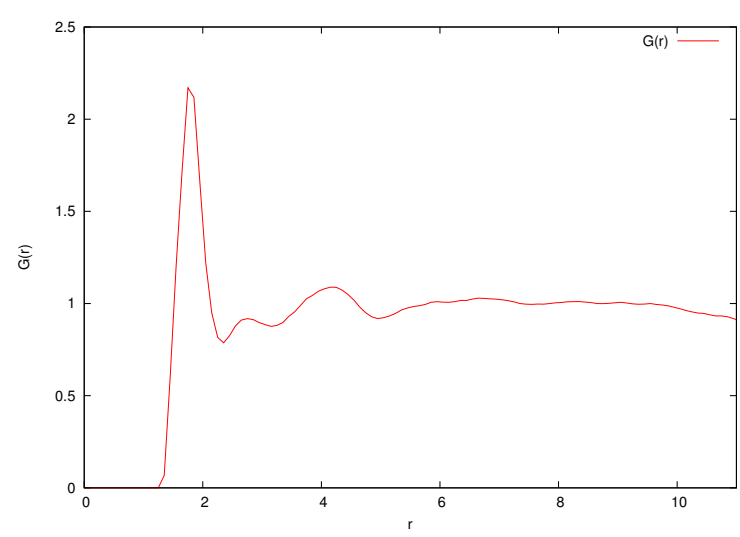

(a) MDDF - OPT (UAHF)

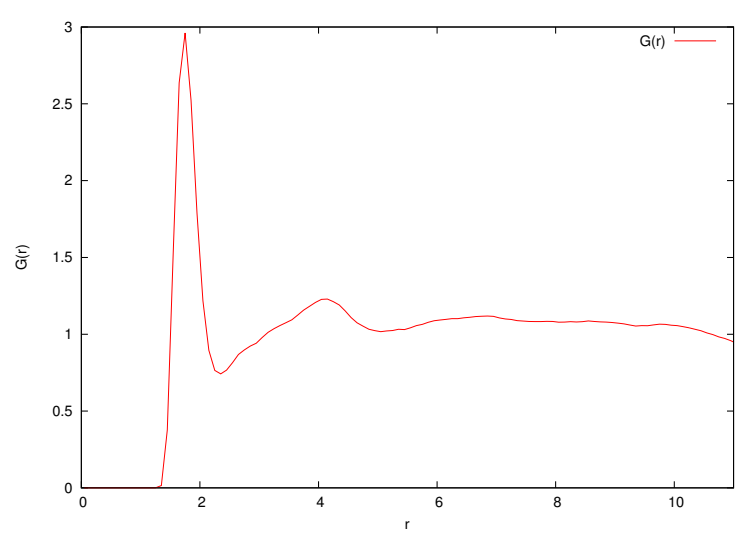

(b) MDDF - TS (UAHF)

Figura 4.23: Distribuição de pares da simulação com o conjunto de cargas UAHF: (a) OPT (b) TS.

Tabela 4.13: Número de moléculas de solvente na primerira camada de solvatação.

\begin{tabular}{|c|l|}
\hline OPT (UFF) & 19 \\
TS (UFF) & 22 \\
OPT (SMD) & 22 \\
TS (SMD) & 23 \\
OPT (UAHF) & 22 \\
TS (UAHF) & 23 \\
\hline
\end{tabular}

de moléculas na primeira camada de solvatação, ambos um pouco acima do número gerado pelo conjunto de cargas UFF.

Em seguida, estudou-se a correlação estatística entre as configurações salvas. Foi calculado a função (3.26) e realizado um ajuste com a expressão (3.28).

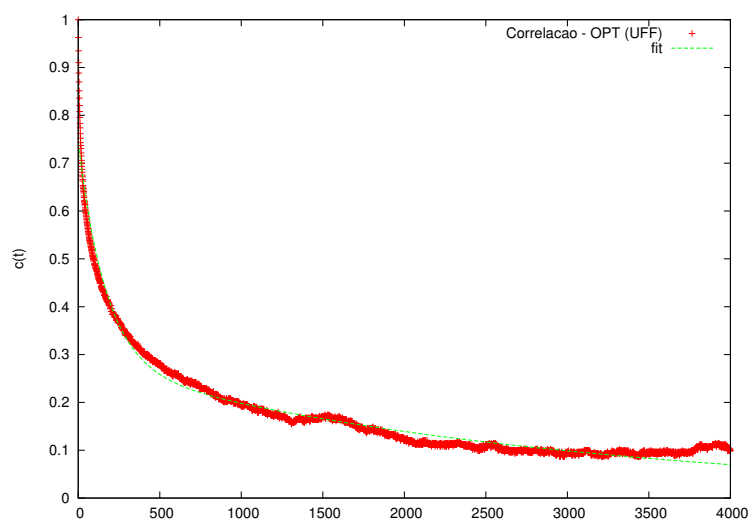

(a) Correlação - OPT (UFF)

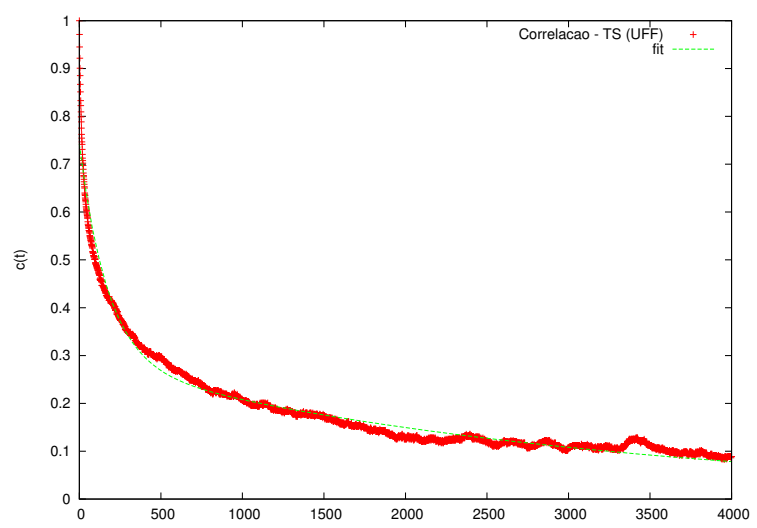

(b) Correlação - TS (UFF)

Figura 4.24: Correlação estatística da simulação com as cargas UFF, e seu respectivo ajuste: (a) OPT (b) TS. 


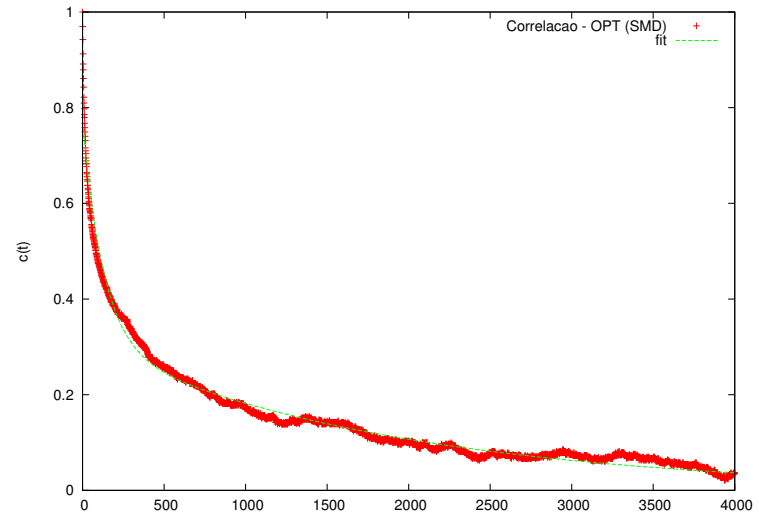

(a) Correlação - OPT (SMD)

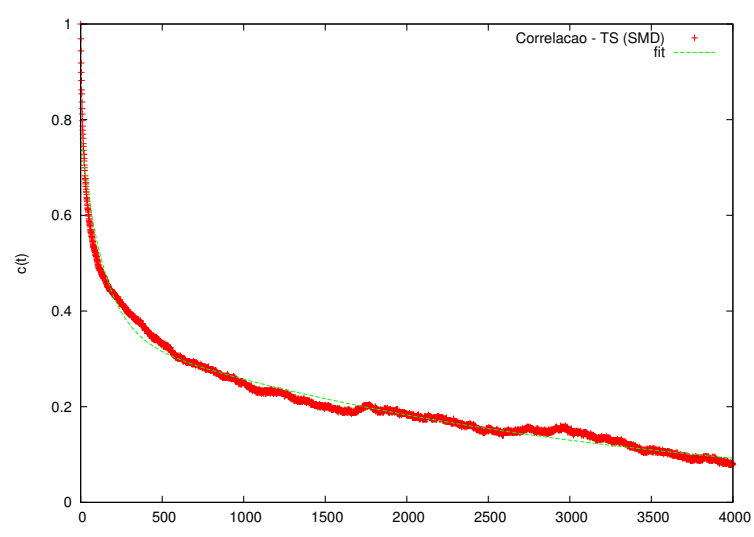

(b) Correlação - TS (SMD)

Figura 4.25: Correlação estatística da simulação com as cargas SMD, e seu respectivo ajuste: (a) OPT (b) TS.

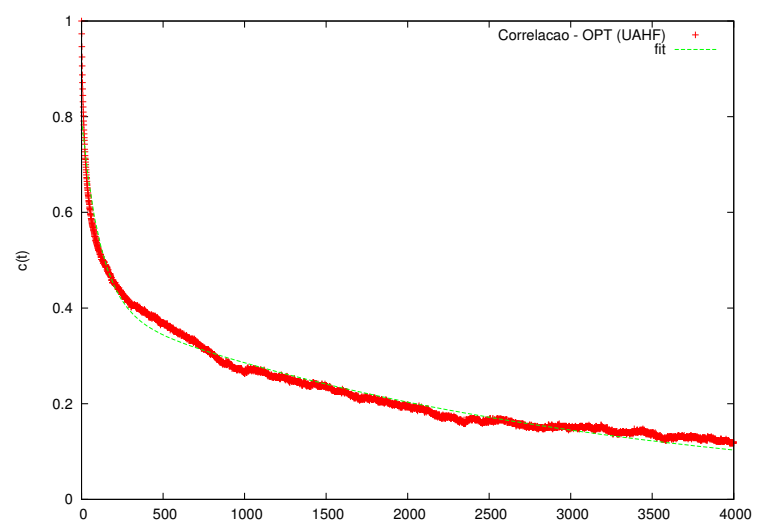

(a) Correlação - OPT (UAHF)

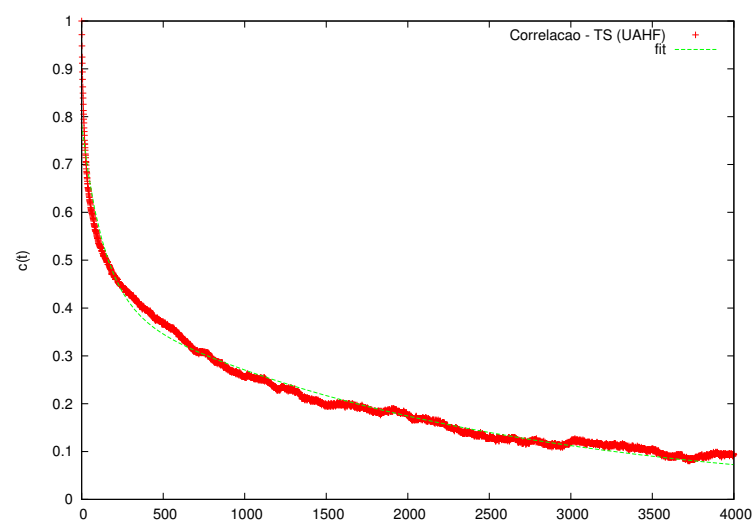

(b) Correlação - TS (UAHF)

Figura 4.26: Correlação estatística da simulação com as cargas UAHF, e seu respectivo ajuste: (a) OPT (b) TS.

Observamos que depois de um intervalo de 4000 ciclos MC, as configurações estão satisfatoriamente descorrelacionadas. Mesmo assim, através dos ajustes feitos nas correlações acima, podemos investigar intervalos menores que 4000 de maneira que as configurações sejam ainda descorrelacionadas. Na Tabela 4.23 estão os valores dos ajustes (3.28) para intervalos de 4000 e 3000 ciclos.

Assim, concluimos que as configurações estão suficientemente descorrelacionadas num intervalo de 3000 ciclos de MC. Para uma simualação de 400000 ciclos, isso nos dá um conjunto de 133 configurações estatisticamente descorrelacionadas. 
Tabela 4.14: Correlação estatística.

\begin{tabular}{|c|cc|}
\hline Método & $c(4000)$ & $c(3000)$ \\
\hline OPT (UFF) & 0.07 & 0.10 \\
TS (UFF) & 0.08 & 0.11 \\
OPT (SMD) & 0.04 & 0.06 \\
TS (SMD) & 0.09 & 0.12 \\
OPT (UAHF) & 0.10 & 0.14 \\
TS (UAHF) & 0.07 & 0.11 \\
\hline
\end{tabular}

O próximo passo foi analisar as ligações de hidrogênio entre o soluto e o solvente. Para isso, contou-se a quantidade de ligações de $\mathrm{H}$ em cada sítio atômico do soluto, e tirou-se uma média sobre as 133 configurações descorrelacionadas. Isto é, configurações separadas de 3000 ciclos MC entre si. A proposta para estudar a estrutura eletrônica da solução foi realizar um único cálculo quântico do sistema solvatado contendo a molécula de soluto, a primeira camada de solvatação explícita $3^{\prime}-\mathrm{dGMP}\left[\left(\mathrm{H}_{2} \mathrm{O}\right)_{n}\right]^{-}$( $n$ é o número de moléculas de água na primeira camada de solvatação) e o restante das moléculas de solvente tratadas como cargas pontuais, as quais o valor da carga se encontra na Tabela 3.3. Para selecionar o sistema buscouse uma das configurações que continha precisamente o número médio de ligações de hidrogênio soluto-solvente em cada sítio atômico. Construiuse, então, o sistema com o número de moléculas de água explícitas dado pela Tabela 4.23 e o restante como cargas pontuais associados a essa configuração. Os resultados para o orbitais SOMO de cada cálculo estão representados nas Fig. 4.27, 4.28 e 4.29.

Observa-se que em todos os casos o orbital SOMO na geometria otimizada possui caráter $\pi^{*}$ localizado sobre a base nitrogenada, concordando portanto com o mecanismo de dissociação. No caso do conjunto de cargas gerado pela cavitação UFF, vemos que o orbital $\pi^{*}$ contradiz o orbital previsto pela solvatação implícita PCM, obtido por essa mesma metodologia. A saber, o orbital previsto pelo PCM (UFF) é um orbital de dipolo Fig. 4.17. Isso aponta que mesmo com as cargas geradas por uma metodologia que, em PCM, descreve um SOMO com caráter de dipolo, a solvatação explícita indica uma tendência do elétron adicional se alocar sobre a base 


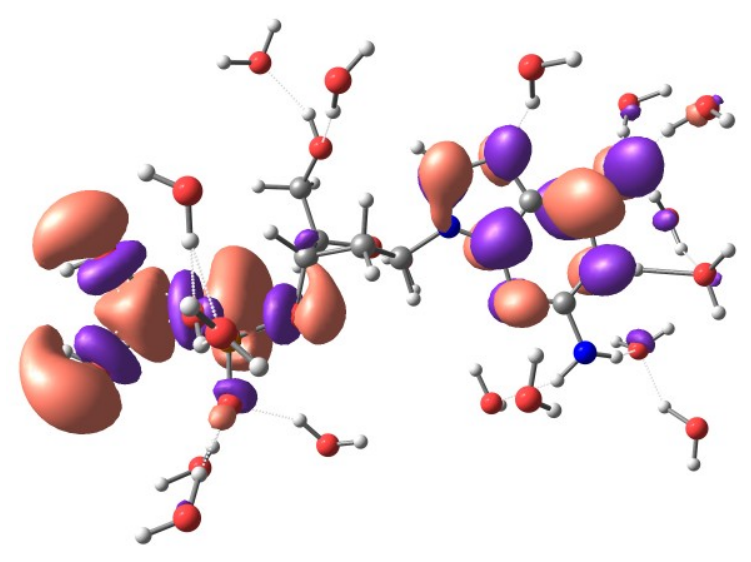

(a) SOMO - OPT (UFF)

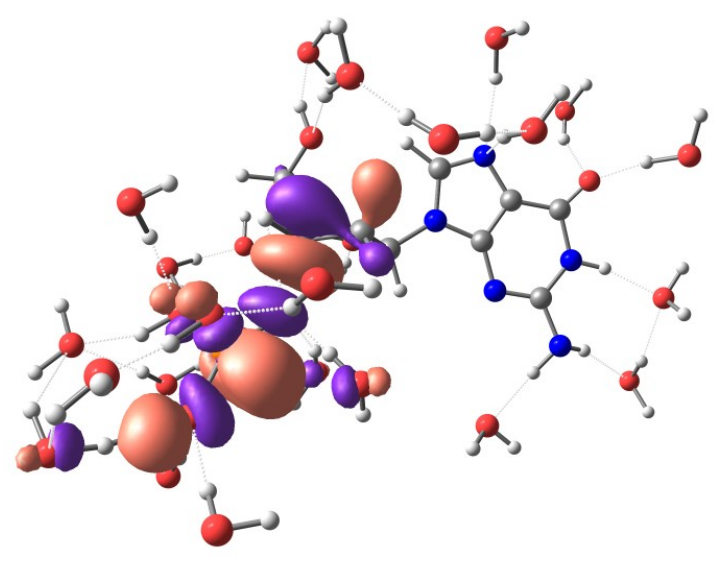

(b) SOMO - TS (UFF)

Figura 4.27: SOMO da geometria obtida através da simulação com o conjunto de cargas (UFF): (a) OPT (b) TS.

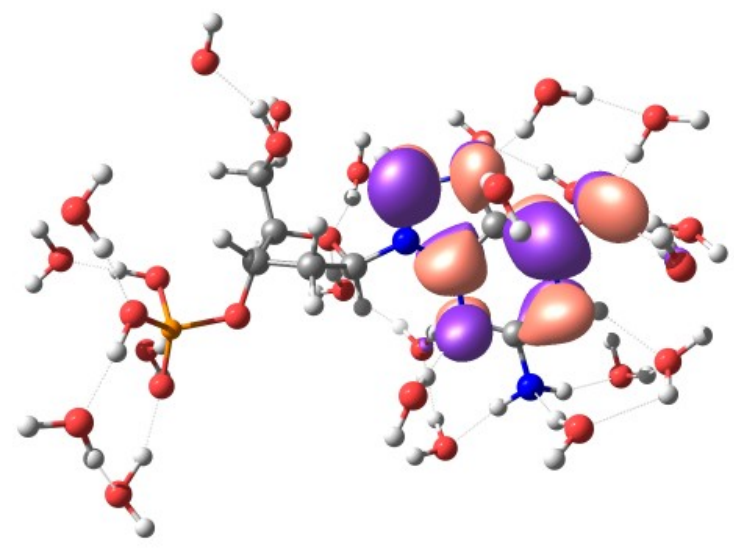

(a) SOMO - OPT (SMD)

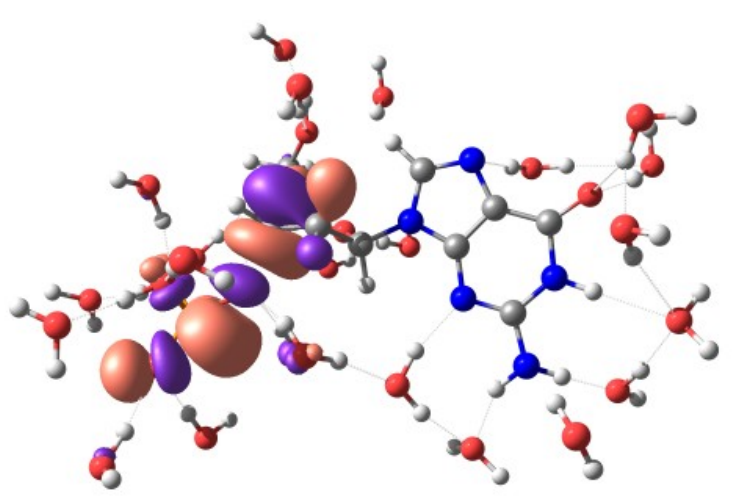

(b) SOMO - TS (SMD)

Figura 4.28: SOMO da geometria obtida atrvés da simulação com o conjunto de cargas (SMD): (a) OPT (b) TS.

nitrogenada. Nos outros casos (SMD e UAHF), os orbitais obtidos com a simulação computacional estão em ótima concordância com os previstos pela solvatação implícita. Com relação aos estados de transição, todos os orbitais SOMO obtidos são de natureza $\sigma^{*}$ ao longo da ligação $\mathrm{C}(8)-\mathrm{O}(2)$, e também estão de acordo com os orbitais previstos por PCM (inclusive na metodologia UFF).

Por último, buscou-se estimar as barreiras de energia livre associadas à dissociação através da teoria da perturbação termodinâmica (sç. 3.1.6), fazendo-se o uso do ciclo da Fig. 3.2. Primeiramente, obtiveram-se as energias livres de solvatação em cada um dos métodos. Para calcular o 


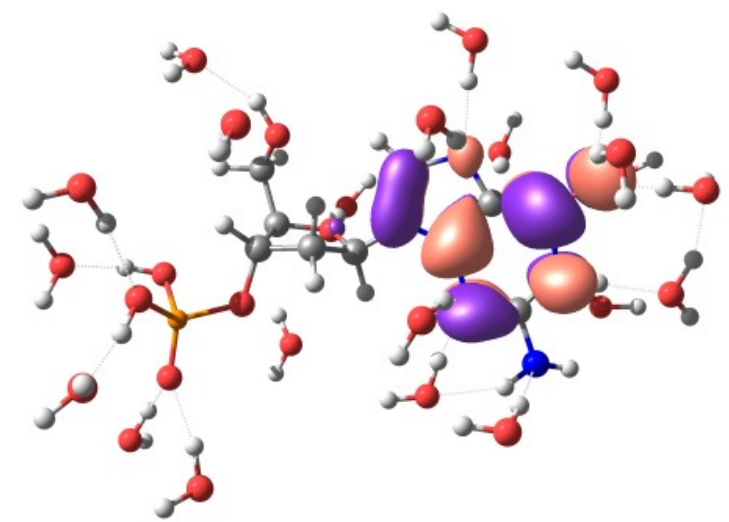

(a) SOMO - OPT (UAHF)

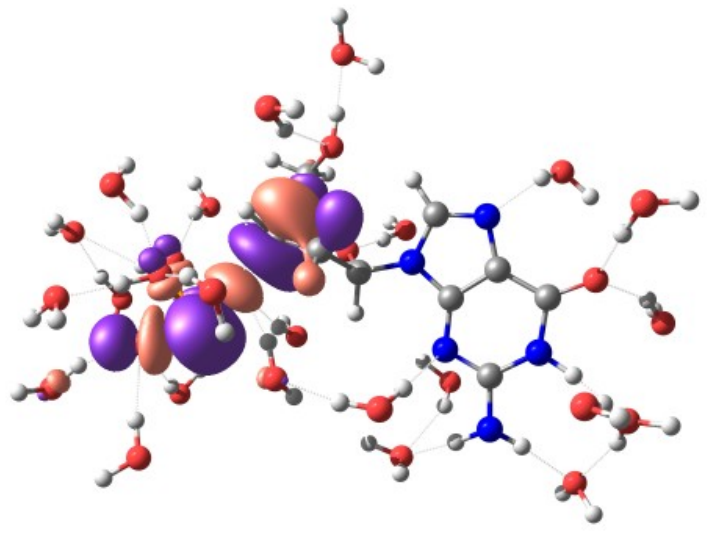

(b) SOMO - TS (UAHF)

Figura 4.29: SOMO da geometria obtida através da simulação com o conjunto de cargas (UAHF): (a) OPT (b) TS.

$\Delta G_{\text {solv }}$ através da equação (3.34), os parâmetros do campo de força foram divididos da seguinte forma:

$$
\begin{aligned}
q: & 100 \% \rightarrow 97.5 \% \rightarrow 95 \% \rightarrow 92.5 \% \rightarrow 90 \% \rightarrow 85 \% \rightarrow 80 \% \rightarrow \\
& \rightarrow 75 \% \rightarrow 70 \% \rightarrow 65 \% \rightarrow 60 \% \rightarrow 55 \% \rightarrow 50 \% \rightarrow 45 \% \rightarrow \\
& \rightarrow 40 \% \rightarrow 35 \% \rightarrow 30 \% \rightarrow 25 \% \rightarrow 20 \% \rightarrow 10 \% \rightarrow 0 \%
\end{aligned}
$$

$$
\epsilon: 100 \% \rightarrow 75 \% \rightarrow 50 \% \rightarrow 25 \% \rightarrow 0.01 \%
$$

$$
\sigma: 100 \% \rightarrow 80 \% \rightarrow 60 \% \rightarrow 40 \% \rightarrow 20 \% \rightarrow 0 \%
$$

As simulações foram realizadas perturbativamente, onde a média das diferenças de energia livre entre um determinado passo da sequência (4.7) e o passo seguinte, em cada simulação, foi obtida na amostragem do primeiro passo. Para as cargas, os resultados para as diferenças de energia livre em cada simulação estão dispostos na Tabela 4.24, a seguir. Os resultados se encontram nas Tabelas 4.25 e 4.26. O mesmo procedimento foi realizado para o estado de transição. Os valores obtidos estão nas Tabelas 4.27, 4.28 
e 4.29 .

Tabela 4.15: $\Delta G$, em kcal $/ \mathrm{mol}$, da molécula $3^{\prime}-\mathrm{dGMP}^{-}$da geometria otimizada - perturbação das cargas $q$.

\begin{tabular}{|c|ccc|}
\hline$q$ & $\Delta G(\mathrm{UFF})(\mathrm{kcal} / \mathrm{mol})$ & $\Delta G(\mathrm{SMD})(\mathrm{kcal} / \mathrm{mol})$ & $\Delta G(\mathrm{UAHF})(\mathrm{kcal} / \mathrm{mol})$ \\
\hline $100 \%-97.5 \%$ & $-9.28 \pm 0.05$ & $-7.94 \pm 0.05$ & $-7.68 \pm 0.04$ \\
$97.5 \%-95 \%$ & $-9.08 \pm 0.05$ & $-7.70 \pm 0.04$ & $-7.47 \pm 0.05$ \\
$95 \%-92.5 \%$ & $-10.48 \pm 0.01$ & $-7.58 \pm 0.04$ & $-7.29 \pm 0.03$ \\
$92.5 \%-90 \%$ & $-6.72 \pm 0.02$ & $-7.36 \pm 0.05$ & $-7.06 \pm 0.03$ \\
$90 \%-85 \%$ & $-16.01 \pm 0.09$ & $-13.96 \pm 0.07$ & $-13.48 \pm 0.02$ \\
$85 \%-80 \%$ & $-14.43 \pm 0.08$ & $-13.02 \pm 0.02$ & $-12.55 \pm 0.07$ \\
$80 \%-75 \%$ & $-13.37 \pm 0.04$ & $-12.11 \pm 0.02$ & $-11.69 \pm 0.08$ \\
$75 \%-70 \%$ & $-12.56 \pm 0.04$ & $-11.13 \pm 0.03$ & $-10.71 \pm 0.07$ \\
$70 \%-65 \%$ & $-11.85 \pm 0.00$ & $-10.12 \pm 0.03$ & $-9.76 \pm 0.04$ \\
$65 \%-60 \%$ & $-11.14 \pm 0.03$ & $-9.14 \pm 0.01$ & $-8.81 \pm 0.04$ \\
$60 \%-55 \%$ & $-10.41 \pm 0.01$ & $-8.16 \pm 0.04$ & $-7.84 \pm 0.02$ \\
$55 \%-50 \%$ & $-9.71 \pm 0.02$ & $-7.21 \pm 0.05$ & $-6.93 \pm 0.03$ \\
$50 \%-45 \%$ & $-8.92 \pm 0.01$ & $-6.24 \pm 0.08$ & $-5.94 \pm 0.01$ \\
$45 \%-40 \%$ & $-8.16 \pm 0.01$ & $-5.39 \pm 0.00$ & $-5.15 \pm 0.00$ \\
$40 \%-35 \%$ & $-6.70 \pm 0.08$ & $-4.73 \pm 0.01$ & $-4.37 \pm 0.00$ \\
$35 \%-30 \%$ & $-5.28 \pm 0.04$ & $-3.92 \pm 0.01$ & $-3.63 \pm 0.03$ \\
$30 \%-25 \%$ & $-4.47 \pm 0.05$ & $-2.97 \pm 0.07$ & $-2.76 \pm 0.04$ \\
$25 \%-20 \%$ & $-3.89 \pm 0.07$ & $-2.19 \pm 0.02$ & $-2.06 \pm 0.04$ \\
$20 \%-10 \%$ & $-5.27 \pm 0.02$ & $-2.50 \pm 0.01$ & $-2.25 \pm 0.05$ \\
$10 \%-0 \%$ & $-0.59 \pm 0.02$ & $-0.26 \pm 0.03$ & $-0.11 \pm 0.05$ \\
\hline Total & $-178.32 \pm 0.73$ & $-143.62 \pm 0.68$ & $-137.54 \pm 0.74$ \\
\hline
\end{tabular}

Tabela 4.16: $\Delta G$, em kcal $/ \mathrm{mol}$, da molécula $3^{\prime}$-dGMP ${ }^{-}$da geometria otimizada - perturbação dos parâmetros $\epsilon$.

\begin{tabular}{|c|c|}
\hline$\epsilon$ & $\Delta G(\mathrm{kcal} / \mathrm{mol})$ \\
\hline $100 \%-75 \%$ & $-4.42 \pm 0.01$ \\
$75 \%-50 \%$ & $-5.05 \pm 0.01$ \\
$50 \%-25 \%$ & $-6.15 \pm 0.01$ \\
$25 \%-0.01 \%$ & $-9.11 \pm 0.09$ \\
\hline Total & $-24.73 \pm 0.12$ \\
\hline
\end{tabular}

Com os resultados das simulações, podemos calcular as energias livres de solvatação para cada uma das geometrias e, com o uso do ciclo da Fig. 3.2 e de (4.5), estimar a barreira de energia livre da reação em solução. Para calculá-la através do ciclo termodinâmico com a simulação computacional, deve-se levar em conta a energia de polarização do soluto, uma vez que o cálculo das cargas para o campo de força foi realizado com o soluto 
Tabela 4.17: $\Delta G$, em kcal/mol, da molécula $3^{\prime}-\mathrm{dGMP}^{-}$da geometria otimizada - perturbação dos parâmetros $\sigma$.

\begin{tabular}{|c|c|}
\hline$\sigma$ & $\Delta G(\mathrm{kcal} / \mathrm{mol})$ \\
\hline $100 \%-80 \%$ & $3.21 \pm 0.15$ \\
$80 \%-60 \%$ & $3.25 \pm 0.25$ \\
$60 \%-40 \%$ & $3.62 \pm 0.14$ \\
$40 \%-20 \%$ & $4.03 \pm 0.15$ \\
$20 \%-0 \%$ & $1.56 \pm 0.07$ \\
\hline Total & $15.68 \pm 0.76$ \\
\hline
\end{tabular}

Tabela 4.18: $\Delta G$, em kcal $/ \mathrm{mol}$, da molécula $3^{\prime}$-dGMP ${ }^{-}$do estado de transição - perturbação das cargas $q$.

\begin{tabular}{|c|ccc|}
\hline$q$ & $\Delta G(\mathrm{UFF})(\mathrm{kcal} / \mathrm{mol})$ & $\Delta G(\mathrm{SMD})(\mathrm{kcal} / \mathrm{mol})$ & $\Delta G(\mathrm{UAHF})(\mathrm{kcal} / \mathrm{mol})$ \\
\hline $100 \%-97.5 \%$ & $-6.52 \pm 0.02$ & $-6.18 \pm 0.03$ & $-6.49 \pm 0.02$ \\
$97.5 \%-95 \%$ & $-6.30 \pm 0.01$ & $-5.96 \pm 0.03$ & $-6.30 \pm 0.01$ \\
$95 \%-92.5 \%$ & $-6.05 \pm 0.02$ & $-5.88 \pm 0.02$ & $-6.03 \pm 0.01$ \\
$92.5 \%-90 \%$ & $-5.84 \pm 0.02$ & $-5.67 \pm 0.01$ & $-5.83 \pm 0.04$ \\
$90 \%-85 \%$ & $-11.25 \pm 0.02$ & $-10.67 \pm 0.02$ & $-11.09 \pm 0.01$ \\
$85 \%-80 \%$ & $-10.39 \pm 0.03$ & $-9.87 \pm 0.04$ & $-10.21 \pm 0.03$ \\
$80 \%-75 \%$ & $-9.41 \pm 0.05$ & $-8.87 \pm 0.04$ & $-9.17 \pm 0.03$ \\
$75 \%-70 \%$ & $-8.57 \pm 0.04$ & $-8.04 \pm 0.05$ & $-8.29 \pm 0.02$ \\
$70 \%-65 \%$ & $-7.78 \pm 0.01$ & $-7.15 \pm 0.05$ & $-7.51 \pm 0.03$ \\
$65 \%-60 \%$ & $-6.96 \pm 0.02$ & $-6.37 \pm 0.01$ & $-6.69 \pm 0.01$ \\
$60 \%-55 \%$ & $-6.18 \pm 0.04$ & $-5.68 \pm 0.02$ & $-5.87 \pm 0.01$ \\
$55 \%-50 \%$ & $-5.37 \pm 0.02$ & $-4.93 \pm 0.02$ & $-5.10 \pm 0.04$ \\
$50 \%-45 \%$ & $-4.63 \pm 0.01$ & $-4.30 \pm 0.01$ & $-4.41 \pm 0.06$ \\
$45 \%-40 \%$ & $-3.90 \pm 0.01$ & $-3.65 \pm 0.03$ & $-3.77 \pm 0.05$ \\
$40 \%-35 \%$ & $-3.22 \pm 0.03$ & $-2.99 \pm 0.04$ & $-3.11 \pm 0.03$ \\
$35 \%-30 \%$ & $-2.61 \pm 0.06$ & $-2.42 \pm 0.06$ & $-2.49 \pm 0.02$ \\
$30 \%-25 \%$ & $-1.98 \pm 0.04$ & $-1.88 \pm 0.04$ & $-1.87 \pm 0.02$ \\
$25 \%-20 \%$ & $-1.44 \pm 0.03$ & $-1.40 \pm 0.03$ & $-1.36 \pm 0.02$ \\
$20 \%-10 \%$ & $-1.61 \pm 0.01$ & $-1.37 \pm 0.03$ & $-1.44 \pm 0.01$ \\
$10 \%-0 \%$ & $-0.02 \pm 0.03$ & $0.20 \pm 0.02$ & $0.04 \pm 0.03$ \\
\hline Total & $-110.04 \pm 0.53$ & $-103.08 \pm 0.60$ & $-106.99 \pm 0.50$ \\
\hline
\end{tabular}

Tabela 4.19: $\Delta G$, em kcal $/ \mathrm{mol}$, da molécula $3^{\prime}-\mathrm{dGMP}^{-}$do estado de transição - perturbação dos parâmetros $\epsilon$.

\begin{tabular}{|c|c|}
\hline$\epsilon$ & $\Delta G(\mathrm{kcal} / \mathrm{mol})$ \\
\hline $100 \%-75 \%$ & $-4.44 \pm 0.01$ \\
$75 \%-50 \%$ & $-5.07 \pm 0.01$ \\
$50 \%-25 \%$ & $-6.17 \pm 0.02$ \\
$25 \%-0.01 \%$ & $-9.13 \pm 0.05$ \\
\hline Total & $-24.81 \pm 0.09$ \\
\hline
\end{tabular}


Tabela 4.20: $\Delta G$, em kcal $/ \mathrm{mol}$, da molécula $3^{\prime}$-dGMP ${ }^{-}$do estado de transição - perturbação dos parâmetros $\sigma$.

\begin{tabular}{|c|c|}
\hline$\sigma$ & $\Delta G(\mathrm{kcal} / \mathrm{mol})$ \\
\hline $100 \%-80 \%$ & $3.59 \pm 0.21$ \\
$80 \%-60 \%$ & $3.06 \pm 0.09$ \\
$60 \%-40 \%$ & $5.23 \pm 0.43$ \\
$40 \%-20 \%$ & $4.00 \pm 0.39$ \\
$20 \%-0 \%$ & $1.46 \pm 0.07$ \\
\hline Total & $17.34 \pm 1.19$ \\
\hline
\end{tabular}

polarizado (esse fator já está incluído no cálculo da barreira de energia livre em PCM). Assim, temos a expressão:

$$
\Delta G=\Delta \Delta G_{\text {solv }}+\Delta \Delta G_{\text {pol }}+\Delta G_{\text {gas }}
$$

Os termos da expressão (4.10) estão dispostos na Tabela 4.21 e na Tabela 4.22 .

Tabela 4.21: Diferença das energias de polarização $\Delta \Delta G_{p o l}$, em kcal $/ \mathrm{mol}$.

\begin{tabular}{|c|c|}
\hline Método & $\Delta \Delta G_{\text {pol }}(\mathrm{kcal} / \mathrm{mol})$ \\
\hline UFF & -12.73 \\
SMD & -35.97 \\
UAHF & -7.14 \\
\hline
\end{tabular}

Tabela 4.22: Barreiras de energia livres da dissociação, $\Delta G$, e a diferença entre o $\Delta G_{\text {solv }}$ do estado de transição e estado otimizado.

\begin{tabular}{|c|c|c|}
\hline Método & $\Delta \Delta G_{\text {solv }}(\mathrm{kcal} / \mathrm{mol})$ & $\Delta G(\mathrm{kcal} / \mathrm{mol})$ \\
\hline PCM (UFF) & 10.13 & 20.07 \\
MC (UFF) & $69.86 \pm 3.42$ & $67.07 \pm 3.42$ \\
\hline PCM (SMD) & 6.42 & 3.92 \\
MC (SMD) & $42.12 \pm 3.44$ & $16.09 \pm 3.44$ \\
\hline PCM (UAHF) & 17.87 & 27.80 \\
MC (UAHF) & $32.13 \pm 3.40$ & $34.93 \pm 3.40$ \\
\hline
\end{tabular}

Concluímos que a barreira de energia livre obtida da simulação computacional com as cargas UFF são incompatíveis com a barreira obtida em PCM com essa mesma metodologia. O modelo de solvatação UFF parece não tratar de maneira adequada o sistema carregado, assim como sua energia de solvatação. Quando utilizada com uma base difusa (D95*-Sch), a cavidade parece insuficiente para acomodar o excesso de carga da espécie 
aniônica, fazendo com que parte significativa do SOMO possa se encontrar no exterior da cavidade. Embora conclusões definitivas exijam estudos adicionais, esse argumento é compatível com os orbitais mostrados nas Figs. 4.13(a) e 4.27(a), podendo justificar o problema nas cargas geradas pelo ajuste CHELPG nesse modelo da cavitação, o que torna o modelo UFF inconveniente para esse tipo de estudo. Por outro lado, os resultados obtidos com a metodologia PCM/UAHF e com as simulações computacionais realizadas com cargas UAHF estão razoavelmente próximos. Entretanto, as cavidades nas metodologias UFF e UAHF são bastante próximas (observamos isso ao comparar o volume das esferas da cavidade centradas em cada sítio atômico) e a integração da equação (3.5) em ambas as metodologias é a mesma (IEF). Conluímos assim que a diferença essencial entre os resultados obtidos com os métodos UFF e UAHF tanto para o estudo com PCM quanto na geração dos conjuntos de cargas utilizados nas simulações computacionais é devida aos diferentes conjuntos de funções base. A base compacta 6-31G(d) gera orbitais virtuais com caráter compatível com estados aniônicos, porém com energias muito imprecisas[58]. Dessa forma, é questionável se essa base possa fornecer resultados precisos, pois a densidade de carga do ânion deve ser significativamente mais difusa que a da espécie neutra. A metodologia SMD, por sua vez, gerou cavidades relativamente próximas, porém ainda menores, às obtidas com os procedimentos UFF e UAHF. Porém, ao tratar a densidade eletrônica quântica na integração da equação (3.5), além de se utilizar de uma série de parâmetros que corrigem efeitos de cargas difusas com tensões superficiais, o método parece descrever de maneira mais adequada o excesso de carga fora da cavidade, permitindo utilizar bases mais difusas. Nesse sentido, o método SMD seria mais adequado ao estudo de interesse, pois descreve corretamente a estrutura eletrônica da molécula $3^{\prime}$-dGMP ${ }^{-}$e, consequentemente, gera um conjunto de cargas CHELPG mais apropriado para a simulação computacional. Entretanto, nos cálculos da barreira de energia livre em modelo de solvatação implícita, o método SMD parece subestimar 
a barreira em cerca de $\sim 12 \mathrm{kcal} / \mathrm{mol}$ quando comparada à obtida com solvatação explícita. Isso pode sugerir uma deficiência no uso de SMD com o funcional B3LYP.

Efeitos de solvente explícito sobre a dissociação da ligação $\mathrm{C}_{3^{\prime}}-\mathrm{O}_{3^{\prime}}$ do nucleotídeo $3^{\prime}-\mathrm{dGMP}^{-}$foram estudados na literatura. No trabalho do Laaksonen e Schyman[10], a estrutura eletrônica foi investigada ao longo do caminho de reação, tratando explicitamente o soluto e 21 moléculas de água. Nesse nível de descrição, o ânion apresenta, em sua geometria otimizada, SOMO com caráter misto $\pi^{*}$ (sobre a base nitrogenada) e de dipolo (na vizinhança dos grupos $\mathrm{OH}$ do fosfato quanto $\mathrm{NH}$ da base). Isso sugere que os modelos de solvatação utilizados podem não ter sido apropriados, na medida em que mantiveram, ainda que parcialmente, a característica essencial do sistema em fase gasosa (SOMO do estado fundamental com caráter de dipolo). Além disso, Smyth e Kohanoff [11] realizaram dinâmica molecular ab initio com 100 moléculas de água na caixa de simulção, e obteve-se para a $3^{\prime}$-dGMP ${ }^{-}$uma barreira de energia livre de $\sim 6 \mathrm{kcal} / \mathrm{mol}$ à temperatura de $T=300 \mathrm{~K}$. Embora esse resultado esteja significativamente abaixo da barreira obtida no presente trabalho $(\sim 16 \mathrm{kcal} / \mathrm{mol}$ $\mathrm{MC}(\mathrm{SMD})$ ), tal discrepância é razoável se observarmos importantes diferenças metodológicas entre os dois cálculos, a saber, utilizou-se o funcional híbrido PBE-correlação e troca, um conjunto de base TZVP-GTH e condições do contorno periódicas nas paredes da caixa de simulação. 


\section{Capítulo 5}

\section{Conclusões e Considerações Finais}

De uma maneira geral, investigou-se de maneira sistemática a influência da solvatação em água, em um modelo implícito e um explícito, nos parâmetros que descrevem a interação entre o nucleotídeo 3'-dGMP e o elétron adicional, além de estudar a fundo as estruturas eletrônicas envolvidas no processo.

Concluiu-se, primeiramente, que a geometria otimizada no vácuo é suficiente para descrever a estrutura eletrônica em meio aquoso, assim como o estado de transição. Observou-se variações desprezíveis, em PCM, nas estruturas dos orbitais SOMO dessas geometrias quando comparadas às otimizadas em meios contínuos. Além disso, notou-se pouca mudança nas energias eletrônicas ao se realizar a mesma comparação. A última conclusão relacionada aos modelos de solvatação implícita é que o método PCM de construção da cavidade e de descrição das cargas de polarização é um fator de importância central no estudo de estruturas eletrônicas e termoquímicas de sistemas moleculares e reações em meio aquoso. Investigouse as estruturas eletrônicas por meio das metologias UFF, SMD e UAHF e, mesmo em estudos preliminares observou-se uma mudança fenomenológica na descrição dos orbitais sob a metodologia UFF, quando comparada às outras duas. Concluiu-se que o método SMD parece descrever de maneira razoável a solvatação implícita da molécula $3^{\prime}$-dGMP ${ }^{-}$, levando em consideração o excesso de carga fora da cavidade construída.

Em seguida, no estudo do modelo de solvatação explícita, ao se cons- 
truir os campos de força OPLS para a simulação, notou-se uma essencial diferença entre os conjuntos de cargas dos diversos métodos. A saber, o conjunto de cargas obtidos pelo método UFF descreve uma densidade eletrônica significativa sobre o grupo fosfato, o que a princípio aponta uma deficiência sistemática do método ao tratar sistemas carregados. Em seguida, concluiu-se que, de fato, a estrutura eletrônica do ânion em meio aquoso possui um SOMO de caráter $\pi^{*}$ localizado sobre a base nitrogenada, como proposto pelo mecanismo de dissociação e também como não é possível observar em fase gasosa. O estudo detalhado dos modelos de solvatação é necessário para uma descrição satisfatória do elétron adicional no nucleotídeo em meio aquoso.

Do ponto de vista computacional, buscar uma média entre as configurações do solvente geradas pela simulação computacional mostrou-se um procedimento razoavelmente eficaz para estudar propriedades eletrônicas em modelos de solvatação explícita, sendo assim uma alternativa para métodos de maiores custos computacionais como QM/MM tradicional.

Recentemente um trabalho foi publicado por Chen et al.[59] no qual realizou-se um benchmarking sobre o cálculo de barreiras de energia livre em SMD com o uso da teoria do funcional da densidade (DFT). A investigação concluiu que o funcional B3LYP utilizado no presente trabalho parece possuir uma tendência sistemática de subestimar a barreira de ativação associada à ruptura $\mathrm{C}-\mathrm{O}$. Entretanto, observou-se um desempenho relativamente eficaz do funcional M06-2X, podendo ser uma possível alternativa no refinamento dos cálculos realizados.

O projeto possui perspectivas de realizar a mesma investigação com outros métodos de estrutura eletrônica e outros métodos de solvatação. Em seguida, pretende-se estender o estudo para os outros nucleotídeos do DNA e RNA, podendo assim finalizar um estudo completo sobre a interação entre esses sistemas e elétrons de baixas energias. 


\section{Apêndice A}

\section{Geometrias}

Nesse apêndice, encontram-se as geometrias obtidas no trabalho. 
Tabela A.1: Geometria da espécie neutra 3'-dGMP, $\mathbf{R}_{n}$, com o método DFT/B3LYP/D95*_Sch. As coordenadas estão em Å.

\begin{tabular}{|c|ccc|}
\hline Átomo & $\mathrm{x}$ & $\mathrm{y}$ & $\mathrm{z}$ \\
\hline $\mathrm{O}(1)$ & -4.480 & 6.552 & 4.671 \\
$\mathrm{O}(2)$ & -0.902 & 8.060 & 2.840 \\
$\mathrm{C}(3)$ & -1.330 & 5.239 & 3.883 \\
$\mathrm{H}(4)$ & -0.250 & 5.239 & 3.699 \\
$\mathrm{C}(5)$ & -2.096 & 5.962 & 2.760 \\
$\mathrm{H}(6)$ & -1.606 & 5.865 & 1.788 \\
$\mathrm{H}(7)$ & -3.118 & 5.579 & 2.696 \\
$\mathrm{C}(8)$ & -2.141 & 7.405 & 3.250 \\
$\mathrm{H}(9)$ & -2.997 & 7.960 & 2.858 \\
$\mathrm{C}(10)$ & -2.172 & 7.255 & 4.788 \\
$\mathrm{H}(11)$ & -1.534 & 8.020 & 5.248 \\
$\mathrm{C}(12)$ & -3.568 & 7.391 & 5.391 \\
$\mathrm{H}(13)$ & -3.515 & 7.097 & 6.450 \\
$\mathrm{H}(14)$ & -3.875 & 8.447 & 5.328 \\
$\mathrm{O}(15)$ & -1.620 & 5.964 & 5.081 \\
$\mathrm{~N}(16)$ & 2.340 & 1.479 & 3.259 \\
$\mathrm{H}(17)$ & 2.824 & 2.372 & 3.263 \\
$\mathrm{H}(18)$ & 2.865 & 0.741 & 3.719 \\
$\mathrm{O}(19)$ & -1.558 & -0.777 & 4.388 \\
$\mathrm{C}(20)$ & -1.078 & 0.334 & 4.200 \\
$\mathrm{C}(21)$ & -1.674 & 1.648 & 4.242 \\
$\mathrm{~N}(22)$ & -2.974 & 2.038 & 4.516 \\
$\mathrm{C}(23)$ & -2.958 & 3.345 & 4.401 \\
$\mathrm{H}(24)$ & -3.798 & 4.010 & 4.568 \\
$\mathrm{~N}(25)$ & -1.707 & 3.850 & 4.063 \\
$\mathrm{C}(26)$ & -0.872 & 2.760 & 3.964 \\
$\mathrm{~N}(27)$ & 0.456 & 2.799 & 3.663 \\
$\mathrm{C}(28)$ & 1.007 & 1.607 & 3.624 \\
$\mathrm{~N}(29)$ & 0.316 & 0.446 & 3.864 \\
$\mathrm{H}(30)$ & 0.778 & -0.453 & 3.752 \\
$\mathrm{P}(31)$ & -0.836 & 9.630 & 2.483 \\
$\mathrm{O}(32)$ & 0.506 & 10.115 & 2.056 \\
$\mathrm{O}(33)$ & -1.503 & 10.284 & 3.825 \\
$\mathrm{O}(34)$ & -2.027 & 9.892 & 1.383 \\
$\mathrm{H}(35)$ & -5.348 & 6.596 & 5.100 \\
$\mathrm{H}(36)$ & -1.418 & 11.253 & 3.831 \\
$\mathrm{H}(37)$ & -1.638 & 10.008 & 0.499 \\
\hline & & & \\
\hline
\end{tabular}


Tabela A.2: Geometria da espécie carregada $3^{\prime}-\mathrm{dGMP}^{-}, \mathbf{R}_{a}$, obtida com o método DFT/B3LYP/D95*-Sch. As coordenadas estão em A.

\begin{tabular}{|c|c|c|c|}
\hline Átomo & $\mathrm{x}$ & $\mathrm{y}$ & $\mathrm{Z}$ \\
\hline $\mathrm{O}(1)$ & -4.430 & 6.538 & 4.662 \\
\hline $\mathrm{O}(2)$ & -0.841 & 8.115 & 2.885 \\
\hline $\mathrm{C}(3)$ & -1.244 & 5.242 & 3.951 \\
\hline $\mathrm{H}(4)$ & -0.157 & 5.220 & 3.808 \\
\hline $\mathrm{C}(5)$ & -1.954 & 5.962 & 2.790 \\
\hline $\mathrm{H}(6)$ & -1.410 & 5.873 & 1.846 \\
\hline $\mathrm{H}(7)$ & -2.967 & 5.564 & 2.670 \\
\hline $\mathrm{C}(8)$ & -2.049 & 7.408 & 3.271 \\
\hline $\mathrm{H}(9)$ & -2.925 & 7.920 & 2.863 \\
\hline $\mathrm{C}(10)$ & -2.123 & 7.265 & 4.808 \\
\hline $\mathrm{H}(11)$ & -1.498 & 8.033 & 5.279 \\
\hline $\mathrm{C}(12)$ & -3.532 & 7.404 & 5.370 \\
\hline $\mathrm{H}(13)$ & -3.511 & 7.143 & 6.440 \\
\hline $\mathrm{H}(14)$ & -3.839 & 8.456 & 5.266 \\
\hline $\mathrm{O}(15)$ & -1.570 & 5.974 & 5.130 \\
\hline $\mathrm{N}(16)$ & 2.293 & 1.375 & 3.162 \\
\hline $\mathrm{H}(17)$ & 2.821 & 2.246 & 3.202 \\
\hline $\mathrm{H}(18)$ & 2.802 & 0.584 & 3.566 \\
\hline $\mathrm{O}(19)$ & -1.627 & -0.778 & 4.404 \\
\hline $\mathrm{C}(20)$ & -1.120 & 0.323 & 4.203 \\
\hline $\mathrm{C}(21)$ & -1.680 & 1.650 & 4.273 \\
\hline $\mathrm{N}(22)$ & -2.961 & 2.075 & 4.590 \\
\hline $\mathrm{C}(23)$ & -2.907 & 3.385 & 4.494 \\
\hline $\mathrm{H}(24)$ & -3.721 & 4.074 & 4.688 \\
\hline $\mathrm{N}(25)$ & -1.651 & 3.856 & 4.129 \\
\hline $\mathrm{C}(26)$ & -0.852 & 2.744 & 3.990 \\
\hline $\mathrm{N}(27)$ & 0.464 & 2.749 & 3.645 \\
\hline $\mathrm{C}(28)$ & 0.980 & 1.541 & 3.570 \\
\hline $\mathrm{N}(29)$ & 0.262 & 0.398 & 3.826 \\
\hline $\mathrm{H}(30)$ & 0.718 & -0.510 & 3.739 \\
\hline $\mathrm{P}(31)$ & -0.897 & 9.705 & 2.530 \\
\hline $\mathrm{O}(32)$ & 0.448 & 10.252 & 2.181 \\
\hline $\mathrm{O}(33)$ & -1.705 & 10.276 & 3.833 \\
\hline $\mathrm{O}(34)$ & -2.032 & 9.870 & 1.349 \\
\hline $\mathrm{H}(35)$ & -5.340 & 6.843 & 4.823 \\
\hline $\mathrm{H}(36)$ & -2.143 & 11.145 & 3.666 \\
\hline $\mathrm{H}(37)$ & -1.601 & 10.090 & 0.495 \\
\hline
\end{tabular}


Tabela A.3: Geometria do estado de transição da espécie carregada $3^{\prime}$-dGMP ${ }^{-}, \mathbf{R}_{a}^{T S}$, obtida com o método DFT/B3LYP/D95*_Sch. As coordenadas estão em Å.

\begin{tabular}{|c|c|c|c|}
\hline Átomo & $\mathrm{x}$ & $\mathrm{y}$ & Z \\
\hline $\mathrm{O}(1)$ & -4.551 & 6.471 & 4.715 \\
\hline $\mathrm{O}(2)$ & -0.765 & 8.126 & 2.841 \\
\hline $\mathrm{C}(3)$ & -1.338 & 5.244 & 3.947 \\
\hline $\mathrm{H}(4)$ & -0.253 & 5.255 & 3.792 \\
\hline $\mathrm{C}(5)$ & -2.077 & 5.935 & 2.783 \\
\hline $\mathrm{H}(6)$ & -1.506 & 5.888 & 1.850 \\
\hline $\mathrm{H}(7)$ & -3.057 & 5.466 & 2.624 \\
\hline $\mathrm{C}(8)$ & -2.254 & 7.340 & 3.291 \\
\hline $\mathrm{H}(9)$ & -3.018 & 7.958 & 2.827 \\
\hline $\mathrm{C}(10)$ & -2.259 & 7.246 & 4.802 \\
\hline $\mathrm{H}(11)$ & -1.637 & 8.033 & 5.255 \\
\hline $\mathrm{C}(12)$ & -3.661 & 7.358 & 5.404 \\
\hline $\mathrm{H}(13)$ & -3.608 & 7.102 & 6.476 \\
\hline $\mathrm{H}(14)$ & -3.997 & 8.404 & 5.309 \\
\hline $\mathrm{O}(15)$ & -1.672 & 5.970 & 5.127 \\
\hline $\mathrm{N}(16)$ & 2.311 & 1.475 & 3.166 \\
\hline $\mathrm{H}(17)$ & 2.817 & 2.358 & 3.214 \\
\hline $\mathrm{H}(18)$ & 2.841 & 0.695 & 3.569 \\
\hline $\mathrm{O}(19)$ & -1.550 & -0.787 & 4.398 \\
\hline $\mathrm{C}(20)$ & -1.072 & 0.329 & 4.201 \\
\hline $\mathrm{C}(21)$ & -1.669 & 1.639 & 4.273 \\
\hline $\mathrm{N}(22)$ & -2.963 & 2.028 & 4.585 \\
\hline $\mathrm{C}(23)$ & -2.945 & 3.339 & 4.490 \\
\hline $\mathrm{H}(24)$ & -3.777 & 4.007 & 4.684 \\
\hline $\mathrm{N}(25)$ & -1.702 & 3.845 & 4.132 \\
\hline $\mathrm{C}(26)$ & -0.872 & 2.757 & 3.992 \\
\hline $\mathrm{N}(27)$ & 0.444 & 2.798 & 3.648 \\
\hline $\mathrm{C}(28)$ & 0.994 & 1.605 & 3.573 \\
\hline $\mathrm{N}(29)$ & 0.307 & 0.441 & 3.827 \\
\hline $\mathrm{H}(30)$ & 0.791 & -0.452 & 3.747 \\
\hline $\mathrm{P}(31)$ & -0.737 & 9.654 & 2.447 \\
\hline $\mathrm{O}(32)$ & 0.543 & 10.328 & 2.024 \\
\hline $\mathrm{O}(33)$ & -1.472 & 10.368 & 3.746 \\
\hline $\mathrm{O}(34)$ & -1.910 & 9.866 & 1.283 \\
\hline $\mathrm{H}(35)$ & -5.394 & 6.458 & 5.211 \\
\hline $\mathrm{H}(36)$ & -1.369 & 11.333 & 3.686 \\
\hline $\mathrm{H}(37)$ & -1.462 & 10.131 & 0.461 \\
\hline
\end{tabular}


Tabela A.4: Geometria otimizada da espécie neutra 3'-dGMP em PCM/UFF, com o método DFT/B3LYP/D95*_Sch. As coordenadas estão em Å.

\begin{tabular}{|c|c|c|c|}
\hline Átomo & $\mathrm{x}$ & $\mathrm{y}$ & $\mathrm{Z}$ \\
\hline $\mathrm{O}(1)$ & -4.445 & 6.432 & 4.722 \\
\hline $\mathrm{O}(2)$ & -0.886 & 8.105 & 2.902 \\
\hline $\mathrm{C}(3)$ & -1.300 & 5.269 & 3.873 \\
\hline $\mathrm{H}(4)$ & -0.224 & 5.254 & 3.672 \\
\hline $\mathrm{C}(5)$ & -2.075 & 6.005 & 2.765 \\
\hline $\mathrm{H}(6)$ & -1.587 & 5.928 & 1.791 \\
\hline $\mathrm{H}(7)$ & -3.094 & 5.617 & 2.692 \\
\hline $\mathrm{C}(8)$ & -2.131 & 7.438 & 3.283 \\
\hline $\mathrm{H}(9)$ & -2.984 & 7.997 & 2.894 \\
\hline $\mathrm{C}(10)$ & -2.172 & 7.263 & 4.815 \\
\hline $\mathrm{H}(11)$ & -1.567 & 8.040 & 5.297 \\
\hline $\mathrm{C}(12)$ & -3.572 & 7.332 & 5.417 \\
\hline $\mathrm{H}(13)$ & -3.506 & 7.067 & 6.482 \\
\hline $\mathrm{H}(14)$ & -3.934 & 8.368 & 5.337 \\
\hline $\mathrm{O}(15)$ & -1.555 & 5.986 & 5.083 \\
\hline $\mathrm{N}(16)$ & 2.321 & 1.447 & 3.267 \\
\hline $\mathrm{H}(17)$ & 2.861 & 2.307 & 3.310 \\
\hline $\mathrm{H}(18)$ & 2.822 & 0.626 & 3.593 \\
\hline $\mathrm{O}(19)$ & -1.612 & -0.740 & 4.396 \\
\hline $\mathrm{C}(20)$ & -1.089 & 0.365 & 4.192 \\
\hline $\mathrm{C}(21)$ & -1.674 & 1.674 & 4.225 \\
\hline $\mathrm{N}(22)$ & -2.975 & 2.078 & 4.496 \\
\hline $\mathrm{C}(23)$ & -2.944 & 3.388 & 4.381 \\
\hline $\mathrm{H}(24)$ & -3.777 & 4.063 & 4.541 \\
\hline $\mathrm{N}(25)$ & -1.688 & 3.877 & 4.050 \\
\hline $\mathrm{C}(26)$ & -0.861 & 2.780 & 3.952 \\
\hline $\mathrm{N}(27)$ & 0.462 & 2.796 & 3.655 \\
\hline $\mathrm{C}(28)$ & 1.004 & 1.591 & 3.623 \\
\hline $\mathrm{N}(29)$ & 0.290 & 0.440 & 3.869 \\
\hline $\mathrm{H}(30)$ & 0.759 & -0.462 & 3.807 \\
\hline $\mathrm{P}(31)$ & -0.833 & 9.665 & 2.493 \\
\hline $\mathrm{O}(32)$ & 0.552 & 10.092 & 2.115 \\
\hline $\mathrm{O}(33)$ & -1.531 & 10.359 & 3.784 \\
\hline $\mathrm{O}(34)$ & -1.973 & 9.911 & 1.353 \\
\hline $\mathrm{H}(35)$ & -5.323 & 6.486 & 5.131 \\
\hline $\mathrm{H}(36)$ & -1.651 & 11.322 & 3.688 \\
\hline $\mathrm{H}(37)$ & -1.607 & 9.844 & 0.452 \\
\hline
\end{tabular}


Tabela A.5: Geometria otimizada da espécie neutra 3'-dGMP em PCM/SMD, com o método DFT/B3LYP/D95*-Sch. As coordenadas estão em Å.

\begin{tabular}{|c|ccc|}
\hline Átomo & $\mathrm{x}$ & $\mathrm{y}$ & $\mathrm{z}$ \\
\hline $\mathrm{O}(1)$ & -4.548 & 6.821 & 4.955 \\
$\mathrm{O}(2)$ & -0.957 & 8.023 & 2.841 \\
$\mathrm{C}(3)$ & -1.459 & 5.188 & 3.810 \\
$\mathrm{H}(4)$ & -0.379 & 5.257 & 3.647 \\
$\mathrm{C}(5)$ & -2.231 & 5.969 & 2.741 \\
$\mathrm{H}(6)$ & -1.776 & 5.891 & 1.751 \\
$\mathrm{H}(7)$ & -3.269 & 5.625 & 2.692 \\
$\mathrm{C}(8)$ & -2.201 & 7.390 & 3.291 \\
$\mathrm{H}(9)$ & -3.051 & 7.992 & 2.966 \\
$\mathrm{C}(10)$ & -2.156 & 7.198 & 4.827 \\
$\mathrm{H}(11)$ & -1.367 & 7.832 & 5.249 \\
$\mathrm{C}(12)$ & -3.453 & 7.536 & 5.548 \\
$\mathrm{H}(13)$ & -3.350 & 7.270 & 6.610 \\
$\mathrm{H}(14)$ & -3.613 & 8.621 & 5.474 \\
$\mathrm{O}(15)$ & -1.809 & 5.810 & 5.054 \\
$\mathrm{~N}(16)$ & 2.424 & 1.567 & 3.509 \\
$\mathrm{H}(17)$ & 2.929 & 2.438 & 3.647 \\
$\mathrm{H}(18)$ & 2.909 & 0.732 & 3.830 \\
$\mathrm{O}(19)$ & -1.479 & -0.830 & 4.214 \\
$\mathrm{C}(20)$ & -0.983 & 0.308 & 4.067 \\
$\mathrm{C}(21)$ & -1.643 & 1.574 & 4.047 \\
$\mathrm{~N}(22)$ & -2.989 & 1.894 & 4.179 \\
$\mathrm{C}(23)$ & -3.022 & 3.206 & 4.082 \\
$\mathrm{H}(24)$ & -3.915 & 3.813 & 4.154 \\
$\mathrm{~N}(25)$ & -1.772 & 3.773 & 3.891 \\
$\mathrm{C}(26)$ & -0.873 & 2.727 & 3.872 \\
$\mathrm{~N}(27)$ & 0.468 & 2.818 & 3.711 \\
$\mathrm{C}(28)$ & 1.077 & 1.641 & 3.727 \\
$\mathrm{~N}(29)$ & 0.406 & 0.451 & 3.895 \\
$\mathrm{H}(30)$ & 0.941 & -0.418 & 3.900 \\
$\mathrm{P}(31)$ & -0.860 & 9.583 & 2.450 \\
$\mathrm{O}(32)$ & 0.527 & 9.921 & 1.972 \\
$\mathrm{O}(33)$ & -1.395 & 10.315 & 3.791 \\
$\mathrm{O}(34)$ & -2.050 & 9.924 & 1.399 \\
$\mathrm{H}(35)$ & -5.354 & 7.067 & 5.439 \\
$\mathrm{H}(36)$ & -1.457 & 11.286 & 3.697 \\
$\mathrm{H}(37)$ & -1.772 & 9.798 & 0.470 \\
\hline & & & \\
& & & \\
\hline
\end{tabular}


Tabela A.6: Geometria otimizada da espécie neutra 3'-dGMP em PCM/UAHF, com o método HF/6-31G(d). As coordenadas estão em $\AA$.

\begin{tabular}{|c|ccc|}
\hline Átomo & $\mathrm{x}$ & $\mathrm{y}$ & $\mathrm{z}$ \\
\hline $\mathrm{O}(1)$ & -4.487 & 6.446 & 4.748 \\
$\mathrm{O}(2)$ & -0.906 & 8.138 & 3.149 \\
$\mathrm{C}(3)$ & -1.311 & 5.314 & 3.997 \\
$\mathrm{H}(4)$ & -0.225 & 5.370 & 3.864 \\
$\mathrm{C}(5)$ & -2.050 & 6.049 & 2.878 \\
$\mathrm{H}(6)$ & -1.520 & 6.006 & 1.932 \\
$\mathrm{H}(7)$ & -3.047 & 5.645 & 2.746 \\
$\mathrm{C}(8)$ & -2.145 & 7.459 & 3.429 \\
$\mathrm{H}(9)$ & -2.975 & 8.023 & 3.028 \\
$\mathrm{C}(10)$ & -2.245 & 7.246 & 4.944 \\
$\mathrm{H}(11)$ & -1.647 & 7.990 & 5.469 \\
$\mathrm{C}(12)$ & -3.658 & 7.305 & 5.488 \\
$\mathrm{H}(13)$ & -3.637 & 7.017 & 6.536 \\
$\mathrm{H}(14)$ & -4.013 & 8.332 & 5.425 \\
$\mathrm{O}(15)$ & -1.680 & 5.965 & 5.184 \\
$\mathrm{~N}(16)$ & 2.248 & 1.520 & 3.114 \\
$\mathrm{H}(17)$ & 2.811 & 2.350 & 3.129 \\
$\mathrm{H}(18)$ & 2.730 & 0.662 & 3.314 \\
$\mathrm{O}(19)$ & -1.577 & -0.641 & 4.307 \\
$\mathrm{C}(20)$ & -1.067 & 0.438 & 4.118 \\
$\mathrm{C}(21)$ & -1.641 & 1.740 & 4.217 \\
$\mathrm{~N}(22)$ & -2.923 & 2.138 & 4.552 \\
$\mathrm{C}(23)$ & -2.890 & 3.417 & 4.484 \\
$\mathrm{H}(24)$ & -3.704 & 4.079 & 4.690 \\
$\mathrm{~N}(25)$ & -1.660 & 3.913 & 4.119 \\
$\mathrm{C}(26)$ & -0.854 & 2.832 & 3.955 \\
$\mathrm{~N}(27)$ & 0.446 & 2.850 & 3.599 \\
$\mathrm{C}(28)$ & 0.971 & 1.664 & 3.507 \\
$\mathrm{~N}(29)$ & 0.277 & 0.518 & 3.748 \\
$\mathrm{H}(30)$ & 0.752 & -0.365 & 3.646 \\
$\mathrm{P}(31)$ & -0.792 & 9.556 & 2.496 \\
$\mathrm{O}(32)$ & 0.589 & 9.975 & 2.323 \\
$\mathrm{O}(33)$ & -1.704 & 10.428 & 3.442 \\
$\mathrm{O}(34)$ & -1.640 & 9.528 & 1.161 \\
$\mathrm{H}(35)$ & -5.370 & 6.463 & 5.119 \\
$\mathrm{H}(36)$ & -1.829 & 11.337 & 3.158 \\
$\mathrm{H}(37)$ & -1.128 & 9.305 & 0.380 \\
\hline & & & \\
\hline
\end{tabular}


Tabela A.7: Geometria otimizada da molécula $3^{\prime}$-dGMP ${ }^{-}$em PCM/UFF, com o método DFT/B3LYP/D95*-Sch. As coordenadas estão em Å.

\begin{tabular}{|c|ccc|}
\hline Átomo & $\mathrm{x}$ & $\mathrm{y}$ & $\mathrm{z}$ \\
\hline $\mathrm{O}(1)$ & -4.439 & 6.427 & 4.747 \\
$\mathrm{O}(2)$ & -0.877 & 8.118 & 2.944 \\
$\mathrm{C}(3)$ & -1.291 & 5.270 & 3.889 \\
$\mathrm{H}(4)$ & -0.214 & 5.253 & 3.690 \\
$\mathrm{C}(5)$ & -2.062 & 6.017 & 2.788 \\
$\mathrm{H}(6)$ & -1.572 & 5.945 & 1.814 \\
$\mathrm{H}(7)$ & -3.082 & 5.630 & 2.710 \\
$\mathrm{C}(8)$ & -2.111 & 7.448 & 3.315 \\
$\mathrm{H}(9)$ & -2.970 & 8.007 & 2.936 \\
$\mathrm{C}(10)$ & -2.163 & 7.257 & 4.846 \\
$\mathrm{H}(11)$ & -1.558 & 8.028 & 5.337 \\
$\mathrm{C}(12)$ & -3.563 & 7.320 & 5.448 \\
$\mathrm{H}(13)$ & -3.499 & 7.048 & 6.512 \\
$\mathrm{H}(14)$ & -3.923 & 8.358 & 5.374 \\
$\mathrm{O}(15)$ & -1.546 & 5.975 & 5.105 \\
$\mathrm{~N}(16)$ & 2.317 & 1.438 & 3.250 \\
$\mathrm{H}(17)$ & 2.860 & 2.295 & 3.300 \\
$\mathrm{H}(18)$ & 2.815 & 0.612 & 3.569 \\
$\mathrm{O}(19)$ & -1.624 & -0.744 & 4.363 \\
$\mathrm{C}(20)$ & -1.097 & 0.361 & 4.168 \\
$\mathrm{C}(21)$ & -1.678 & 1.672 & 4.211 \\
$\mathrm{~N}(22)$ & -2.976 & 2.078 & 4.485 \\
$\mathrm{C}(23)$ & -2.940 & 3.389 & 4.382 \\
$\mathrm{H}(24)$ & -3.771 & 4.067 & 4.547 \\
$\mathrm{~N}(25)$ & -1.683 & 3.876 & 4.054 \\
$\mathrm{C}(26)$ & -0.860 & 2.777 & 3.947 \\
$\mathrm{~N}(27)$ & 0.463 & 2.790 & 3.650 \\
$\mathrm{C}(28)$ & 1.000 & 1.584 & 3.608 \\
$\mathrm{~N}(29)$ & 0.282 & 0.434 & 3.845 \\
$\mathrm{H}(30)$ & 0.748 & -0.470 & 3.776 \\
$\mathrm{P}(31)$ & -0.858 & 9.705 & 2.524 \\
$\mathrm{O}(32)$ & 0.551 & 10.099 & 2.160 \\
$\mathrm{O}(33)$ & -1.637 & 10.452 & 3.718 \\
$\mathrm{O}(34)$ & -1.915 & 9.841 & 1.267 \\
$\mathrm{H}(35)$ & -5.319 & 6.489 & 5.152 \\
$\mathrm{H}(36)$ & -1.839 & 11.500 & 3.549 \\
$\mathrm{H}(37)$ & -1.467 & 9.667 & 0.417 \\
\hline & & & \\
\hline
\end{tabular}


Tabela A.8: Geometria otimizada da molécula 3'-dGMP ${ }^{-}$em PCM/SMD, com o método DFT/B3LYP/D95*-Sch. As coordenadas estão em A.

\begin{tabular}{|c|c|c|c|}
\hline Átomo & $\mathrm{x}$ & $\mathrm{y}$ & $\mathrm{Z}$ \\
\hline $\mathrm{O}(1)$ & -4.570 & 6.788 & 4.913 \\
\hline $\mathrm{O}(2)$ & -0.973 & 8.043 & 2.840 \\
\hline $\mathrm{C}(3)$ & -1.492 & 5.199 & 3.700 \\
\hline $\mathrm{H}(4)$ & -0.417 & 5.317 & 3.525 \\
\hline $\mathrm{C}(5)$ & -2.289 & 6.020 & 2.682 \\
\hline $\mathrm{H}(6)$ & -1.865 & 5.970 & 1.676 \\
\hline $\mathrm{H}(7)$ & -3.333 & 5.693 & 2.652 \\
\hline $\mathrm{C}(8)$ & -2.229 & 7.423 & 3.274 \\
\hline $\mathrm{H}(9)$ & -3.068 & 8.053 & 2.973 \\
\hline $\mathrm{C}(10)$ & -2.181 & 7.180 & 4.802 \\
\hline $\mathrm{H}(11)$ & -1.400 & 7.814 & 5.242 \\
\hline $\mathrm{C}(12)$ & -3.482 & 7.492 & 5.528 \\
\hline $\mathrm{H}(13)$ & -3.376 & 7.199 & 6.583 \\
\hline $\mathrm{H}(14)$ & -3.643 & 8.579 & 5.486 \\
\hline $\mathrm{O}(15)$ & -1.825 & 5.792 & 4.984 \\
\hline $\mathrm{N}(16)$ & 2.393 & 1.387 & 3.271 \\
\hline $\mathrm{H}(17)$ & 2.879 & 2.268 & 3.117 \\
\hline $\mathrm{H}(18)$ & 2.942 & 0.777 & 3.876 \\
\hline $\mathrm{O}(19)$ & -1.446 & -0.830 & 4.464 \\
\hline $\mathrm{C}(20)$ & -0.960 & 0.360 & 4.363 \\
\hline $\mathrm{C}(21)$ & -1.587 & 1.602 & 4.262 \\
\hline $\mathrm{N}(22)$ & -2.961 & 1.920 & 4.183 \\
\hline $\mathrm{C}(23)$ & -2.993 & 3.201 & 3.887 \\
\hline $\mathrm{H}(24)$ & -3.909 & 3.775 & 3.794 \\
\hline $\mathrm{N}(25)$ & -1.755 & 3.787 & 3.711 \\
\hline $\mathrm{C}(26)$ & -0.801 & 2.788 & 4.072 \\
\hline $\mathrm{N}(27)$ & 0.510 & 2.765 & 3.617 \\
\hline $\mathrm{C}(28)$ & 1.095 & 1.605 & 3.751 \\
\hline $\mathrm{N}(29)$ & 0.504 & 0.489 & 4.378 \\
\hline $\mathrm{H}(30)$ & 0.944 & -0.394 & 4.123 \\
\hline $\mathrm{P}(31)$ & -0.851 & 9.611 & 2.493 \\
\hline $\mathrm{O}(32)$ & 0.528 & 9.943 & 2.004 \\
\hline $\mathrm{O}(33)$ & -1.351 & 10.313 & 3.864 \\
\hline $\mathrm{O}(34)$ & -2.063 & 9.994 & 1.480 \\
\hline $\mathrm{H}(35)$ & -5.364 & 6.966 & 5.443 \\
\hline $\mathrm{H}(36)$ & -1.284 & 11.287 & 3.836 \\
\hline $\mathrm{H}(37)$ & -1.827 & 9.833 & 0.546 \\
\hline
\end{tabular}


Tabela A.9: Geometria otimizada da molécula $3^{\prime}$-dGMP ${ }^{-}$em PCM/UAHF, com o método $\mathrm{HF} / 6-31 \mathrm{G}(\mathrm{d})$. As coordenadas estão em $\AA$.

\begin{tabular}{|c|ccc|}
\hline Átomo & $\mathrm{x}$ & $\mathrm{y}$ & $\mathrm{z}$ \\
\hline $\mathrm{O}(1)$ & -4.540 & 6.560 & 4.760 \\
$\mathrm{O}(2)$ & -0.932 & 8.174 & 3.184 \\
$\mathrm{C}(3)$ & -1.389 & 5.296 & 3.815 \\
$\mathrm{H}(4)$ & -0.308 & 5.415 & 3.675 \\
$\mathrm{C}(5)$ & -2.148 & 6.139 & 2.791 \\
$\mathrm{H}(6)$ & -1.657 & 6.155 & 1.823 \\
$\mathrm{H}(7)$ & -3.163 & 5.780 & 2.668 \\
$\mathrm{C}(8)$ & -2.181 & 7.502 & 3.454 \\
$\mathrm{H}(9)$ & -3.006 & 8.123 & 3.131 \\
$\mathrm{C}(10)$ & -2.236 & 7.171 & 4.951 \\
$\mathrm{H}(11)$ & -1.577 & 7.843 & 5.503 \\
$\mathrm{C}(12)$ & -3.625 & 7.278 & 5.548 \\
$\mathrm{H}(13)$ & -3.596 & 6.888 & 6.562 \\
$\mathrm{H}(14)$ & -3.903 & 8.330 & 5.598 \\
$\mathrm{O}(15)$ & -1.752 & 5.847 & 5.072 \\
$\mathrm{~N}(16)$ & 2.237 & 1.321 & 2.984 \\
$\mathrm{H}(17)$ & 2.767 & 2.150 & 2.787 \\
$\mathrm{H}(18)$ & 2.789 & 0.639 & 3.476 \\
$\mathrm{O}(19)$ & -1.509 & -0.663 & 4.583 \\
$\mathrm{C}(20)$ & -1.013 & 0.476 & 4.404 \\
$\mathrm{C}(21)$ & -1.562 & 1.733 & 4.366 \\
$\mathrm{~N}(22)$ & -2.910 & 2.130 & 4.409 \\
$\mathrm{C}(23)$ & -2.907 & 3.372 & 4.088 \\
$\mathrm{H}(24)$ & -3.783 & 3.991 & 4.074 \\
$\mathrm{~N}(25)$ & -1.674 & 3.897 & 3.773 \\
$\mathrm{C}(26)$ & -0.738 & 2.883 & 4.118 \\
$\mathrm{~N}(27)$ & 0.504 & 2.766 & 3.488 \\
$\mathrm{C}(28)$ & 1.016 & 1.598 & 3.566 \\
$\mathrm{~N}(29)$ & 0.427 & 0.529 & 4.210 \\
$\mathrm{H}(30)$ & 0.808 & -0.371 & 3.985 \\
$\mathrm{P}(31)$ & -0.802 & 9.596 & 2.548 \\
$\mathrm{O}(32)$ & 0.582 & 9.984 & 2.330 \\
$\mathrm{O}(33)$ & -1.652 & 10.484 & 3.537 \\
$\mathrm{O}(34)$ & -1.698 & 9.614 & 1.243 \\
$\mathrm{H}(35)$ & -5.404 & 6.597 & 5.172 \\
$\mathrm{H}(36)$ & -1.745 & 11.403 & 3.275 \\
$\mathrm{H}(37)$ & -1.221 & 9.379 & 0.443 \\
\hline & & & \\
\hline
\end{tabular}




\section{Referências Bibliográficas}

[1] B Boudaïffa, P Cloutier, D Hunting, M a Huels, and L Sanche. Resonant formation of DNA strand breaks by low-energy (3 to $20 \mathrm{eV}$ ) electrons. Science (New York, N.Y.), 287(5458):1658-60, March 2000.

[2] Chun-Rong Wang, Jenny Nguyen, and Qing-Bin Lu. Bond breaks of nucleotides by dissociative electron transfer of nonequilibrium prehydrated electrons: a new molecular mechanism for reductive DNA damage. Journal of the American Chemical Society, 131(32):11320-2, August 2009.

[3] Léon Sanche. Biological chemistry: Beyond radical thinking. Nature, 461:358-359, 2009.

[4] Elahe Alizadeh and Léon Sanche. Precursors of Solvated Electrons in Radiobiological Physics and Chemistry. Chemical Reviews, 112(11):5578-5602, November 2012.

[5] Sascha Gohlke and Eugen Illenberger. Probing biomolecules: Gas phase experiments and biological relevance. Europhysics News, 33(6):207-209, November 2002.

[6] Chun-Rong Wang, Ting Luo, and Qing-Bin Lu. On the lifetimes and physical nature of incompletely relaxed electrons in liquid water. Physical chemistry chemical physics : PCCP, 10(30):4463-70, August 2008.

[7] Xiaoguang Bao, Jing Wang, Jiande Gu, and Jerzy Leszczynski. DNA strand breaks induced by near-zero-electronvolt electron attachment 
to pyrimidine nucleotides. Proceedings of the National Academy of Sciences of the United States of America, 103(15):5658-63, April 2006.

[8] Jiande Gu, Jerzy Leszczynski, and HF Schaefer III. Interactions of electrons with bare and hydrated biomolecules: From nucleic acid bases to DNA segments. Chemical Reviews, 2012.

[9] Jack Simons. How Do Low-Energy Electrons Cause DNA-Strand Breaks? Accounts of Chemical Research, 39(10):772-779, 2006.

[10] Patric Schyman and Aatto Laaksonen. On the effect of low-energy electron induced DNA strand break in aqueous solution: A theoretical study indicating guanine as a weak link in DNA. Journal of the American Chemical Society, pages 12254-12255, 2008.

[11] Maeve Smyth and Jorge Kohanoff. Excess electron interactions with solvated dna nucleotides: Strand breaks possible at room temperature. Journal of the American Chemical Society, (Figure 1):1-4, 2012.

[12] José David Mangueira Vianna, Adalberto Fazzio, and Sylvio Canuto. Teoria Quântica de Moléculas e Sólidos. Livraria da Física, 2004.

[13] Peter Atkins and Roland Friedman. Molecular Quantum Mechanics. Oxford University Press, 1997.

[14] Linus Pauling and E. Bright Wilson Jr. Introduction to Quantum Mechanics with Applications to Chemistry. Mcgraw Hill, 1935.

[15] Nelson H. Morgon and Kaline Coutinho. Métodos de Química Teórica e Modelagem Molecular. Livraria da Física, 2007.

[16] Axel D. Becke. A new mixing of hartree-fock and local densityfunctional theories. The Journal of Chemical Physics, 98(2):13721377, 1993.

[17] Donald A. McQuarrie and John D. Simon. Molecular Thermodynamics. University Science Books, 1999. 
[18] Chunyang Peng and H. Bernhard Schlegel. Combining synchronous transit and quasi-newton methods to find transition states. Israel Journal of Chemistry, 33(4):449-454, 1993.

[19] Chunyang Peng, Philippe Y. Ayala, H. Bernhard Schlegel, and Michael J. Frisch. Using redundant internal coordinates to optimize equilibrium geometries and transition states. Journal of Computational Chemistry, 17(1):49-56, 1996.

[20] H. Bernhard Schlegel. Geometry optimization. Wiley Interdisciplinary Reviews: Computational Molecular Science, 1(5):790-809, 2011.

[21] David B. Cook. Handbook of Computational Quantum Chemistry. Oxford University Press, 1998.

[22] Nancy A. Richardson, Steven S. Wesolowski, and Henry F. Schaefer III. Electron affinity of the guanine-cytosine base pair and structural perturbations upon anion formation. Journal of the American Chemical Society, (23):10163-10170, 2002.

[23] S. Huzinaga. Gaussian Type Functions for Polyatomic Systems. I . Journal of Chemical Physics, (42):1293, 1965.

[24] T. H. Dunning. Gaussian Basis Functions for Use in Molecular Calculations. I. Contraction of (9s5p) Atomic Basis Sets for the First Row Atoms. Journal of Chemical Physics, (53):2823, 1970.

[25] M. J. Frisch, G. W. Trucks, H. B. Schlegel, G. E. Scuseria, M. A. Robb, J. R. Cheeseman, G. Scalmani, V. Barone, B. Mennucci, G. A. Petersson, H. Nakatsuji, M. Caricato, X. Li, H. P. Hratchian, A. F. Izmaylov, J. Bloino, G. Zheng, J. L. Sonnenberg, M. Hada, M. Ehara, K. Toyota, R. Fukuda, J. Hasegawa, M. Ishida, T. Nakajima, Y. Honda, O. Kitao, H. Nakai, T. Vreven, J. A. Montgomery, Jr., J. E. Peralta, F. Ogliaro, M. Bearpark, J. J. Heyd, E. Brothers, K. N. Kudin, V. N. Staroverov, R. Kobayashi, J. Normand, K. Raghavachari, A. Rendell, J. C. Burant, S. S. Iyengar, J. Tomasi, M. Cossi, N. Rega, J. M. Millam, 
M. Klene, J. E. Knox, J. B. Cross, V. Bakken, C. Adamo, J. Jaramillo, R. Gomperts, R. E. Stratmann, O. Yazyev, A. J. Austin, R. Cammi, C. Pomelli, J. W. Ochterski, R. L. Martin, K. Morokuma, V. G. Zakrzewski, G. A. Voth, P. Salvador, J. J. Dannenberg, S. Dapprich, A. D. Daniels, Ö. Farkas, J. B. Foresman, J. V. Ortiz, J. Cioslowski, and D. J. Fox. Gaussian 09 Revision D.01. Gaussian Inc. Wallingford CT 2009 .

[26] M. J. Frisch, G. W. Trucks, H. B. Schlegel, G. E. Scuseria, M. A. Robb, J. R. Cheeseman, J. A. Montgomery, Jr., T. Vreven, K. N. Kudin, J. C. Burant, J. M. Millam, S. S. Iyengar, J. Tomasi, V. Barone, B. Mennucci, M. Cossi, G. Scalmani, N. Rega, G. A. Petersson, H. Nakatsuji, M. Hada, M. Ehara, K. Toyota, R. Fukuda, J. Hasegawa, M. Ishida, T. Nakajima, Y. Honda, O. Kitao, H. Nakai, M. Klene, X. Li, J. E. Knox, H. P. Hratchian, J. B. Cross, V. Bakken, C. Adamo, J. Jaramillo, R. Gomperts, R. E. Stratmann, O. Yazyev, A. J. Austin, R. Cammi, C. Pomelli, J. W. Ochterski, P. Y. Ayala, K. Morokuma, G. A. Voth, P. Salvador, J. J. Dannenberg, V. G. Zakrzewski, S. Dapprich, A. D. Daniels, M. C. Strain, O. Farkas, D. K. Malick, A. D. Rabuck, K. Raghavachari, J. B. Foresman, J. V. Ortiz, Q. Cui, A. G. Baboul, S. Clifford, J. Cioslowski, B. B. Stefanov, G. Liu, A. Liashenko, P. Piskorz, I. Komaromi, R. L. Martin, D. J. Fox, T. Keith, M. A. AlLaham, C. Y. Peng, A. Nanayakkara, M. Challacombe, P. M. W. Gill, B. Johnson, W. Chen, M. W. Wong, C. Gonzalez, and J. A. Pople. Gaussian 03, Revision C.02. Gaussian, Inc., Wallingford, CT, 2004.

[27] Lars Onsager. Electric moments of molecules in liquids. Journal of the American Chemical Society, 58(8):1486-1493, 1936.

[28] John G. Kirkwood. On the theory of dielectric polarization. Journal of Chemical Physics, 4(9):592-601, 1936.

[29] John G. Kirkwood. The dielectric polarization of polar liquids. Journal of Chemical Physics, 7:911, 1939. 
[30] O Tapia and O. Goscinski. Self consistent reaction field theory of solvent effects. Molecular Physics, 29(6):1653-1661, 1975.

[31] J. Rivail and D. Rinaldi. A quantum chemical approach to dielectric solvent effects in molecular liquids. Chemical Physics, 18(1-2):233-242, 1976.

[32] A. K. Rappe, C. J. Casewit, K. S. Colwell, W. A. Goddard, and W. M. Skiff. UFF, a full periodic table force field for molecular mechanics and molecular dynamics simulations. Journal of the American Chemical Society, 114(25):10024-10035, 1992.

[33] Benedetta Mennucci and Jacopo Tomasi. Continuum solvation models: A new approach to the problem of solute's charge distribution and cavity boundaries. The Journal of Chemical Physics, 106(12):5151-5158, 1997.

[34] Vincenzo Barone, Maurizio Cossi, and Tomasi Jacopo. A new definition of cavities for the computation of solvation free energies by the polarizable continuum model. Journal of Chemical Physics, 107:3210, 1997.

[35] Aleksandr V. Marenich, Christopher J. Cramer, and Donald G. Truhlar. Universal solvation model based on solute electron density and on a continuum model of the solvent defined by the bulk dielectric constant and atomic surface tensions. The Journal of Physical Chemistry $B$, 113(18):6378-6396, 2009.

[36] Abraham. Nitzan. Chemical Dynamics in Condensed Phases: Relaxation, Transfer, and Reactions in Condensed Molecular Systems. Oxford University Press, 2006.

[37] Sylvio Canuto. Solvation Effects on Molecules and Biomolecules: Computational Methods and Applications. Springer Verlag, 2008. 
[38] Jacopo Tomasi, Benedetta Mennucci, and Roberto Cammi. Quantum Mechanical Continuum Solvation Models. Chemical Reviews, 105(8):2999-3093, August 2005.

[39] M. P. Allen and D. J. Tildesley. Computer Simulation of Liquids. Clarendon Press, 1987.

[40] Daan Frenkel and Berend Smit. Understanding Molecular Simulation: From Algorithms to Applications. Academic Press, 2002.

[41] William L. Jorgensen, David S. Maxwell, and Julian Tirado-Rives. Development and Testing of the OPLS All-Atom Force Field on Conformational Energetics and Properties of Organic Liquids. Journal of the American Chemical Society, 118(45):11225-11236, 1996.

[42] Wendy D. Cornell, Piotr Cieplak, Christopher I. Bayly, Ian R. Gould, Kenneth M. Merz, David M. Ferguson, David C. Spellmeyer, Thomas Fox, James W. Caldwell, and Peter A. Kollman. A second generation force field for the simulation of proteins, nucleic acids, and organic molecules. Journal of the American Chemical Society, 117(19):51795197, 1995.

[43] Curt M. Breneman and Kenneth B. Wiberg. Determining atomcentered monopoles from molecular electrostatic potentials. the need for high sampling density in formamide conformational analysis. Journal of Computational Chemistry, 11(3):361-373, 1990.

[44] K. Coutinho. Modelo Discreto de Solvente. Solvatocromismo no Espectro de Absorção Molecular. Tese de Doutorado - USP, 1997.

[45] C. E. Bistafa. Efeito de Solvente no Espectro de Absorção da 5Fluorouracil. Análise de Diferentes Procedimentos Teóricos. Dissertação de Mestrado - USP, 2011.

[46] Herbert C. Georg, Kaline Coutinho, and Sylvio Canuto. Solvent effects on the uv-visible absorption spectrum of benzophenone in water: 
A combined monte carlo quantum mechanics study including solute polarization. Journal of Chemical Physics, 126:034507, 2007.

[47] Sylvio Canuto, Kaline Coutinho, and Daniel Trzesniak. New developments in monte carlo/quantum mechanics methodology. the solvatochromism of $\beta$-carotene in different solvents. Advances in Quantum Chemistry, 41:161-183, 2002.

[48] K. Coutinho, H.C. Georg, T. L. Fonseca, V. Ludwig, and S. Canuto. An efficient statistically converged average configuration for solvent effects. Chemical Physics Letters, 437:148-152, 2007.

[49] Mark E. Tuckerman. Statistical Mechanics: Theory and Molecular Simulation. Oxford Press, 2010.

[50] Fernando da Silva. Estudo teórico de propriedades eletrônicas e da solvatação de carbonatos orgânicos em meio aquoso. Dissertação de Mestrado - USP, 2011.

[51] William L. Jorgensen, J. Kathleen Buckner, Stephane Boudon, and Julian Tirado Rives. Efficient computation of absolute free energies of binding by computer simulations. application to the methane dimer in water. The Journal of Chemical Physics, 89(6):3742-3746, 1988.

[52] Casey P. Kelly, Christopher J. Cramer, and Donald G. Truhlar. Aqueous Solvation Free Energies of Ions and Ion - Water Clusters Based on an Accurate Value for the Absolute Aqueous Solvation Free Energy of the Proton. The Journal of Physical Chemistry B, pages 16066-16081, 2006.

[53] Antonio R. da Cunha, Evandro L. Duarte, M. Teresa Lamy, and Kaline Coutinho. Protonation/deprotonation process of emodin in aqueous solution and pka determination: Uv/visible spectrophotometric titration and quantum/molecular mechanics calculations. Chemical Physics, 440(0):69-79, 2014. 
[54] Kaline Coutinho and Sylvio Canuto. DICE: A Monte Carlo program for molecular liquid simulations. University of São Paulo, 2003.

[55] B. Hess, D. van der Spoel, and E. Lindahl. GROMACS USER MANUAL - Version 4.5.4. 2010.

[56] William L. Jorgensen, David S. Maxwell, and Julian Tirado-Rives. Development and Testing of the OPLS All-Atom Force Field on Conformational Energetics and Properties of Organic Liquids. Journal of the American Chemical Society, 118:11225-11236, 1996.

[57] Julianto Pranata, Scott G. Wierschke, and William L. Jorgensen. Opls potential functions for nucleotide bases. relative association constants of hydrogen-bonded base pairs in chloroform. Journal of the American Chemical Society, 113(8):2810-2819, 1991.

[58] Alberto Modelli and Paul D. Burrow. Electron attachment to the azaderivatives of furan, pyrrole, and thiophene. The Journal of Physical Chemistry A, 108(26):5721-5726, 2004.

[59] Hsing-Yin Chen, Po-Yu Yang, Hui-Fen Chen, Chai-Lin Kao, and LiWenm Liao. DFT reinvestigation of DNA strand breaks induced by electron attachment. The journal of physical chemistry. B, 118:1113744, 2014. 